\title{
NEEDS INVESTIGATION METHODS COMPATIBLE WITH KEY END USER LIMITATION (NICKEL): A TOOL FOR SELECTING USER CENTERED NEEDS ELICITATION METHODS FOR OLDER ADULTS
}

\author{
By \\ Joash Sujan Samuel Roy, \\ B. Eng., Anna University, India, 2013
}

\author{
A thesis \\ presented to Ryerson University \\ in partial fulfillment of the \\ requirements for the degree of \\ Master of Applied Science \\ in \\ Mechanical and Industrial Engineering
}

Toronto, Ontario, Canada, 2018

CJoash Sujan Samuel Roy 2018 


\section{AUTHOR'S DECLARATION FOR ELECTRONIC SUBMISSION OF A THESIS}

I hereby declare that I am the sole author of this thesis. This is a true copy of the thesis, including any required final revisions, as accepted by my examiners.

I authorize Ryerson University to lend this thesis to other institutions or individuals for the purpose of scholarly research.

I further authorize Ryerson University to reproduce this thesis by photocopying or by other means, in total or in part, at the request of other institutions or individuals for the purpose of scholarly research.

I understand that my thesis may be made electronically available to the public. 


\title{
ABSTRACT \\ NICKEL (NEEDS INVESTIGATION METHODS COMPATIBLE WITH KEY END USER LIMITATION): A TOOL FOR SELECTING USER CENTERED NEEDS ELICITATION METHODS FOR OLDER ADULTS
}

\author{
Joash Sujan Samuel Roy \\ Master of Applied Science \\ 2018 \\ Mechanical and Industrial Engineering, \\ Ryerson University
}

During the design process older and/or disabled adults are often left out of the needs elicitation process because many of the User Centered Needs Elicitation Methods (UCNEM) are not accessible to these individuals. This thesis explains the development of NICKEL, a decisionsupport tool which allows users to determine UCNEMs that fit the human capability of the older and/or disabled adult participants in their study. Three levels of the cognitive, visual, hearing and physical human capabilities required for 19 UCNEMs are determined using a survey and focus group with expert designers/researchers. A user study is carried out to determine the usability and usefulness of NICKEL with novice and expert designers/researchers. Major findings indicated that NICKEL is an easy to use and useful tool for users when determining appropriate UCNEMs for older and disabled adults. Future work could include adding other capabilities such as interpersonal skills and adding new methods to NICKEL. 


\section{Acknowledgements}

I would first like to express my thanks and sincere gratitude to my advisors Prof. Deborah Fels and Prof. W. Patrick Neumann for the continuous support of my study and related research, for their patience, motivation, and immense knowledge. Their guidance helped me in all the time of research and writing of this thesis.

Besides my supervisors, I would like to thank the rest of my thesis committee: Prof. Mohammad Abdoli-Eramaki, Prof. Filippo Salustri, and Prof. Ahmed Ghasempoor, for their insightful comments and encouragement. I would also like to thank the experts who were involved in reviewing and validating the contributions that were published as part of this research. I would also like to thank the members of Inclusive media and design center and Human factors engineering lab for their support throughout the research. In addition, I would like to thank my family for their love, support, and encouragement during this process.

I want to also express my sincere thanks to all the people who participated in my research study: 38 participants from Age-Well for the survey study and 18 participants in the final user study. I could not have completed this research without their help and support. I would also like to thank them for their quality feedback. I could not have done it without them. Funding was graciously provided by the Age-Well, NCE. 


\section{Table of Contents}

AUTHOR'S DECLARATION FOR ELECTRONIC SUBMISSION OF A THESIS .................. ii

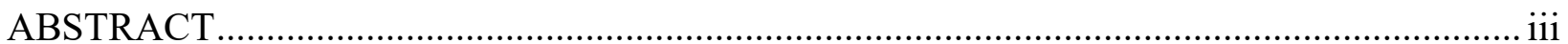

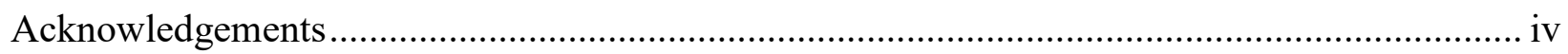

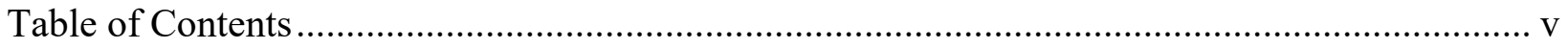

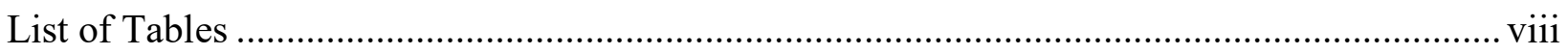

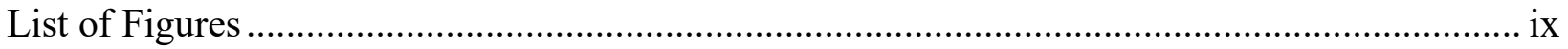

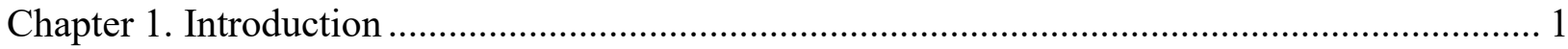

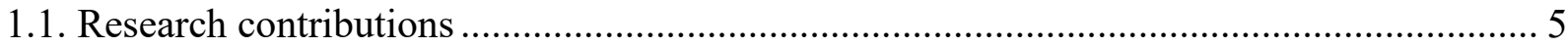

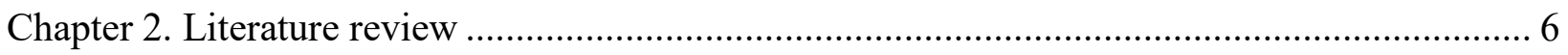

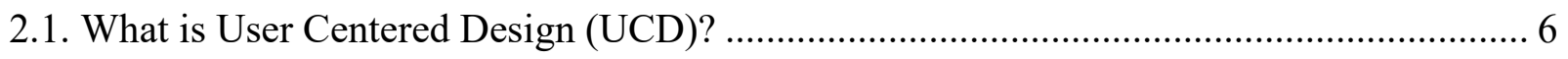

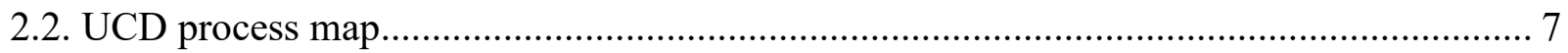

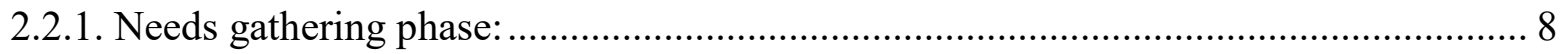

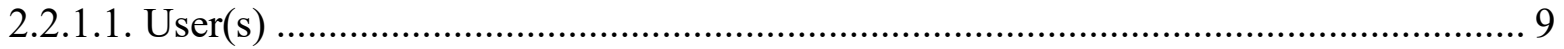

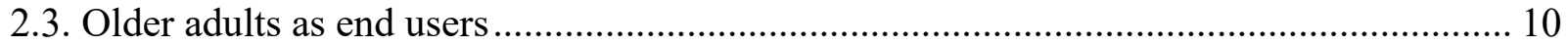

2.4. UCNEM usage in older adult community .......................................................... 16

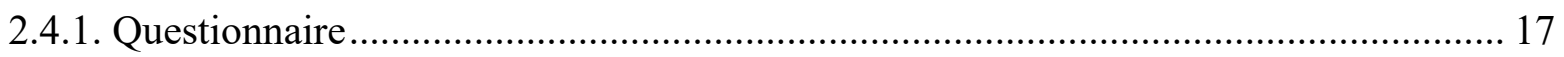

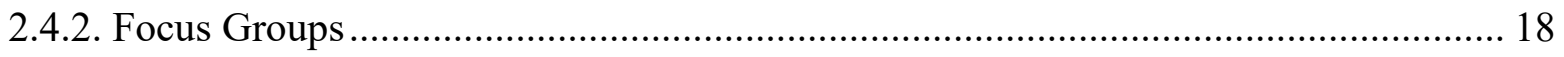

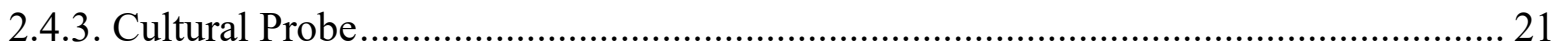

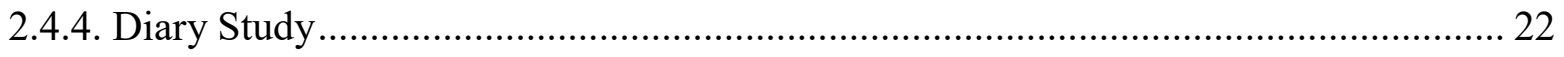

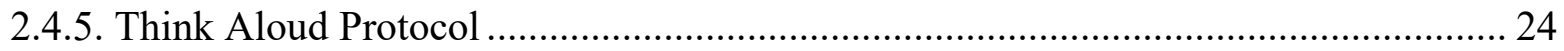

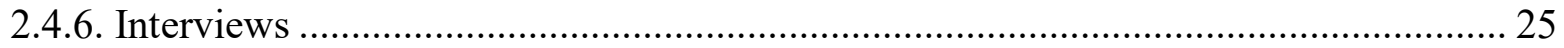

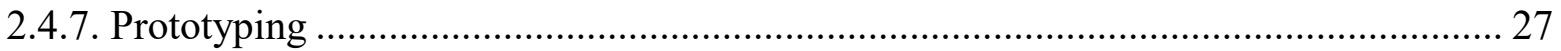

2.5. Application of human factors in product design ..................................................... 28

2.6. Human factors in needs elicitation? ..................................................................... 31 


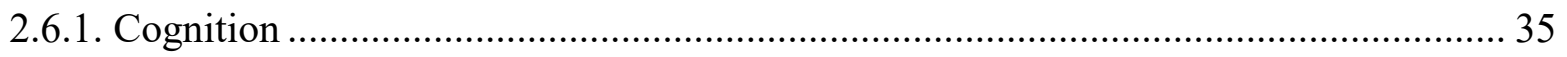

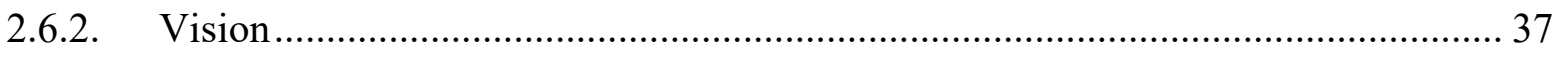

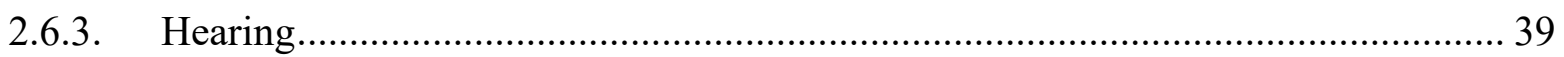

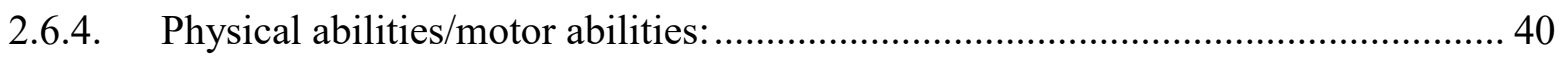

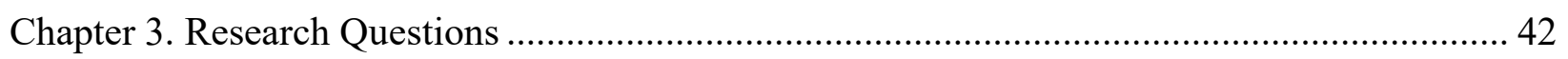

Chapter 4. Matching Human Capabilities with User Centered Needs Elicitation Methods .......... 43

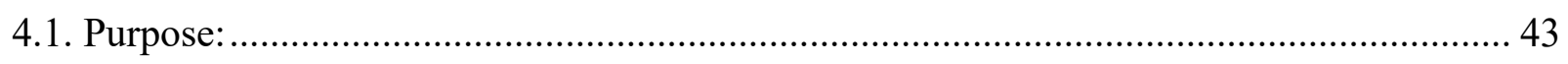

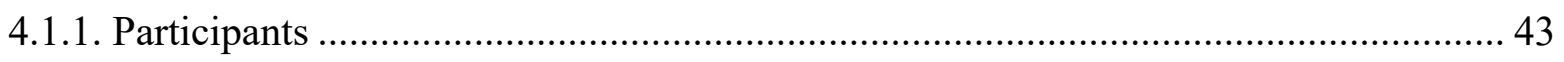

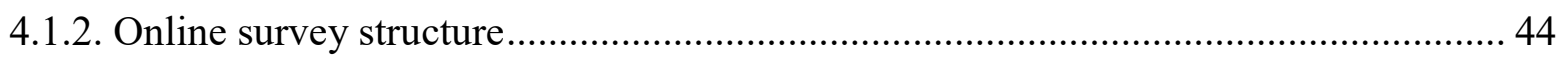

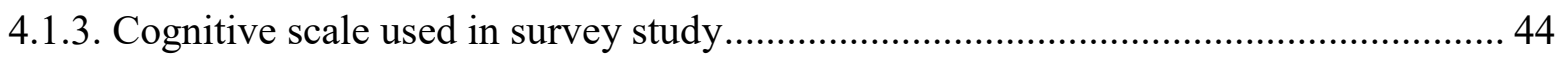

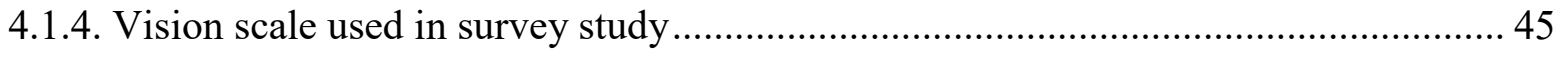

4.1.5. Auditory range used in survey study …………........................................................ 45

4.1.6. Physical abilities/ motor dexterity used in survey study ............................................. 46

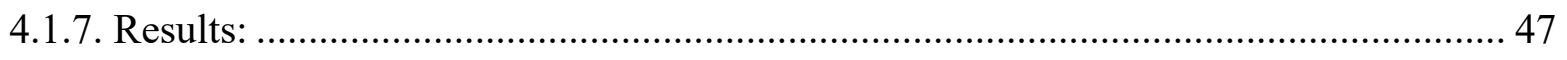

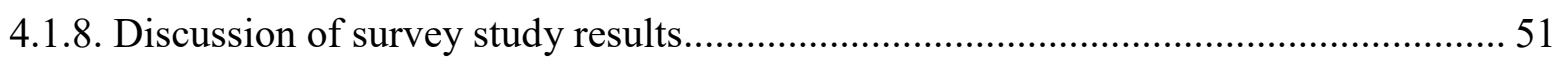

4.2. Populating the non-significant and blank cells in Table 1 ............................................... 52

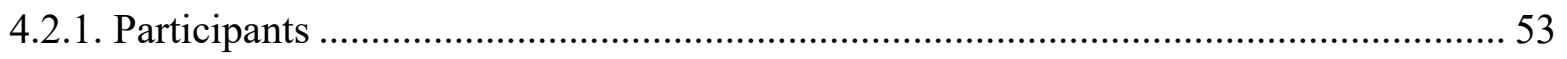

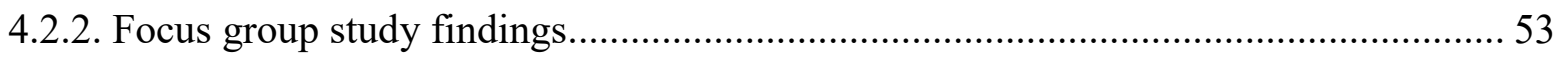

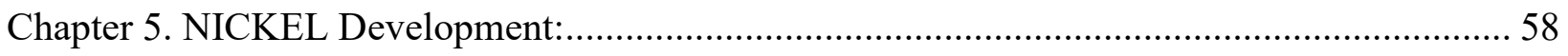

5.1. Vision of NICKEL (Needs Elicitation Methods Compatible with Key End User

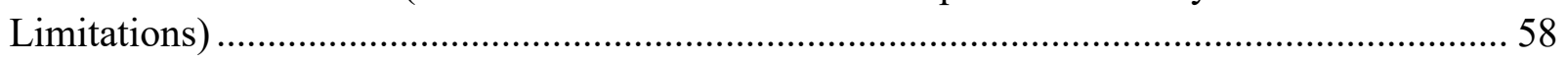

5.2. Database creation for development of NICKEL ........................................................ 58

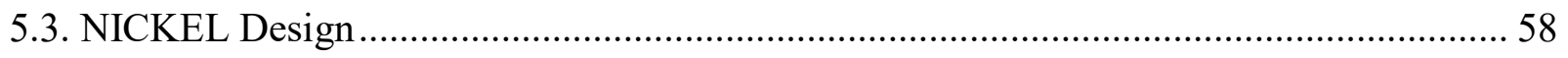

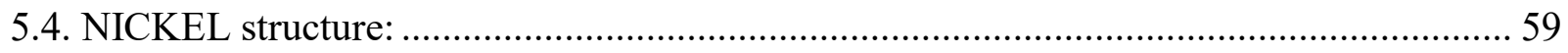

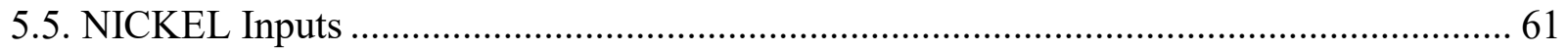

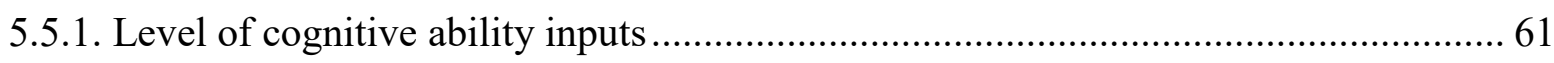

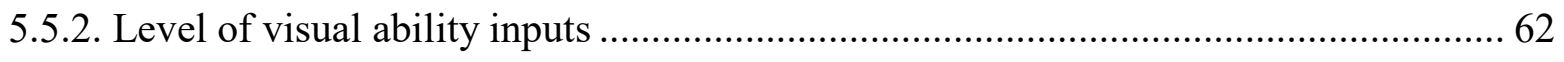




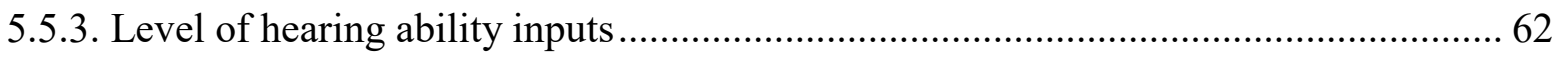

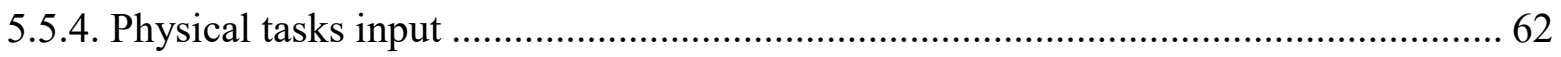

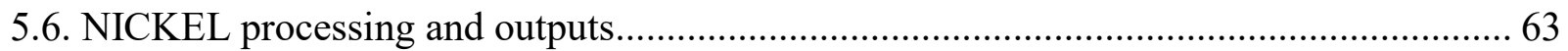

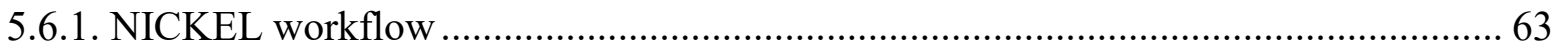

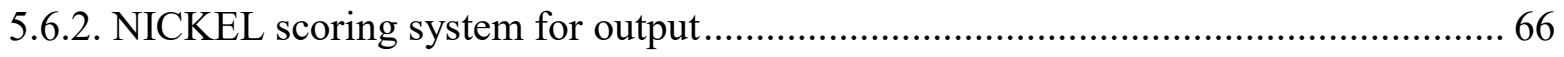

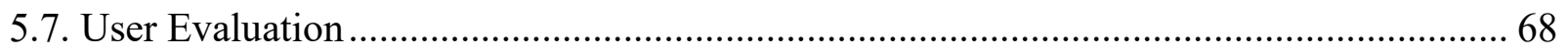

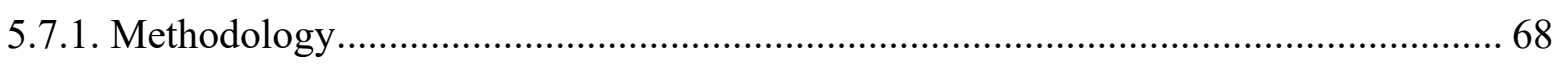

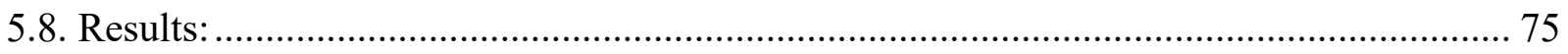

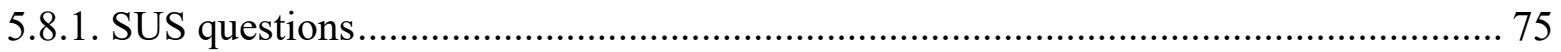

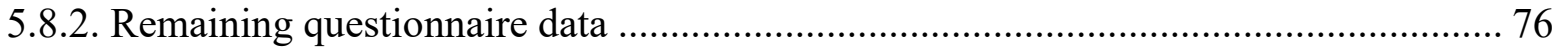

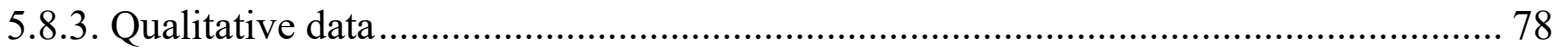

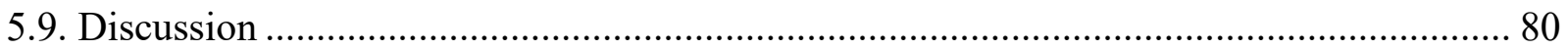

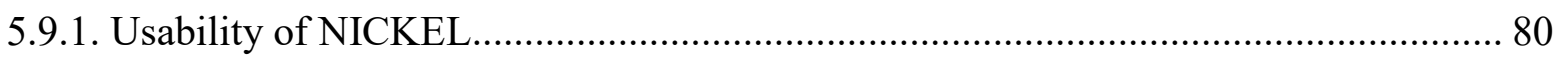

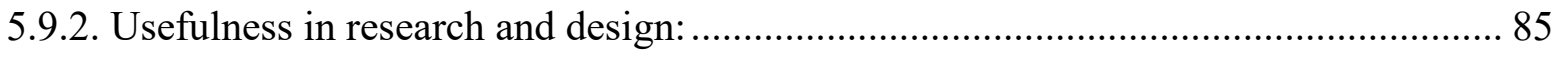

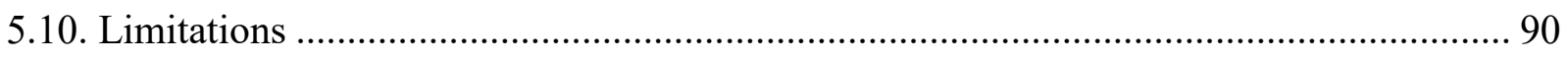

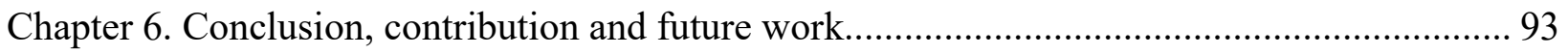

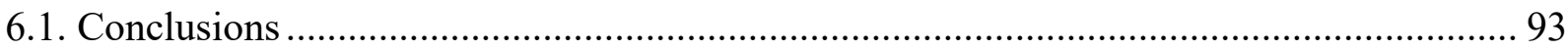

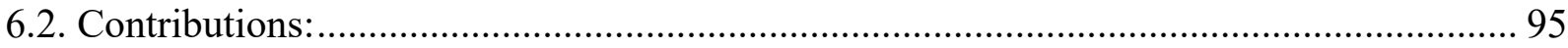

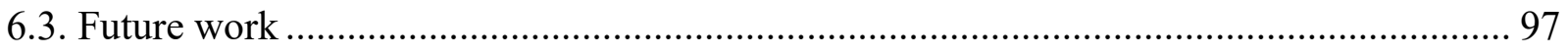

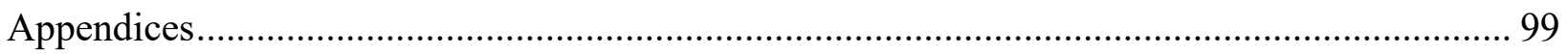

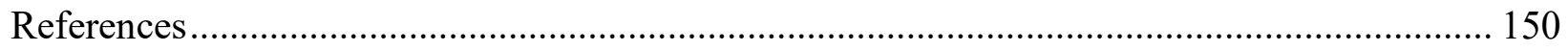




\section{List of Tables}

Table 1: Categorical label of statistical mode for acceptable level of cognition and the level of difficulty to participate in UCNEMs due to varied visual and hearing abilities (Not highlighted and marked with $\mathrm{a}^{*}=$ statistically significant; Highlighted in yellow - statistically insignificant, but mode value still used due number of responses $>5$; Blank cells $=$ Statistically insignificant with fewer than five responses) --------------------------------------------------------48

Table 2: Physical capabilities necessary to participate in the different UC needs elicitation methods $(\mathrm{Y}=$ Yes (Capability required), $\mathrm{N}=$ No (Capability not required)) -------------------49

Table 3: Scale used to determine difficulty to participate in UCNEM and their numerical values

Table 4: Scoring of the level of difficulty to participate in UCNEM with different hearing and visual abilities -----------------------------------------------------------------------------------------------66

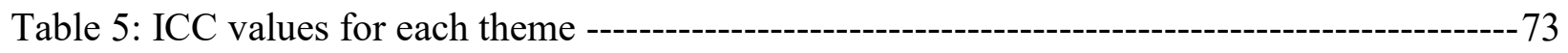

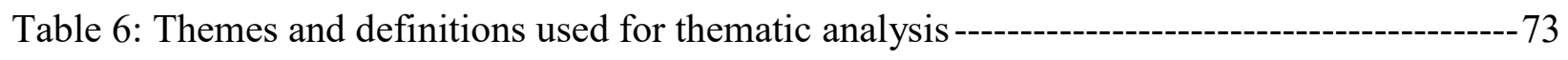

Table 7: Chi square results for SUS scale ---------------------------------------------------------------75

Table 8: Chi square results for significant likert scale questions from Section 4 to 7 of the post study questionnaire 


\section{List of Figures}

Figure 1: Summary of User-Centered Design methods selection criteria in use in the literature-35

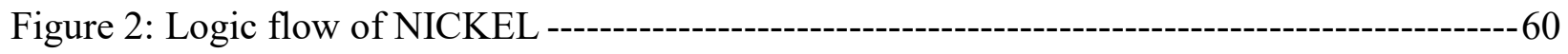

Figure 3: Screenshot of the NICKEL tool where inputs of potential participant's cognitive, hearing, visual and physical abilities are entered.

Figure 4: Screenshot of NICKEL outputs and below the outputs is the description of the UCNEM and general guidelines to be considered while conducting needs elicitation studies with older

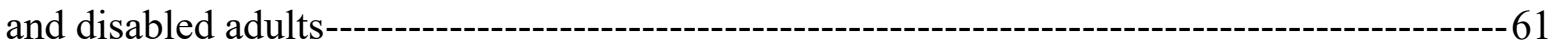

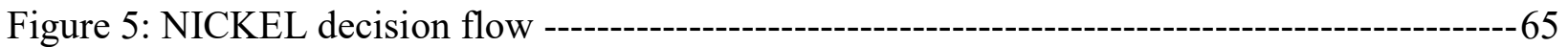

Figure 6: Mean SUS scores and standard deviation bars for novice and expert participants $>71.4$

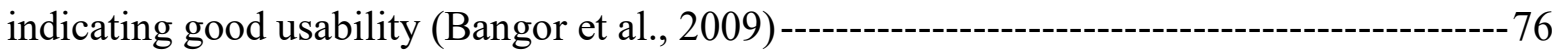

Figure 7:Frequency distribution of positive and negative comments from participants for each theme

Figure 8: Percent of comments from expert and novice participants for each theme $-79$ 


\section{Chapter 1. Introduction}

User requirements or needs elicitation for products and technologies are the processes of discovering user requirements through consultation with stakeholders, from system documents, domain knowledge, and market studies (Sommerville \& Sawyer, 1997). It is important to carry out user requirements elicitation studies at the early stages of the design process because they let researchers and designers understand the needs of the stakeholders associated with the products and technology. Involving users and conducting requirements gathering studies help to increase the product and system quality (Kujala, 2003). It is also crucial to carefully and thoroughly identify the stakeholders because, choosing the wrong participant will affect the quality of data (Sharp, Finkelstein, \& Galal, 1999). However, older and disabled adults who engage in the user requirements elicitation process tend to have different disabilities that will change the way they can participate and thus affect the type of UCNEM that can be used (Lines \& Hone, 2002; Sujan, Fels, \& Neumann, 2017; Sujan, Neumann, \& Fels, 2016).

Measuring and fulfilling requirements of older adults in the development of assistive devices can result in successful products, reduced product recalls and avoidance of frequent design modifications (Martin, Murphy, Crowe, \& Norris, 2006). Capturing needs and desires as well as system requirements from older adults is part of a human-centered or inclusive design. According to British standards institute (2005) "The design of mainstream products and/or services that are accessible to, and usable by, as many people as reasonably possible ... without the need for special adaptation or specialized design" (p.8). Included in the system development process is the involvement of potential users in all the stages of the design process (Sun, 2013).

Applying the principles of inclusive design can aid designers in serving the needs that the end user requires of a product and can enhance safety and agency for the individual (Shah \& 
Robinson, 2006). Despite an increasing older adult population, organizations and researchers tend to concentrate on producing technologies aimed at younger audiences because companies want products that suit the masses so that profits are maximized or it is too difficult to engage older adults (Eisma et al., 2004).

Although some designers and engineers adopt the practice of involving end users in the early stages of the product development process, different factors, such as the use of proxies instead of real end users impact the quality of data collected (Martin et al., 2006). As a result, there is an increased chance of usability issues with proposed products because older adults will not get a chance to report the functionalities and attributes which are important to them. (Eisma et al., 2004). This data on the needs of the end user cannot be captured if proxies are used in the needs elicitation study instead of actual end users.

Despite the increased recognition of the importance of requirements gathering in the design process, older and disabled adults are often left out in the design process (Keates \& Clarkson, 2003). There are various reasons why designers/researchers do not include older and disabled adults in needs elicitation process including (1) limited established inclusive UCNEM available; (2) lack of resources to conduct research (Putnam \& Rose, 2009); (3) designers design for themselves assuming all end users are similar to them (Crilly \& Clarkson, 2006; Keates \& Clarkson, 2003); and (4) designers may lack the knowledge or experience to choose the right research methodology for their project and participants (Ellis \& Levy, 2010; McDonagh-Philip \& Bruseberg, 2002).

Although there are many UCNEM available, very little information has been generated on the extent to which they have been used in designing for older adults. Older adults may have a 
varying and diverse set of human capabilities such as cognition, physical and perceptual abilities that are different from younger users. This makes it difficult for designer/researchers to determine the compatible method that can be used with the end of the curve user population. As a result, older adults have generally been excluded from the development process, particularly of assistive technologies, or are being consulted at the end of the design process (Soares, 2012). Despite the importance of human capabilities in the needs gathering process for older adults, the traditional requirements elicitation process only takes factors such as problem statement, project domain and final customers (Ferre \& Bevan, 2011; Hickey \& Davis, 2003a, 2003b) into consideration when UCNEM are selected. The inclusion of human capability demands from the participants to accommodate them in the UCNEM is often overlooked.

To address this issue, a new tool called NICKEL has been developed with the goal of providing a more inclusive and user-centered needs elicitation methods selection process for designers based on the prospective participant's cognitive, motor and perceptual abilities. NICKEL can be used by novice researchers and designers who are working with older and disabled adults to determine compatible UCNEMs. NICKEL requires that designers/researchers consider their potential participant's or user's cognitive, physical, hearing and visual abilities as inputs and provides compatible UCNEM as outputs.

To describe how NICKEL was developed and evaluated, the following research questions will be answered in this thesis:

1. What are the level of human capabilities needed by older adults to participate in the different user participatory needs gathering methods in terms of visual and hearing abilities, motor skills and cognitive abilities? This research question will be addressed in chapter 4 of this thesis. 
2. How can the knowledge on level of human capabilities in terms of visual and hearing abilities, motor skills and cognitive impairment be used to develop a tool that assists in determining the UCNEM? This research question will be addressed in chapter 5 of this thesis.

3. Is the Needs Elicitation Methods Compatible with Key End User Limitations (NICKEL) tool an effective, viable and usable tool for novice designers, developers, and researchers to determine UCNEM methods compatible with older/disabled participants? This research question will be addressed in chapter 5 of this thesis. 


\subsection{Research contributions}

The research contributions for the thesis are:

1. A theoretical contribution where an assessment framework containing the cognitive, visual, hearing demands and the physical capabilities required to participate in 19 UCNEM was created. A survey was administered with experts to populate the database when there was no literature on the demands and capabilities required from older and/or disabled adults to participate in a specific method.

2. This framework is the foundation of NICKEL, which is a tool used to determine UCNEM based on the prospective participant human capabilities identified by the designer/developer users of NICKEL. NICKEL allows the user to input four human factor (HF) components: cognition, vision, hearing, and physical abilities. NICKEL uses a ranking system which provides a list of five colour coded UCNEMs, where the UCNEM coded in green is the best fit for the participant capabilities selected, yellow is somewhat compatible but still recommended and red is the UCNEM that is least compatible and least recommended. Having more than one recommended UCNEM provides a range of options for users to consider.

3. NICKEL has also been evaluated with novice, and expert designers and researchers in order to evaluate NICKEL's usability and usefulness, and understand the impact the suggested UCNEMs on users. NICKEL then is an applied and technical contribution of this thesis. Also, if NICKEL is integrated with other tools/ frameworks which uses other factors such as type of data, number of participants, cost to conduct the study, human resources available there is a chance that there might not be any UCNEM in the output. 


\section{Chapter 2. Literature review}

This chapter provides background and review of general user-centered design (UCD) methods from different fields of study, specifically, for gathering needs of older adults to develop assistive products and technologies. Also, this chapter provides an examination of the different criteria or factors considered when designing needs gathering methods. Topics in this chapter are primarily used to describe the different approaches used in the field of user-centered design which motivated and led to the creation of NICKEL.

\subsection{What is User Centered Design (UCD)?}

UCD methods and usability testing are sometimes confused and misunderstood as the same. Hence, it is imperative to clarify the difference between UCD and usability in the context of this thesis. UCD is a design approach comprising of a variety of methods where users are consulted primarily regarding their needs and are involved usually in all phases of the design process especially during the needs gathering and users testing stages. UCD also includes a set of methods where users contribute to the design by being involved as direct or indirect partners with designers throughout the entire design process (Abras, Maloney-Krichmar, \& Preece, 2004). Both of these approaches involve gathering needs from the end users which are usually used in the first stage of the UCD process. Usability testing is a set of methods in user-centered design that specifically measure usefulness, efficiency, effectiveness, learnability, satisfaction, accessibility and ease of use of designs (ISO 9241-11, 2017; Rubin, J., \& Chisnell, 2008; Vredenburg, Isensee, \& Righi, 2004). Requirements elicitation is considered unnecessary in certain instances (A.M. Davis \& Zowghi, 2006) and often occurs in the final phase of a UCD process once there is an interface or prototype product to assess, or for a penultimate step in case the UCD process involves revisiting or modifying the existing design based on user feedback. 
In general, ISO 13407 describes user-centered design as a multi-disciplinary design approach based on the active involvement of users to improve the understanding of user and task requirements (ISO, 1999; ISO 9241-11, 2017). UCD incorporates human factors (HF) and ergonomics knowledge and techniques with the objective of improving human working conditions, and counteracting the possible adverse effects of the product on the user, safety, and performance (Mao, Vredenburg, Smith, \& Carey, 2005).

According to a study conducted by Rauch \& Wilson (1995) with the participants of the CHI conference in 1994, it was evident that UCD was not popular or not considered important as part of the product development process (PDP) by computer scientists and engineers. A follow-up study conducted by Vrendenburg at the CHI 2000 conference showed early signs of acceptance of the concept of usability and importance of UCD in the PDP (Vredenburg, Mao, Smith, \& Carey, 2002). With the awareness on the importance of UCD, there is also literature indicating the recent adaptations of UCD in healthcare, design and evaluation of mobile applications for older adults (Ghazali, Ariffin, \& Omar, 2014; Jochems, 2016). In terms of User Centered Needs Elicitation Methods (UCNEM), the study conducted by Hussain, Slany, \& Holzinger (2009) indicates the increased adaption of UCNEM and usability evaluation methods in mainstream technology by HCI practitioners with able-bodied users (Hussain et al., 2009). Only limited literature could be found indicating the increased adaption of UCNEM with older and/or disabled adults, which indicates that less effort has been made to include older and/or disabled adults in the design process.

\subsection{UCD process map}

Every UCD process should have the following four phases: 1) Needs gathering and analysis; 2) design; 3) evaluation; and 4) deployment of the product in the market (Gorransson, 
Gulliksen, \& Boivie, 2003). A detailed research conducted by Khong (2000) mapped out the UCD methods such as interviews, camera probes, prototyping, etc. which can be used in each stage of product development process (PDP) developed by Pugh (1991). These UCD methods related to requirements elicitation stage in PDP will be further explained in section 2.4 of this thesis. It is important to note that many of the methods in PDP are still used in current research and design practices. Considering the established UCD design phases and a pool of UCD methods available it is up to the designer or researcher to determine which methods are appropriate to use for a specific product or scenario. Needs gathering is a more important stage of the design phase and affects the other stages of the PDP process (Javed, Maqsood, \& Durrani, 2004; Lloyd, Rosson, \& Arthur, 2002). The necessity for needs gathering and involvement of older and/or disabled adults in needs gathering will be described in the next section.

\subsubsection{Needs gathering phase:}

Before discussing the needs gathering process, it is essential to understand what "the need of a user" is. According to Witkin \& Altschuld, (1995) "A need is generally considered to be a discrepancy or gap between what is, or the present state of affairs in regard to the group and situation of interest, and what should be, or a desired state of affairs" (p.4). In general, needs gathering is usually performed by designers or researchers who are involved in designing the final product (Pressman, 2005). However, larger companies often hire agencies and/or independent researchers to conduct needs assessment, market research or usability studies for their products.

According to Witkin \& Altschuld (1995), there are two phases of conducting assessments: pre-assessment and main assessment. The pre-assessment phase includes: 1) defining the purpose of the needs gathering exercise; 2) setting up the management plan for needs gathering; 3) identifying major needs areas or issues; 4) determining the data to be collected and researching 
existing methods to be used to collect the data required; and 5) how the collected data will be used in the research (Witkin \& Altschuld, 1995). As part of the pre-assessment, of the needs elicitation, every designer or product developers have to identify their stakeholder and goals to be met. Stakeholders comprise of individuals or companies who are impacted by the success or failure of the system or product (Nuseibeh \& Easterbrook, 2000). Also, choosing the right stakeholder is important to gather reliable and rich data.

The main assessment phase is where the actual data gathering process occurs. As part of the main assessment stage, the person conducting the needs assessment also determines the scope and boundaries of the procedure.

\subsubsection{User(s)}

Eason (2005) classified users into three categories: primary, secondary and tertiary users. Secondary users or occasional users are defined as the ones who are not in direct contact with the user interface or use the product less frequently (Tenhue, 2016). Tertiary users are those who are affected by the introduction of the system or the influence of its purchase (eg. sales personnel, people who buy the product as a gift but do not directly or indirectly use the product). Legislators and decision-makers are also considered tertiary users. Legislators are usually the government bodies, auditors and legal representatives who essentially produce guidelines and legislation for a particular product or series of products, which then, in turn, can have an impact on its production. The management committee consists of people who make decisions that concern the development of the system or product. This user group will include managers of the development team and financial executives.

Primary users are the ones who are inclined to be in direct contact with the product or the system. Hence, end users fall into this category. End users can again be divided into novice user, 
expert user, disabled user and so on. They play a vital role in both needs elicitation and usability testing especially in case of interactive systems such as web interfaces, software, and applications.

By 2050, more than 2 billion people in the world will be considered older adults (Sustar, Pfeil, \& Zaphiris, 2008). According to Stats Canada, 33\% of the older adults who are 65 years of age and above are considered to be legally disabled (Government of Canada, 2015b). Since older and/or disabled adults will make up a significant proportion of the user population in the future, it is important for researchers and designers to consider them in the needs elicitation studies and incorporate their needs in the product features and characteristics.

\subsection{Older adults as end users}

Although Vredenburg's study conducted in 2000 indicated that engineers and scientists had initial interest in the inclusion of the user perspective in product design, most considerations were for average, healthy adults. However, there is a wide variety of potential users including older adults and people with disabilities. Despite being a large singular group within the population, they are left out of the design process which means the unique needs of older adults are often not considered by companies (Keates \& Clarkson, 2003).

One of the primary reasons, for this reason, is that when designers start the design process, they instinctively consider themselves as the end user which defeats the purpose of UCD (Cooper, 2004). As mentioned earlier in this document, the limited inclusion of end users in needs elicitation can negatively affect the end product and user satisfaction. Therefore, it is necessary to understand the dissatisfaction of the products used by older and/or disabled adults, why they are dissatisfied and how it relates to exclusion of older and/or disabled in the needs elicitation process.

Statistics Canada mentions that 8 out of 10 older adults use assistive devices (Government of Canada, 2015a). But, even with the high recorded use of assistive devices among older adults, 
there are multiple studies from the past two decades which show that older adults dislike and are dissatisfied with those assistive devices on which they depend:

1. One of the earliest studies showing dissatisfaction with assistive technology or consumer products was conducted by Phillips \& Zhao (1993). Results from studies conducted with 227 adults showed that most of their assistive devices were found to be not useful and $29.3 \%$ of the devices were completely abandoned due to dissatisfaction.

2. A study conducted by Riemer-Reiss \& Wacker (2000) with 115 older adults showed that $32.4 \%$ of the participants discontinued their assistive devices. Around $47 \%$ of the individuals who discontinued their assistive product used it before discontinuing it and $6.4 \%$ never used the product. The primary reasons for the non-usage of a purchased assistive devices were lack of reliability, ineffectiveness, and lack of comfort.

3. In 2010 Joode, Heugten, Verhey, \& Boxtel conducted a systematic review where they identified 25 studies to determine the usability of assistive devices and technologies with cognitively deficient patients. The studies showed that most of the patients were dissatisfied with their assistive devices with the primary reason to dissatisfaction being the lack of confidence in using the devices.

4. Numerous tetraplegic ${ }^{1}$ patients have reported difficulty in being able to use a computer for messaging services, typing or even pushing a single button. This has led to reported user frustrations and dissatisfactions (Folan, Barclay, Cooper, \& Robinson, 2015).

5. In a recent study conducted with older Hispanic nationals on the functional limitations and unmet needs of assistive technologies. Orellano, Rivero, Lizama, \& Jutai (2017) found that older adults needed the designers to fix deficits in their assistive devices related to activities of daily

\footnotetext{
${ }^{1}$ Tetraplegia is a paralysis, where the person will be having partial or total loss of use of all four limbs and body.
} 
living, which concurred with the findings from another research study conducted by Cheek, Nikpour, \& Nowlin (2005). This again shows the lack of attention given to the user needs when the product was initially developed.

All this evidence on dissatisfaction and abandonment by older adults points to products being unable to meet the needs of this user population and could be deemed failures. From these studies, $65 \%$ of the reasons behind the non-use and dissatisfaction by participants related to usability issues such as screen interface accessibility issues, incompatible dimensions and so on. A study conducted by Mann, Goodall, Justiss, \& Tomita (2002) with 873 older adult participants showed the following as the top reasons for the dissatisfaction and nonuse of assistive devices:

1. $30.5 \%$ reported that they would try an assistive only if it is necessary to use.

2. $23.9 \%$ found the assistive device unnecessary.

3. $3.9 \%$ reported their devices were heavy.

4. $2 \%$ of the participants reported that the assistive device is too complicated to use.

5. $0.8 \%$ of the participants reported that the product was not compatible with the user.

Also when the Quebec User Evaluation of Satisfaction with Assistive technology (QUEST2.0) questionnaire was given to the patients in the Italian territorial health service providers, most assistive technology users reported dissatisfaction with their devices. Usability issues such as simplicity to use, compatibility of the device with the person in terms of size, features and comfort were the primary factors mentioned by the patients for their decision on whether to use or abandon an assistive device (Federici \& Borsci, 2011).

If older and/or disabled adults are facing usability issues with assistive technologies that are supposed to be specifically designed to support their needs, it would seem unlikely that more mainstream devices such as cell phones and televisions are even less usable by this population. In 
a study conducted to assess the usability of the touchscreen mobile features with older adults, Page (2014) reported that participants aged 65 years and over had a high difficulty interacting with the phone's touchscreen. This occurred because of small text and menu sizes, difficulty typing text, and difficulty locating finding applications all of which were difficult to navigate due to limited hand dexterity.

In general, many of the usability issues that have been reported by the users in the different studies could be solved if the developers or designers of the products involved the end users in their design process. Limited inclusion of end users not only causes usability issues but will also lead to product failure which can be seen as evidence in the studies discussed earlier in the literature. User involvement in the design process has a direct correlation with system usage and the user satisfaction (Baroudi, Olson, \& Ives, 1986). Despite all the reported dissatisfaction, abandonment of devices and inconsistencies between the product features and needs of the user and the importance of involving users in the design process, older and disabled adults are often left out of the design process especially during the needs gathering phase (Keates \& Clarkson, 2003).

There are various reported reasons on why designers do not include older and/or disabled adults in the design process.

1. Technology developers and designers find it easier to research and design for people in their own age group with similar needs rather than designing for a wide range of users having a wide range of needs and expectations (Keates \& Clarkson, 2003). This is because they are either unaware of the needs of older and/or disabled users or do not know how to accommodate their needs in the design process. 
2. Younger, older and disabled adults will have different experiences on using modern technologies compared to the younger users which makes it difficult for them to discuss it in the design process. Older adults feel that this experiential gap limits their ability to contribute significantly to needs elicitation or a design study discussion (Eisma et al., 2003). It is the role of the designers to make participants comfortable and find ways to keep them from feeling excluded in the design process due to their lack of experience.

3. The needs of the older and/or disabled adult population are varied which makes it complex to incorporate it into the design. Hence, designers may be inclined to ignore the inputs provided by this user group, thereby not following the guidelines of user-centered and inclusive design needs gathering processes (Goodman, Cassim, Langdon, \& Clarkson, 2007).

4. When companies conduct research, designers tend to take shortcuts on recruiting participants for convenience purposes. For example, Crilly \& Clarkson (2006) report on designers reasoning as "We tend to use wives, and friends and things. We don't go out of our way to do research."

5. Budget constraints affect the extent to which user studies are even conducted. Reduced budgets hinder designers and researchers from recruiting wider range of user groups for a needs elicitation study. Limited availability of funds can also prevent the management to hire professionals for running the research studies (Putnam \& Rose, 2009).

6. Most product manufacturers either outsource the needs gathering process to third party market research companies or get the required data from them (Hirasawa, Yamada-Kawai, Kasai, \& Ogata, 2010; Kaczmirek \& Wolff, 2007). In this case, company designers are unable to involve actual end users in the design process. This practice runs the possibility of the third party research 
companies missing data during analyses which might be essential for the product design. Hence there is a possibility that the end product might not have all the features required by the end user.

"We don't carry out consumer research, we get it from the market research department. we interpret it the best we can." (McDonagh-Philip \& Bruseberg, 2002, p.34).

7. Lack of skills to conduct a needs gathering study with the end users was identified as one of the major factors on why older and disabled adults are left out of the design process (Goodman et al., 2007; Keates \& Clarkson, 2003).

This lack of skill can be from either the lack of experience conducting needs gathering studies or lack of understanding of the methods available and the scenario under which each method can be used. Comments such as "I need to know about writing questions to get meaningful answers"," some of the questions were too open, others too closed, it is necessary to tease the individual to understand their real views...", " it needs to be done properly and professionally; I think a trained moderator would probably do the job better" (p.33) were common in a case study carried out with two by McDonagh-Philip (2002). Even when designers and engineers conduct user studies themselves, not all the UCNEMs are used to gather needs from their consumers. For example, using usability questionnaires such as ISOMetrics (Hamborg \& Gediga, 1997) to capture user opinions or feedback on the usability of systems provides less reliable data if user experience designers plan on revising their interactive design. A think aloud protocol with a combination of usability questionnaire could provide more reliable qualitative data (Charters, 2003). To address such issues, a UCD planner tool was developed which uses factors such as the type of data required, the effort required, cost and so on to determine a UCNEM (Ferre \& Bevan, 2011).

Also, there are studies showing the difficulty faced in conducting focus groups studies with people having sensory impairment and hearing difficulties without the recruitment of interpreters. 
This led to difficulty in collecting information from deaf participants in a study conducted by Kroll, Barbour, \& Harris, 2007 (p.63). A better option would have been to administer a survey method when an interpreter could not be hired. If professional researchers and designers face such problems, it would not be surprising that novice and new designers would find difficulty gathering proper data from the end user. Based on the above scenario it seems that deciding on the UCNEM that best fits target end users or research methodology is important to gather data and make the participant comfortable in the study.

Determining the most appropriate methods to be used in research and design either comes through using a UCD planner tool or through the knowledge of deciding compatible methods to be used with older and disabled adults. It would seem that designers lack the knowledge and willingness to engage older adults and/or adults with disabilities in their research or design study for a large variety of reasons. This lack of knowledge likely stems from the early stages of a design or engineering career where less emphasis is given to human factors and users in their university courses and projects (Neumann, Village, Bristow, \& Salustri, 2015).

There is an opportunity to develop a solution which assists novice designers, engineers and researchers working with older and disabled users in determining a UCNEM which is compatible with their participant's human capabilities which will be addressed in this thesis.

\subsection{UCNEM usage in older adult community}

Since there is a need to develop a solution to determine compatible UCNEMs it is important to review how these methods are used in the research and design processes. For my research, a UCNEM is selected based on the following conditions: (1) if the method involves direct user participation; and (2) it is a standard method used in research studies. 
This literature review section 2.4 (2.4.1 to 2.4 .7$)$ was performed at the beginning of the research and was published at the International Conference on Human Interface and the Management of Information (Sujan et al., 2016).

\subsubsection{Questionnaire}

Questionnaires are often used in psychological and social science studies, although its usage on an HCI or user need analysis context is comparatively minimal (Arsand \& Demiris, 2008).

Here, the feasibility and some of the ways in which questionnaires have been used with older adult populations is summarized. According to a study conducted by Troyer, \& Rich (2002) questionnaires have been used as a meta-memory self-reporting tool, which allows the researcher to measure the everyday memory problems amongst the targeted older adult population. Twentyone items that addressed various emotions and perceptions of concern to the participants' current memory ability were used in the questionnaire. Another study conducted with older adults having subjective memory complaints aimed to develop a questionnaire to measure the perceptions of older adults' help-seeking behaviour (Hurt, Burns, Brown, \& Barrowclough, 2010). Additional measures were taken using the Geriatric Depression Scale and Memory Functioning Scale to capture depression level due to memory impairment and to assess their memory complaints. Although these questionnaires are being used to understand the older adult's capabilities, designers have given less importance of understanding whether these extensive questionnaires can be used successfully with people having disabilities.

Mruntinga.et.al (2014) shows the questionnaire designed to measure the client centeredness of a home care service imposes a cognitive burden on the older participants because it is too long and difficult to understand. There are also difficulties imposed upon the study 
participants who are blind or have low vision (Kaczmirek \& Wolff, 2007). Especially people with tunnel vision will have difficulty having a full visual overview of the survey page. For example, if person with low vision uses a magnifier in paper/computer to answer a list of survey questions starting with the same words, there is a chance that the survey participant misses a question when moving the enlarger to the next line. Font size also affects the ability of older adults having low vision, to successfully complete the surveys. Although 12-point font is used in general while writing documents, it is not preferred by older adults as they increase the eye strain due to increased reading time. A study conducted by Bernard, Liao, \& Mills (2001) with 27 older adults indicates that older adults prefer sans serif 14 point font rather than the standard 12 point font. Therefore, there are different difficulty faced by older and/or disabled adults to participate in survey studies and guidelines needs to be considered while designing surveys for older adults (Bernard et al., 2001; Kaczmirek \& Wolff, 2007). Based on the findings from the articles, most of the scenarios where questionnaires are used with older adults tended to gather information on their social life, illness, psychological ability and opinion. Also, older and/or disabled adults with cognition and visual problems face difficulty while participating in a survey study unless the necessary guidelines are followed.

\subsubsection{Focus Groups}

"Focus group is a group interview technique where the moderator guides the interview while a small group discusses the topics that the moderator raises" (Morgan, 1997b, p.1). The focus group method is a very important qualitative tool for exploring a particular topic in which is little known (Hawthorne et al., 2006). The benefit of the focus group method is that it creates an interaction between the moderator and the participants: it allows the moderator to get a full 
explorative view of the participants without the decontextualization that usually occurs with questionnaires (Claes \& Heymans, 2008).

Six papers were identified where focus groups have been used as a primary method of data collection with older adults. One example of a structured focus group process is that developed and deployed by researchers from the World Health Organization Quality of Life (WHOQOL) (Hawthorne et al., 2006). They conducted a focus group that aimed at eliciting key concepts of life among older adults in a multi-cultural scenario. Since the sessions were conducted at multiple locations guidelines for conducting the sessions were established that included a timeframe for conducting the group, number of groups, preparation for conducting the groups, procedure and structure of the focus groups discussion (Den Oudsten, Lucas-Carrasco, \& Green, 2011). The guidelines were designed for adults over 80 years of age and four to six members in each group. Researchers were only able to partially complete their discussion due to the many strict guidelines set by WHOQOL. Claes \& Heymans (2008) insists if a focus group study was being conducted where participants were recruited from only one age-based user group, it would narrow the focus, which involves the risk of fixating on the solution and leaving other relevant solutions unexplored.

In a focus group, moderators can begin the session at a point that participants cannot follow making the information from session less useful or unrepresentative of actual participant opinions. To address this issue researchers from the University of Salford implemented a roundtable concept where participants were brought together and thoroughly briefed about the topic to be discussed (Raynes, Coulthard, Glenister, \& Temple, 2004). An increase in the confidence level of the participants about the topic to be discussed was observed. Findings from the papers reviewed show that there are multiple ways of conducting a focus group and as a result, there were many key 
issues that must be considered. Apart from these issues, the participant's capability also needs to be considered when conducting focus group session.

In a focus group study conducted by Lines \& Hone (2002) with older adults, indicates that older adults tend to lose their attention to the topic quickly when the focus groups were loosely structured. The moderators of the focus group session, had difficulty managing the participants and directing them back into topic, due to their limited attention and memory. When moderators conducted a structured focus group with the same participants, they still had difficulty having the older adults focused in the topic due to their limited attention. Although the outcome of this experiment favoured the structured focus groups, where moderators found it relatively easy to gather the required data, the depth of information obtained was limited. In the case of conducting focus groups with participants who were Deaf or hard of hearing, studies show that, although the communication between the hearing and Deaf participants takes long time due to the real time captioning issues or due to some Deaf participant's language deficiency, effective data were be gathered from the participants as long as there is an interpreter and proper technical setup is provided. The above studies were concentrated on gathering information to assess the mental ability, behaviour and identifying the problem faced in conducting focus groups with older adults.

Results from the papers reviewed show that the focus group method can be an effective way to identify user needs even if it is time-consuming and difficult to be conducted with older and/or disabled adults. It has also been accepted by the older community because it helps them put forward their opinions in a supportive environment (Pattison \& Stedmon, 2006). Therefore, the following criteria need to be taken into consideration to conduct effective focus group studies: 1) if a focus group study is conducted predominantly with older and/or disabled adults, make sure the participants in the focus group studies are grouped with participants of similar abilities as this 
makes the conversation easier; 2) when conducting a focus group study with Deaf participants make sure to have enough interpreters if the moderator does not understand sign language; 3) when conducting focus groups with hard of hearing participants, the moderator need to provide enough time to for the participant to listen to the conversation thoroughly even if they are using hearing aid.

\subsubsection{Cultural Probe}

When the designer does not know the group of participants for whom the products are being developed, it is difficult to understand the culture, attitude, behaviour, and preferences. According to Boehner, Vertesi, Sengers, \& Dourish (2007), cultural probes are a way to identify user needs. This method involves using digital cameras, diaries, paper prototyping and other materials. These probes are given to the participants with instruction to complete tasks such as "take a picture of the part of the device which you find problematic", "write down step by step how you carried out using the application and the issues faced". This will be later analyzed by designers which will initiate the user involvement with designers in the PDP process (Gaver, Dunne, \& Pacenti, 1999). The major criterion in conducting a culture probe activity is that the design kit should contain materials that will support the goal of the researcher. Also, the researcher should not make any addition or modification of the kit halfway through the process to justify the results (Caleb-Solly, Flind, \& Vargheese, 2011). For my research, eight papers were identified where a cultural probe method was used as a primary method of data collection which will be described below.

Based on the articles analyzed most studies conducted with the cultural probe methodology

have focused on understanding user needs. From research conducted by (Brown et al., 2014; Caleb-Solly et al., 2011; Leonardi et al., 2009; Wherton et al., 2012a) on using cultural probes as a technique for requirements gathering for developing assistive technology, cameras and diaries 
are the most common probe material to capture rich data. However, for my research, diary studies are considered as a separate UCD method and are discussed in section 2.4.4. Findings from the above sources show that cultural probe method is an efficient way to capture user experiences and data but another qualitative UCD method is required to elicit further information relevant to the design (Wherton et al., 2012a). Despite this advantage there are limitations with using cameras as probe items with older adults who are of low vision or blind participant. This is because they lack the ability to use the probe properly to capture the picture needed unless there are special accessibility options available (Bigham et al., 2010; Kutiyanawala, Kulyukin, \& Nicholson, 2011). Low vision participants might not even have a chance to use the accessibility options when researchers choose to use disposable cameras (Caleb-Solly et al., 2011; Wherton et al., 2012b). Cultural probes require more effort in preparing the kits and evaluating the data, but they provide a higher degree of insight. However, since cultural probes need good visual and cognitive ability, it might not be the best UCNEM to capture data from some older and/ or disabled adults having visual/cognitive disability (Thoring, Luippold, \& Mueller, 2013).

\subsubsection{Diary Study}

The diary study is used widely among medical researchers where patients are requested to keep a track of their treatment or diagnosis in the form of a written diary. Five papers were identified where diary studies have been used as a primary data collection method with older adults.

A diary provides written data on an individual's daily experience (Musil et al., 1998) and provides researchers/ designers with a large quantity of progressive and rich information. However, analyzing the large volume qualitative data generated by the daily reports can be a 
tedious and time-consuming process especially when a diary study can last between several days and several months (Morone, Lynch, Greco, Tindle, \& Weiner, 2008).

The diary study helps us understand the depth of the individual needs of older adults, as it varies across symptoms and each individual might be dealing with different problems ranging from acute to chronic conditions (Verbrugge \& Ascione, 1987). A diary study was conducted by Morone et al., (2008) to identify the effects of meditations on chronic pain, and sleep. Results from twentyseven participant's diaries provided with considerable depth into the experience of older adults, which the quantitative method could not provide. Participants were able to explain their feedback and record their opinions every day, rather than answer survey questions. Diary studies conducted by (Musil et al., 1998; Stoller, 1993; Stoller, Forster, \& Portugal, 1993) have used diary studies as a primary method to collect data from older adults concerning their illness behaviour and their interpretations of symptoms of illness. Although diary study seems to be good method to collect qualitative data on the problems older adults face in their daily lives to identify requirements, diaries cannot be used with all participants. Participants with severe tremor and problems with hand dexterity will be not be able to contribute effectively through this method (Bhidayasiri \& Tarsy, 2012). Also since diaries are written at the end of the day, participants need to have good memory retrieval capability. Therefore diary studies cannot be used with older adults who have less episodic memory retrieval (Guillaume et al., 2009; Maguire \& Frith, 2003).

Results from the articles reviewed shows that diary studies have been used widely by medical researchers to understand older adults' illnesses and the effect of treatment on them, but has been lesser used as an instrument to identify design requirements or user needs for assistive technology or devices. Although the diary study can be an effective way of collecting rich data and has been found to be less expensive, the difficulty faced by participants with limited hand 
dexterity and episodic memory retrieval issues combined the cumbersome process of analyzing the data collected makes it less desirable (Musil et al., 1998).

\subsubsection{Think Aloud Protocol}

The think aloud protocol, also known as verbal protocol, asks people to say out loud everything that they are thinking and trying to do (Jääskeläinen, 2010). The think aloud protocol has been commonly used in usability studies, but also to gather needs or requirements for the future versions of the product/technology. It is useful in studies highlighting problems faced by the participant while carrying out a task or process (Fausset, Mayer, Rogers, \& Fisk, 2016). In HCI, participants are asked to verbalize what they are thinking as they navigate through screens, pages, and menus in a test interface (Chung et al., 2015). This data will later be used as the requirements for the future versions of the product. Talk aloud can be used during exploration as well as when asking users to carry out representative tasks (Fausset et al., 2016). Five published articles were reviewed where Think Aloud Protocol has been used as a primary User Design method.

Think aloud protocol has been shown to be an effective method of understanding the user's view on a product (Mitzner et al., 2010). The same approach is adopted by (Luger, Houston, \& Suls (2014) where the author used the scenario-based think-aloud protocol to evaluate an online diagnosis tool and understand what older adults need in the future version website. The most common issues faced with older adults and people with cognitive disability are a deviation from task protocols (Chung et al., 2015), familiarity with the product or tool (Fausset et al., 2016; Luger et al., 2014), and balancing participant frustration with another task. For older adults, cognitive ability may also add complications to verbal protocol analysis if tasks are cognitively demanding such as 1) memorizing task steps; 2) too many options; 3) disorganized web pages etc., 
Researchers and designers need to recognize that for certain older adults the process of thinking aloud and navigating will be a dual task, and sometimes users cannot perform these tasks simultaneously due to possible limited cognitive and motor abilities (Luger et al., 2014). To address this problem, users can be asked to complete the task first without verbalizing and later perform the task again by thinking aloud. This approach is called retrospective think-aloud protocol (A. Gill, 2011, p.5). Although this approach seems promising, there are chances for older participants to forget what they did in the study if they have memory-related cognitive issues. This methodology can also be challenging for people who are Deaf because signing and controlling a computer is not possible as both required use of the hands. As a result, the Gestural Think Aloud protocol was developed by Roberts \& Fels (2006) which allows deaf participants to use sign language to record their comments/feedback of a task or system through gestures or sign language.

Based on the findings from the articles collected, it is evident that Think Aloud protocol is often used as a user evaluation tool and also as a UCNEM to gather the requirements for the future version of the software/products in the HCI studies with older adult participants.

\subsubsection{Interviews}

An interview in a qualitative research study is a conversation where questions are asked by interviewer elicit the required data from the interviewee. There are three major types of interviews; open-ended, structured and semi-structured (Fontana \& Frey, 1994). Unstructured interviews are also sometimes referred to as 'discovery interviews' where questions are more flexible and are intended to generate qualitative data. Structured interview is also known as closed ended questions which generates quantitative data (Mcleod, 2014). "Semi-structured interview is a qualitative data collection strategy in which the researchers ask the participant a predetermined but open ended questions. The researchers have more control over the topics of the interview rather than in 
unstructured interviews, but in contrast to structured interviews that use closed questions, there is no range of responses to each question" (Ayres, 2008, p.810). Unlike the focus group and thinkaloud protocol the interviewer imposes control on the conversation. Structured interviews have been used in scenarios where the designers need feedback on a product or design and want specific questions answered (Cohen \& Crabtree, 2006; Donker \& Markopoulos, 2002). Seven papers were reviewed where the interview method was used as a primary data collection instrument from older people.

Research conducted by (Jones, 2010; McCann \& Clark, 2005; Nordström, Dunér, Olin, \& Wijk, 2009) used unstructured and semi-structured methods to examine challenges faced by older adults with schizophrenia, to analyze the ways in which older adults with psychiatric disability experience geographical places and social relations, and to develop a patient diagnoses system. To understand the older adult's perception and experiences a structured framework cannot be used because it narrows the user response and will not help the designer/researcher pay attention to the participant's view on the issue (Moyle, 2002). In this scenario, the concept of unstructured interview technique is adopted as it provides the richest source of data compared to the other interview techniques (Fontana \& Frey, 1994). The use of semi-structured interviews not only enables the collection of qualitative rich data on unanticipated individual experiences but also the interviewer gets the information intended to capture with the inclusion of structured questions (Wang, Korotchenko, Clarke, Mortenson, \& Mihailidis, 2013).

Results from the studies reveal that structured interview technique is often used to gather feedback from older participants and unstructured interview technique is used to gather information on older adults' perceptions of illness or the experiences in the daily life. They were not used to gather older adult needs. 
Regardless of the interview type, interviews help the researcher capture the intended information in a qualitative form that is comfortable for participants. However, in the eight articles interviews were only carried out with between 15 to 20 older adults since each session took between 60 to 90 minutes, and the health and mental condition of each individual made the process more complicated.

\subsubsection{Prototyping}

"A paper prototype is a visual representation of what the system will look like. It can be hand drawn or created by using a graphics program. Usually, a paper prototype is used as part of the usability testing, where the user gets a feel of the User Interface" (Vijayan \& Raju, 2011, p11). But paper prototyping is also used by designers in the requirements gathering phase to understand how the interfaces need to be structured for the final design. Paper prototypes can be expressed in two forms: low or high fidelity. The low fidelity paper prototyping requires more cognitive work as the participant must understand the purpose of the design provided by the designer and must create the prototype themselves. This can be frustrating for some older and/or disabled adults when performing the process for multiple scenarios due to increased cognitive, visual and physical ability needed to finish the task given by the designer. Hence it may not be effective to be used with all older participants.

High fidelity prototyping is used as an approach to design high-quality prototypes with the aim of incorporating complete functionality, thereby making the product fully interactive and usable for testing. Due to the high technical knowledge needed, this approach is may not be suitable to be used with older adults who have cognitive issues.

Both types of prototyping can be difficult for the older adults because most individuals lack design vocabulary and the cognitive and/or visual ability to participate in a paper prototyping 
exercise (Hawthorn, 2007). Despite method requiring a significant amount of cognitive, physical and visual effort required from the study participants, results from studies (Rice \& Alm, 2008; Sellen, Massimi, Lottridge, Truong, \& Bittle, 2009; Siek et al., 2011; Vijayan \& Raju, 2011) show that the paper prototyping has been widely and successfully used in HCI studies with older adults to design computer application interfaces and interactive products as it provides designers a clear idea of how the end user wants their product/ technology to work.

The above literature review section on the different UCNEM shows that there are difficulties faced by older adults in each method. This indicates that in the pre-assessment phase of a needs gathering process designers need to assess and determine the UCNEM that fits the older and/or disabled participant's capabilities. Before discussing on the studies performed on how UCNEMs are selected for a research and if the human capabilities/ factors are considered in the UCNEM selection process, it is important to understand how human factors are generally considered in the workplace and design process.

\subsection{Application of human factors in product design}

Accounting for HF in product design or the development cycle suffers from the same problem as in organizations in general. Despite the strict government standards/ regulations and the negative impact of excluding HF from the design process, there is the prevalence of lack of focus to HF in organizations (Johnsen, Kilskar, \& Fossum, 2017; Sætren, Hogenboom, \& Laumann, 2016). The Human Factors Integration Defense Technology Centre (a UK organization established with the aim integrating HF in military defense technologies) created a database with more than 200 methods which includes UCNEM, task analysis methods, human error identification methods etc., Of the 200 methods, 91 methods had in-depth descriptions on how to use them (Stanton \& Salmon, 2004). This database only provides descriptions on how to use the 
UCNEM, once the method to be used are decided. However, due to the vast number of methods available, selection of the methods can be very difficult if they are not clear and the necessary skill set for deciding which method should be used for a specific scenario is lacking. Having a way to support the decision-making process of matching/selecting the most appropriate method to use for any one scenario may be useful.

Although there are several UCD methods available, only a few of those methods such as prototyping, and task analysis can be used during the product development phase. This is because designers or developers take on more substantial roles than the users at this phase compared to the needs gathering or usability evaluation phase. A wide range of HF guidelines and standards exist for the product design, workplace processes, and organizational design, but there are no HF guidelines to design the needs elicitation process.

When designing for a wider population, designers need to take into consideration their end users physical, cognitive, visual and hearing capabilities which are the four components of HF and also the anthropometrics of the population.

The designers need to consider if the participant has tremor, spasticity, any speech impairments if the product is being planned exclusively to operate through voice activation which cannot be used by a speech impaired users, any cognitive issues such as dyslexia, short term or long term memory loss and a lot of other factors. In some cases, designers even need to think about making the design inclusive for users with more severe disabilities such as quadriplegic, Multiple Sclerosis and spinal cord injuries which limits their ability in a variety of tasks. Considering the various limitations of the user abilities there are guidelines on the design of controls, visual displays, colors, auditory displays, panel layout, operating protocols. These guidelines are detailed to the extent of laying down restrictions on the size, the acceptable force required, travel distance, 
spacing, direction of the different control devices such as slide switches, toggle switches etc. In the case of visual displays the regulations are clear on the maximum brightness allowed, the angle of view, permitted character size, character spacing (Denno et al., 1992). The city of Toronto has laid out accessibility design guidelines when it comes to designing the city's routes on how the ramps had to be designed, dimensions of the parking lot, height of tables or drinking fountains, width of the door, height of docks in fishing areas, dimensions of viewing areas in public spaces which the designers need to adhere to in order to get licensing (City of Toronto, 2004). Keeping the guidelines for products aside there are also strict guidelines on designing computer and web interfaces to make them accessible (Ribera et al., 2009). All the above references in this paragraph shows the importance of HF consideration in the design of any product which will be used by humans.

For the usability evaluation phase, there are several formal user participatory UCD methods such as Think aloud protocol, post-study questionnaire, formal usability inspections and informal method such as Heuristic evaluation (Nielsen, 1994) which are primarily used to capture user experiences as discussed in the previous section of this literature review. There have been several research on the different scales such as system usability scale (SUS) (Brooke, Jordan, Thomas, Weerdmeester, \& McClelland, 1996) which capture user experiences. Apart from the traditional think aloud protocol (TAP), research shows that variations of TAP have been developed in order to include participants who are deaf and blind (Chandrashekar, Stockman, Fels, \& Benedyk, 2006; Louise Roberts \& Fels, 2006) in the usability evaluation study. Also, usability scales and other post-study questionnaires can be always administered by following the guidelines developed by Kaczmirek (Kaczmirek \& Wolff, 2007). The paper written by Kaczmirek and Wolff (2007) provides instructions and tips on how to design an accessible survey on a computer and braille for 
blind participants and accessible pencil paper surveys for low vision participants. Although these methods provide a methodological recommendation on how to use the aforementioned methods with blind and low vision users, they fail to provide instruction on how these methods have to be further modified for participants with a more specific visual or hearing disability. For example, a person with 20/160 vision will need a different font size and thickness to read compared a person with 20/100 vision. Considering the above difficulties of engaging a disabled person in a usability evaluation study and the lack of experience of designers which is evident from the studies mentioned in section 2.3 , it is clear that experienced researchers who have primarily worked with older and disabled adults effectively conduct the usability studies compared to their novice counterparts. Despite the above complications, evidence shows that HF has been considered and some research advances have been made to include wide ranges of users in the evaluation study. Although advances have been made to include a wide range of users, a framework is still lacking which helps novice designers and developers to effectively determine the right UCD usability evaluation methods to be used with participants of different cognitive, visual, hearing and motor abilities.

\subsection{Human factors in needs elicitation?}

The needs elicitation phase is an important phase of the design process because there is an increased chance of missing the features/ characteristics that the end users might expect of a product or technology. This leads to designers/researchers/companies revisiting and redesigning the end product which is often expensive. Many problems such as "text too small", "do not like how the product interface is designed", "unable to reach the button" etc., that arise during the usage of final product can be tied to misunderstandings and mistakes made during the requirements gathering phase such as inadequate communication between the designers and users during the 
requirements gathering phase, weak analytical procedures used on the data collected, inadequate responses from users because of misunderstandings with the engineer's technical terms, and lack of appropriate tools to support the requirements gathering process (Kotonya \& Sommerville, 1996). Although there is substantial literature available which shows how to conduct different UCNEM (Kotonya \& Sommerville, 1998; Pohl, 2010; Sharp, Rogers, \& Preece, 2007) very few studies are available which provides insight on which UCNEM might or might not be applicable for different scenarios/factors such process difficulty, time to prepare session, time to obtain requirements, number of stakeholders, budget and so on (Ferre \& Bevan, 2011; Hickey \& Davis, 2003a; Maiden \& Rugg, 1996).

Wood \& Silver (1995) developed a model called Joint Application Development (JAD) which uses a collaborative enhanced user participation model. This model is primarily used in software companies by using elaborate steps to gather requirements through workshops lasting up to five days by involving professionals, business users and experts. Adapting this model has shown to improve the quality of requirements or specification elicited. JAD is shown to work effectively in software development research and customized product development on a smaller scale not but very effective in large business areas as the participants for the requirements elicitation process were selected among themselves within the ranks of managers and staff rather than the involvement of actual users itself (Davidson, 1999). Despite the above disadvantage, JAD has been shown to work effectively in software development research and customized product development on a smaller scale (Davidson, 1999). A model of requirements elicitation which combines usage scenarios, prototyping, and design.

Although different methods and models of UCNEM exist, one method cannot likely be used with all the scenarios to gather user needs efficiently or effectively. Therefore, a mixed 
methods approach was required in order to achieve more data reliability and validity (Jick, 1979). There might be different reasons why designers might use one particular UCNEM in their studies including familiarity and knowledge with a specific method, lack of resources to use other methods, lack of experience or knowledge of other methods, or even time constraints (Dong, Keates, Clarkson, \& Cassim, 2002). In an attempt to assist with matching elicitation methods with projects, Hickey \& Davis, (2003b) created a requirements elicitation model where the elicitation technique was selected based on the characteristics of each UCNEM and the current state of requirements and situation of the project.

A survey study on the practice of UCD methods showed the benefits and weakness of each UCD by analyzing them using different factors which includes speed of execution of UCNEM studies, user involvement, ease of execution, ease of documentation, quality of results, the credibility of results and so on (Vredenburg et al., 2002). These factors were elicited by asking expert UCD designers of the measures on which they determine UCD methods. Another case study conducted by Hickey \& Davis (2003) shows how experts from various domains select the UCNEM based on various conditions such as the stakeholder involved, time available, what kind of data is needed.

An illustration of the different factors considered to select a UCD method has been provided in Figure 1, but much of the prior research discussed in this thesis does not provide a structured framework on how various methods are chosen. This makes the process of deciding a UCNEM time consuming, less effective or possibly even incorrect due to the lack of a structured framework for the designers to use. To address this issues Ferre \& Bevan (2011) developed a tool called usability planner which suggested needs gathering methods based on the project constraints, task constraints, product constraints and user constraints. Project constraints in the usability 
planner tool includes sub criteria which asks the researcher if they need quick results, if they have restricted budget and if they are uncertain of the specification. Task constraints include sub factors asking the researchers if their studies involve performing complex/many tasks. Although the user constraints sections ask if it is difficult to involve participants or if the study requires the participation of disabled participants, no attention to detail is given to the various types of disabilities/unique limited abilities the participant might have. Although in the user constraints section there are criteria to select if the participant has disabilities, it does not inquire in detail the nature of disability in terms of cognition, dexterity, hearing or perception.

Based on the literature search conducted in this thesis, no existing literature was found where the selection of UCNEM is based on detailed consideration of human capabilities. Thus, it is important to describe the ones that I use for this thesis in detail, which is described in sections 2.6.1: Cognition, 2.6.2: Vision, 2.6.3: Hearing and 2.6.4: Physical/motor abilities. 


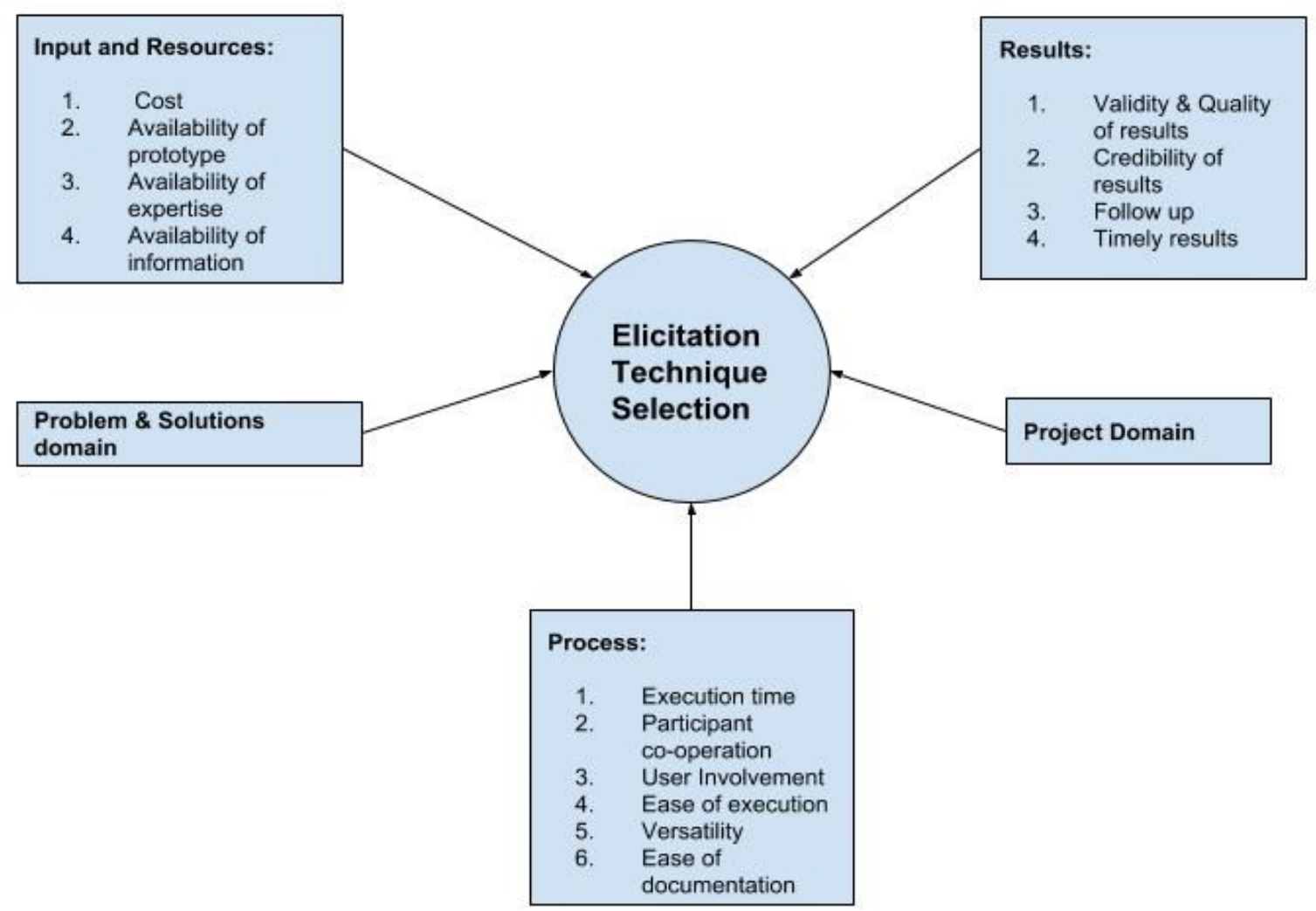

Figure 1: Summary of User-Centered Design methods selection criteria in use in the literature

\subsubsection{Cognition}

"Cognition is a mental process that describes how we acquire, store, transform and use knowledge" (Matlin, 2008,p.2). It encompasses processes such as retention, recall, decision making, reasoning, problem solving, planning and executing actions (Brandimonte, Bruno, \& Collina, 2006).

\section{Cognitively intact:}

Cognitively intact is a person who is described as free of all forms of cognitive impairment. The participant is identified to be free of all kinds of memory impairment, no subjective complaints of cognitive deterioration, no history of neurological or psychiatric disorder and who have independent decision-making skills. 


\section{Moderate cognitive ability:}

"Mild cognitive impairment is a brain function syndrome involving the onset and evolution of cognitive impairments beyond those expected based on the age and education of the individual, but which are not significant enough to interfere with their daily activities" (Petersen et al., 1999). Participants with moderate cognitive ability are said to display symptoms of forgetfulness of recent activities or events which includes delayed recall, difficulty in learning (Petersen, Smith, Invik, Kokmen, \& Tangalos, 1994; Welsh, Butters, \& Hughes, 1991), difficulty in expressive communication, lack of attention (Masur, Sliwinski, Lipton, Blau, \& Crystal, 1994; J. C. Morris et al., 2001), limited decision making and reasoning ability (Kim, Karlawish, \& Caine, 2002; Terry, 1988), often distracted from a performing tasks in workplace. The score ranges for moderate cognitive impairment in different scales are 10 to 26 for Mini-mental state examination (MMSE) scale, 19 to 26 for Montreal cognitive assessment scale (MoCA), 2 to 5 for Cognitive performance scale (CPS) and 3 to 5 for Global deterioration scale (GDS). Survey respondents were given the above description on the characteristics of a participant with moderate cognitive impairment to determine the minimum ability needed to participate in UCNEMs. This level of cognitive impairment can affect the direct participation of people in the needs elicitation process. Francis, Balbo, \& Firth (2009) points out the issue of involving people with Asperger's and autism in the needs elicitation/design process of designing assistive technologies. The main concern identified is the possibility of misunderstanding/misinterpreting of what the study participant talked while

they actually meant something else. Also clarifying these misconceptions with participants having Asperger's or autism can be difficult due to their limited cognition and communication skills. Therefore, there is an increased possibility that it may render the data gathered in the needs elicitation session unreliable which makes the entire design process difficult/failure for the 
researchers and designers. Also moderate cognitive impairment associated with learning disabilities can also affect the needs elicitation process. Hall \& Mallalieu (2003) discusses that users with learning disabilities are related to the characteristics of children such as limited knowledge of computers, low literacy levels, communication difficulties which can again affect the effective data gathering in the needs elicitation process.

\section{Severe cognitive impairment:}

Participants with severe cognitive impairment are reported to be highly to fully dependent on their caregivers for carrying on day to day activities. The participants are reported to look disheveled, have processing, decision, and judgment making capabilities similar to individuals who are 2 to 5 years old and limited communication with only yes-no replies or gestures (Allen, 2011; Reisberg, Ferris, de Leon, \& Crook, 1982). Also involving participants with dementia in the needs elicitation process can be difficult from the beginning of the needs elicitation process itself such as difficulties in obtaining consent, gathering their needs as they might not remember what they said a few minutes earlier and will start conversing in an unintended topic to the study (Astell et al., 2009).

\subsubsection{Vision}

Visual acuity is the measure level of visual clarity that a person possesses.

\section{Sighted:}

A sighted person is expected to have good reading speed with the visual ability ranging between 20/20 to 20/60 (International Council of Ophthalmology, 1988). Even if the person has visual ability in the above range, this does not imply the person has perfect vision (Vimont, 2016). Some people may suffer from problems such as colour blindness, inability to track fast moving 
objects, reduced contrast etc., and still can be classified as sighted people (World Heritage Encyclopedia, 1965).

\section{Low vision:}

"Low vision is a condition caused by eye disease, in which visual acuity is 20/70 or poorer in the better-seeing eye and cannot be corrected or improved with regular eyeglasses" (Scheiman, Scheiman, \& Whittaker, 2006, p.5). The Snellen chart categorizes low vision people having visual acuity between 20/70 and 20/160 (International Council of Ophthalmology, 1988). There are different visual acuity charts such as $\log \mathrm{MAR}$, Jager standard, American point standard and each chart has an equivalent value to the Snellen chart which can be found in Appendix N. People who are classified with low vision will have difficulty reading text from both books/ computers/mobile devices unless some accessibility aid such as magnifier/ increase in font size/ specialized applications are used (Alabdulkader \& Leat, 2010; Buzzi, Buzzi, Leporini, Mori, \& Penichet, 2010). Participants will also have difficulty reading the labels during shopping, unless they have access to a smartphone and use mobile applications such as VizWiz which helps allows low vision/ blind users to take picture of the label and translate it into audio description real time (Bigham, Jayant, et al., 2010). Low vision people can also be affected by other visual problems such as loss of central vision, blurred vision, night blindness and so on.

\section{Blind:}

The American Medical Association classifies anyone with a visual acuity (VA) less than 20/200 as blind (Ray et al., 2016). Although this standard has been argued by other countries such as India, where people with VA less than 20/400 are considered bind (Chawla \& Singh, 2017), 20/200 is widely accepted as the standard to determine a person to be blind. Blind people are 
known to have from very limited to no visual reading and will prefer the help of talking books, braille and/or other non-visual sources (International Council of Ophthalmology, 1988). Like low vision people, blind people also use accessibility aids such as VizWiz, JAWS screen reader, Assisted photography application to read text in computer/mobile phones (Bigham, Jayant, et al., 2010; Bigham, Robert, et al., 2010; Buzzi et al., 2010; Kane, Frey, \& Wobbrock, 2013; Vázquez \& Steinfeld, 2012).

\subsubsection{Hearing}

\section{Hearing persons:}

According to Clark (1981), people with normal hearing to slight hearing loss have an average hearing loss range of -10 to $25 \mathrm{~dB}$. People with slight hearing loss may not even realize the deteriorating hearing it is also deemed to be difficult to diagnose in this stage (Rosenhall, Nordin, Sandstrom, Ahlsen, \& Gillberg, 1999).

\section{Hard of hearing:}

The paper written by Clark (1981) shows that people with a hearing loss level between 26 to $70 \mathrm{~dB}$ are categorized to have mild to moderate hearing loss. People with mild hearing impairment (26-40 dB loss) will often notice that they are not able to understand the conversation clearly in a noisier environment, at a distance, a large group setting or over the phone. They may not be able to listen to consonant sounds like "s", "f" or "th" when having a conversation in a noisier environment (Better Hearing Institute, 2018). While people with mild hearing loss face difficulties maintaining conversation in a group setting, people with moderate hearing need a hearing aid device to maintain even a one on one conversation. This is because normal 
conversational speech is between 50 to $70 \mathrm{~dB}$ (Williamson, 2014) and people with moderate hearing loss of 41 to $70 \mathrm{~dB}$ will not be able to hear this sound (Clark, 1981).

\section{Deaf:}

Clark (1981) shows that anyone with more than $71 \mathrm{~dB}$ hearing loss is categorized as a person with severe hearing impairment or Deaf. Deaf people will not able to participate in conventional UCNEM such as interviews/ think aloud protocol as it requires the participant to engage in verbal conversation. To address modified versions of these methods such as Sign language interviews and sign language think aloud protocols (Louise Roberts \& Fels, 2006) have been developed which will assist Deaf people to engage in the needs elicitation process.

\subsubsection{Physical abilities/motor abilities:}

There are different kinds of physical disabilities which can prevent a person from participating in different UCNEM. These physical disabilities might include muscle weakness, ability to speak, ability to grasp or grasp an object and difficulty in performing complex operations such as push, rotate or turn (Vanderheiden \& Jordan, 2012). Therefore, participants with such physical disabilities or limitations in hand dexterity will need assistive devices/technologies such as chin switch and single switch scanning options to access the computer, mobile or other interfaces (Jennifer, 2000; Adler, Shein, Quintal, Birch, \& Weiss, 2004; Nisbet, 1996; Simpson \& Koester, 1999).

When looking back at the literature two factors stand out on why designers find difficulty deciding how to gather needs from older adults and people with disability. One is the lack of experience in communicating with this user group and deciding appropriate methods to gather needs. The next is, even with the availability of needs elicitation methods selection models and a 
usability planner tool, null or very less attention is given to consider the human capability of a person to participate in the different UCNEMs. This provides a need to develop a framework or tool to support novice designer/ researchers to determine UCNEM for older and disabled adults. To develop a solution/ framework to select UCNEM for older and/or disabled adults based on their human capability, the four primary human factors components: cognition, vision, hearing, and mobility/dexterity needs to be considered. 


\section{Chapter 3. Research Questions}

While there are numerous gaps found in the outcomes of the initial literature research my thesis will focus on the following: (1) There appears to be a lack of focus of HF in the needs gathering phase of the UCD/PDP process (2) There appears to be a lack of experience among designers to determine which UCNEM fits with specific abilities of older adults and/or people with disabilities and (3) It appears that participant capabilities are not considered as factors in determining UCNEM for research or design studies.

The goal of this research is to develop and evaluate a decision support tool for matching human capabilities of potential users with a UCNEM. The target users for such a tool are novice and experienced designers or developers of assistive and/or inclusive mainstream technologies and products. The following research questions will be addressed in the following chapters:

1. What are the level of human capabilities needed to participate in the different UCNEM in terms of visual and hearing abilities, motor skills and cognitive abilities?

2. How can the knowledge on the level of human capabilities in terms of visual and hearing abilities, motor skills and cognitive impairment be used to develop a tool that assists in determining the UCNEM?

3. Is the Needs Elicitation Methods Compatible with Key End User Limitations (NICKEL) tool an effective, viable and usable tool for novice designers, developers, and researchers to determine UCNEM methods compatible with older/disabled participants? 


\section{Chapter 4. Matching Human Capabilities with User Centered Needs Elicitation Methods}

The purpose of this chapter is to address the following research question:

"What are the level of human capabilities needed by older adults to participate in the different user participatory needs gathering methods in terms of visual and hearing abilities, motor skills and cognitive abilities?"

It describes the methodology of the data collection for developing the framework for NICKEL and presents the results and analysis of the data. A chi square test for independence (Mchugh, 2013) was employed to analyze the data and discuss the results with respect to the research questions. For the quantitative analysis, $\mathrm{p}<0.05$ was set as the level of significance.

\subsection{Purpose:}

A survey study was conducted to assess the cognitive, visual, hearing capabilities required by an older and/or disabled person to participate in 19 different UCNEM that were found in the literature. This entire survey study and its results have been published in the Joint meeting of the 48th Annual Conference of the Association of Canadian Ergonomists (ACE) \& 12th International Symposium on Human Factors in Organizational Design and Management (Sujan et al., 2017).

\subsubsection{Participants}

Thirty-eight people participated in the online survey to provide data on the human capabilities required by elderly/disabled participants to participate in the eighteen UCNEM methods. There were seven professional engineers or designers, seven novice engineers or designers, one clinical psychologist, two research psychologists, two occupational therapists, two healthcare researchers, two accessibility and user experience professionals, two doctoral students, one inclusive designer, one human-computer interaction researcher and nine other participants who did not provide their professional details that participated in the study. 
Two participants reported having less than one-year experience in their respective field of interest, eleven participants with two to five years of experience, seven participants with six to ten years of experience, and nine participants with at least ten years of experience conducting needs gathering studies with older adults.

\subsubsection{Online survey structure}

Following informed consent at the beginning of the online survey, participants were asked to respond to 12 questions (see Appendix I for the REB approval and Appendix A for the survey questions). The first four questions captured the participant's primary work or area of interest, experience in the respective area of interest and the experience in conducting needs analysis/gathering studies with older adults. Next, the participants were asked to rate their experience in using each of the UCNEMs. This was followed by asking the participant to rate the level of cognition, level of hearing and vision, and the level of motoric abilities needed by elderly and disabled participants to participate in each UCNEM method. If the survey respondent did not know the minimum ability needed they could select the "I don't know" option provided.

\subsubsection{Cognitive scale used in survey study}

There are many different scales used to assess cognitive ability such as Cognitive performance scale (CPS) (Morris et al., 2016), Mini-mental state examination (MMSE) (Folstein, Folstein, \& McHugh, 1975), Global deterioration scale (GDS) (Reisberg et al., 1982) and Montreal cognitive assessment scale (MoCA) (Nasreddine, 2005) that were considered due to the availability of the score ranges for cognitively intact, moderate cognitive ability and severe cognitive impairment. These methods have been designed and validated to capture a participant's level of memory, attention, ability to delayed recall, construction ability, general knowledge, expressive communication skills or command in language and decision making skills (Cullen, 
O’Neill, Evans, Coen, \& Lawlor, 2007; McDougall, 1990; Morris et al., 1994, 2016; Nasreddine, 2005). For the cognitive ability element, it was not necessary to determine specific areas or causes of cognitive impairment as need elicitation techniques are non-specific. In addition, designers and product developers may have little training or knowledge of specific scales as applied to their potential target user population, which would create a barrier to NICKEL's use. As a result, three relatively coarse-grain categories are used to rate the acceptable cognitive ability (see question 6 in Appendix A) to participate in different UCNEMs. Survey participants were provided with the characteristics and symptoms of participants with different cognitive abilities which were taken from the cognitive scales mentioned above. This approach was used to make it easier for the survey participants to determine the acceptable level of cognitive ability to participate in different UCNEMs. The acceptable level of cognition needed to participate in each UCNEM was thus captured with a three-point scale: cognitively intact; moderate cognitive ability; and severe cognitive impairment.

\subsubsection{Vision scale used in survey study}

In terms of visual ability, Snellen chart values were used in the survey study (International Council of Ophthalmology, 1988; Snellen, 1873) as it is widely used by optometrists (Falkenstein et al., 2008) compared with other scales such as $\log$ MAR (Bailey \& Lovie, 1976).

\subsubsection{Auditory range used in survey study}

Unlike the vision and cognition there are no scales for the auditory level, but the level of hearing ability is determined by the level of hearing loss. The American Speech Language Hearing Association has provided the level of decibel losses to categories different levels of hearing loss from who have mild to profound hearing loss. These levels and the characteristics of the 
participants with different hearing abilities were described in section 2.6 .3 of the literature review chapter and the same descriptions were used in the survey study.

\subsubsection{Physical abilities/ motor dexterity used in survey study}

The physical capabilities required by participants to participate in the different UCNEMs are determined by their ability to perform different physical tasks. After a brainstorming session, it was identified that people need to be able to communicate verbally, physically write, use a computer to participate in the different UCNEM methods. But, disabled adults and/or older adults who have limited physical abilities may face difficulties participating in UCNEMs associated with computer/mobile devices in the conventional manner without any assistance. Assistive technologies and methodologies such as mouth sticks (Toor, Tabiat-Pour, \& Critchlow, 2015), onscreen keyboards (US Patent No. 6008799, 1999), one-handed keyboards or single switch interfaces, joysticks or infrared pointing devices (Turpin et al., 2005) thus may be needed to assist people with limited abilities to use computer/mobile devices. Also, advancements have been made to include Deaf people in Think Aloud Protocol (a UCNEM method) which conventionally requires participants to have verbal communication ability. Roberts \& Fels (2006) developed an inclusive UCNEM called Gestural Think Aloud Protocol (G-TAP) which allows Deaf participants to engage in GTAP by allowing them to use American sign language instead of verbal communication. After the brainstorming session and with the available literature evidence, the following physical tasks were selected based on the different parameters that might affect a participant's ability to interact with another person, paper, computer or mobile tablet device. The data on the different physical abilities required to participate in different UCNEMs were captured by asking survey respondents to answer Yes/No the following questions:

1. Can use a mouse to select options 
2. Can use a mobile/ tablet touchscreen to select options

3. Can gesture/ use sign language

4. Can use keyboard to input text/ type

5. Can use alternative input for text input (switch devices)

6. Can use verbal communication

7. Can move eyes around

8. Can manually write

\subsubsection{Results:}

A chi-square analysis was used to assess whether the questionnaire responses were significantly different from chance. For the categories which were significantly different from chance, a frequency distribution was used to determine the options or level of difficulty with the highest response corresponding to the human factor component in a UCNEM method. Table 1 represents the results for the cognitive and perceptual abilities and Table 2 represents physical abilities. These were then applied as baseline values to populate the database of human capabilities demands that each UCNEM requires.

The responses for many cognitive and physical ability components were significantly different from chance $(\mathrm{p}<0.05)$. Most of the statistically insignificant results occurred for lesser used methods such as cultural probes, card sorting and think-aloud protocols as there were too few responses. The data in Tables 1 and 2 have been classified based on the statistical significance. The fields which are not highlighted and marked with “*” represent the responses which passed the chi-square test for significance and the mode value of the responses obtained were added to Table 1 and 2, fields highlighted in yellow represent the responses which failed the chi-square significance test, but were still subjected to frequency distribution analysis because there were 
more than five responses. The cells that do not have any value represent the data which failed chisquare test for significance and had fewer than five responses.

The different physical tasks necessary to participate in the different UCNEM is provided

\section{in Table 2.}

Table 1: Categorical label of statistical mode for acceptable level of cognition and the level of difficulty to participate in UCNEMs due to varied visual and hearing abilities (Not highlighted and marked with $a^{*}=$ statistically significant; Highlighted in yellow (or grey if printed) - statistically insignificant, but mode value still used due number of responses $>5$; Blank cells $=$ Statistically insignificant with fewer than five responses)

\begin{tabular}{|c|c|c|c|c|c|c|c|}
\hline \multirow[t]{2}{*}{ UCNEM } & \multirow[t]{2}{*}{$\begin{array}{c}\text { Acceptable } \\
\text { cognitive } \\
\text { impairment }\end{array}$} & \multicolumn{3}{|c|}{$\begin{array}{l}\text { Difficulty level for different hearing } \\
\text { abilities to participate in UCNEM }\end{array}$} & \multicolumn{3}{|c|}{$\begin{array}{l}\text { Difficulty level for different visual } \\
\text { abilities to participate in UCNEM }\end{array}$} \\
\hline & & Hearing & $\begin{array}{l}\text { Hard of } \\
\text { hearing }\end{array}$ & Deaf & Sighted & Low vision & Blind \\
\hline $\begin{array}{c}\text { Face to Face } \\
\text { interviews }\end{array}$ & $\begin{array}{c}\text { Moderate } \\
\text { impairment }\end{array}$ & $\begin{array}{c}\text { Not } \\
\text { difficult }^{*}\end{array}$ & $\begin{array}{l}\text { Moderate } \\
\text { difficulty }^{*}\end{array}$ & Difficult ${ }^{*}$ & $\begin{array}{c}\text { Not } \\
\text { difficult }\end{array}$ & Not difficult & $\begin{array}{c}\text { Not } \\
\text { difficult }\end{array}$ \\
\hline $\begin{array}{l}\text { Telephonic } \\
\text { interview }\end{array}$ & $\begin{array}{l}\text { Cognitively } \\
\text { intact }^{*}\end{array}$ & $\begin{array}{l}\text { Not } \\
\text { difficult }^{*}\end{array}$ & $\begin{array}{l}\text { Moderate } \\
\text { difficulty }\end{array}$ & Difficult & $\begin{array}{l}\text { Not } \\
\text { difficult }\end{array}$ & Not difficult & $\begin{array}{c}\text { Not } \\
\text { difficult }\end{array}$ \\
\hline $\begin{array}{l}\text { Interview } \\
\text { (Sign } \\
\text { language) }\end{array}$ & $\begin{array}{l}\text { Cognitively } \\
\text { intact }\end{array}$ & $\begin{array}{c}\text { Not } \\
\text { difficult }\end{array}$ & Not difficult & $\begin{array}{c}\text { Not } \\
\text { difficult }\end{array}$ & $\begin{array}{c}\text { Not } \\
\text { difficult }\end{array}$ & $\begin{array}{l}\text { Moderate } \\
\text { difficulty }\end{array}$ & Difficult \\
\hline $\begin{array}{c}\text { Open-ended } \\
\text { survey } \\
\text { (Online } \\
\text { survey) } \\
\end{array}$ & $\begin{array}{l}\text { Moderate } \\
\text { impairment }\end{array}$ & $\begin{array}{l}\text { Not } \\
\text { difficult* }\end{array}$ & Not difficult & $\begin{array}{c}\text { Not } \\
\text { difficult }\end{array}$ & $\begin{array}{l}\text { Not } \\
\text { difficult }^{*}\end{array}$ & $\begin{array}{l}\text { Moderate } \\
\text { difficulty }\end{array}$ & Difficult \\
\hline $\begin{array}{l}\text { Open ended } \\
\text { survey (paper } \\
\text { type) }\end{array}$ & $\begin{array}{l}\text { Moderate } \\
\text { impairment }^{*}\end{array}$ & $\begin{array}{l}\text { Not } \\
\text { difficult }^{*}\end{array}$ & $\begin{array}{l}\text { Not } \\
\text { difficult }^{*}\end{array}$ & $\begin{array}{l}\text { Not } \\
\text { difficult }^{*}\end{array}$ & $\begin{array}{l}\text { Not } \\
\text { difficult }^{*}\end{array}$ & $\begin{array}{l}\text { Moderate } \\
\text { difficulty }\end{array}$ & Difficult ${ }^{*}$ \\
\hline $\begin{array}{c}\text { Structured } \\
\text { questionnaire } \\
\text { (online } \\
\text { survey) } \\
\end{array}$ & $\begin{array}{l}\text { Moderate } \\
\text { impairment }\end{array}$ & $\begin{array}{l}\text { Not } \\
\text { difficult }^{*}\end{array}$ & $\begin{array}{l}\text { Not } \\
\text { difficult }\end{array}$ & $\begin{array}{l}\text { Not } \\
\text { difficult }^{*}\end{array}$ & $\begin{array}{c}\text { Not } \\
\text { difficult }\end{array}$ & $\begin{array}{l}\text { Moderate } \\
\text { difficulty }\end{array}$ & Difficult \\
\hline $\begin{array}{c}\text { Structured } \\
\text { questionnaire } \\
\text { (paper type) }\end{array}$ & $\begin{array}{c}\text { Moderate } \\
\text { impairment }^{*}\end{array}$ & $\begin{array}{c}\text { Not } \\
\text { difficult }^{*}\end{array}$ & Not difficult & $\begin{array}{c}\text { Not } \\
\text { difficult }\end{array}$ & $\begin{array}{c}\text { Not } \\
\text { difficult }\end{array}$ & $\begin{array}{l}\text { Moderate } \\
\text { difficulty }\end{array}$ & Difficult \\
\hline $\begin{array}{c}\text { Paper } \\
\text { prototyping }\end{array}$ & $\begin{array}{c}\text { Moderate } \\
\text { impairment }\end{array}$ & $\begin{array}{c}\text { Not } \\
\text { difficult }\end{array}$ & Not difficult & $\begin{array}{c}\text { Not } \\
\text { difficult }\end{array}$ & $\begin{array}{c}\text { Not } \\
\text { difficult }\end{array}$ & $\begin{array}{l}\text { Moderate } \\
\text { difficulty }\end{array}$ & Difficult \\
\hline Focus groups & $\begin{array}{c}\text { Moderate } \\
\text { impairment }\end{array}$ & $\begin{array}{c}\text { Not } \\
\text { difficult }^{*}\end{array}$ & $\begin{array}{l}\text { Moderate } \\
\text { difficulty }^{*}\end{array}$ & Difficult ${ }^{*}$ & $\begin{array}{c}\text { Not } \\
\text { difficult }\end{array}$ & Not difficult & $\begin{array}{c}\text { Not } \\
\text { difficult }\end{array}$ \\
\hline $\begin{array}{l}\text { Open Card } \\
\text { sorting }\end{array}$ & $\begin{array}{c}\text { Moderate } \\
\text { impairment }\end{array}$ & & & & & & \\
\hline
\end{tabular}




\begin{tabular}{|c|c|c|c|c|c|c|c|}
\hline $\begin{array}{l}\text { Closed Card } \\
\text { sorting }\end{array}$ & $\begin{array}{c}\text { Moderate } \\
\text { impairment }\end{array}$ & & & & & & \\
\hline $\begin{array}{l}\text { Reverse card } \\
\text { sorting }\end{array}$ & $\begin{array}{c}\text { Moderate } \\
\text { impairment }\end{array}$ & & & & & & \\
\hline $\begin{array}{l}\text { Cultural } \\
\text { probe } \\
\text { (Camera) }\end{array}$ & & $\begin{array}{c}\text { Not } \\
\text { difficult }^{*}\end{array}$ & $\begin{array}{c}\text { Not } \\
\text { difficult }^{*}\end{array}$ & $\begin{array}{c}\text { Not } \\
\text { difficult }\end{array}$ & $\begin{array}{c}\text { Not } \\
\text { difficult }\end{array}$ & $\begin{array}{l}\text { Moderate } \\
\text { difficulty }^{*}\end{array}$ & Difficult ${ }^{*}$ \\
\hline $\begin{array}{l}\text { Cultural } \\
\text { probe (Diary } \\
\text { recording) }\end{array}$ & $\begin{array}{c}\text { Moderate } \\
\text { impairment }\end{array}$ & $\begin{array}{c}\text { Not } \\
\text { difficult }^{*}\end{array}$ & $\begin{array}{c}\text { Not } \\
\text { difficult }^{*}\end{array}$ & $\begin{array}{c}\text { Not } \\
\text { difficult }^{*}\end{array}$ & $\begin{array}{c}\text { Not } \\
\text { difficult }^{*}\end{array}$ & $\begin{array}{c}\text { Not } \\
\text { difficult }\end{array}$ & Difficult ${ }^{*}$ \\
\hline $\begin{array}{l}\text { Cultural } \\
\text { probe (Voice } \\
\text { recorder) }\end{array}$ & & $\begin{array}{c}\text { Not } \\
\text { difficult }^{*}\end{array}$ & $\begin{array}{c}\text { Not } \\
\text { difficult }^{*}\end{array}$ & & $\begin{array}{c}\text { Not } \\
\text { difficult }^{*}\end{array}$ & $\begin{array}{c}\text { Not } \\
\text { difficult }\end{array}$ & $\begin{array}{c}\text { Not } \\
\text { difficult }^{*}\end{array}$ \\
\hline $\begin{array}{c}\text { Think aloud } \\
\text { protocol }\end{array}$ & $\begin{array}{l}\text { Moderate } \\
\text { impairment }\end{array}$ & $\begin{array}{c}\text { Not } \\
\text { difficult }^{*}\end{array}$ & Not difficult & $\begin{array}{c}\text { Not } \\
\text { difficult }\end{array}$ & $\begin{array}{c}\text { Not } \\
\text { difficult }\end{array}$ & Not difficult & Difficult \\
\hline $\begin{array}{c}\text { Think aloud } \\
\text { protocol (sign } \\
\text { language) }\end{array}$ & $\begin{array}{c}\text { Moderate } \\
\text { impairment }\end{array}$ & Difficult ${ }^{*}$ & $\begin{array}{l}\text { Moderate } \\
\text { difficulty }^{*}\end{array}$ & $\begin{array}{c}\text { Not } \\
\text { difficult }^{*}\end{array}$ & $\begin{array}{c}\text { Not } \\
\text { difficult }\end{array}$ & Not difficult & Difficult ${ }^{*}$ \\
\hline $\begin{array}{c}\text { Retrospective } \\
\text { Think Aloud } \\
\text { protocol }\end{array}$ & $\begin{array}{c}\text { Moderate } \\
\text { impairment }\end{array}$ & $\begin{array}{c}\text { Not } \\
\text { difficult }^{*}\end{array}$ & Not difficult & $\begin{array}{c}\text { Not } \\
\text { difficult }\end{array}$ & $\begin{array}{c}\text { Not } \\
\text { difficult }\end{array}$ & Not difficult & Difficult \\
\hline $\begin{array}{l}\text { Mediated } \\
\text { workshop }\end{array}$ & $\begin{array}{c}\text { Moderate } \\
\text { impairment }\end{array}$ & $\begin{array}{c}\text { Not } \\
\text { difficult }^{*}\end{array}$ & $\begin{array}{c}\text { Not } \\
\text { difficult }^{*}\end{array}$ & $\begin{array}{c}\text { Not } \\
\text { difficult }\end{array}$ & $\begin{array}{c}\text { Not } \\
\text { difficult }^{*}\end{array}$ & $\begin{array}{c}\text { Not } \\
\text { difficult }^{*}\end{array}$ & $\begin{array}{c}\text { Not } \\
\text { difficult }^{*}\end{array}$ \\
\hline
\end{tabular}

*Significantly different from chance $(p<0.05)$

Table 2: Physical capabilities necessary to participate in the different UC needs elicitation methods ( $Y=$ Yes (Capability required), $N=$ No (Capability not required))

\begin{tabular}{|c|c|c|c|c|c|c|c|c|}
\hline UCNEM & $\begin{array}{c}\text { Use a } \\
\text { computer } \\
\text { input } \\
\text { device to } \\
\text { select } \\
\text { options }\end{array}$ & $\begin{array}{c}\text { Use a } \\
\text { mobile/ } \\
\text { tablet } \\
\text { touchscre } \\
\text { en } \\
\text { to select } \\
\text { options } \\
\end{array}$ & $\begin{array}{c}\text { Gesture/ } \\
\text { use sign } \\
\text { language }\end{array}$ & $\begin{array}{c}\text { Use } \\
\text { standard } \\
\text { computer } \\
\text { to input } \\
\text { text/type }\end{array}$ & $\begin{array}{c}\text { Use } \\
\text { alternative } \\
\text { input for } \\
\text { text input } \\
\text { (switch } \\
\text { devices) }\end{array}$ & $\begin{array}{c}\text { Verbal } \\
\text { comm } \\
\text { unicati } \\
\text { on }\end{array}$ & $\begin{array}{c}\text { Move } \\
\text { eyes } \\
\text { around }\end{array}$ & $\begin{array}{c}\text { Manually } \\
\text { Write }\end{array}$ \\
\hline $\begin{array}{c}\text { Face to Face } \\
\text { interviews }\end{array}$ & $\mathrm{N}$ & $\mathrm{N}$ & $\mathrm{N}$ & $\mathrm{N}$ & $\mathrm{N}$ & $\mathrm{Y}$ & $\mathrm{N}$ & $\mathrm{N}$ \\
\hline $\begin{array}{l}\text { Telephonic } \\
\text { interview }\end{array}$ & $\mathrm{N}$ & $\mathrm{N}$ & $\mathrm{N}$ & $\mathrm{N}$ & $\mathrm{N}$ & Y & $\mathrm{N}$ & $\mathrm{N}$ \\
\hline $\begin{array}{l}\text { Interview } \\
\text { (Sign } \\
\text { language) }\end{array}$ & $\mathrm{N}$ & $\mathrm{N}$ & $\mathrm{Y}$ & $\mathrm{N}$ & $\mathrm{N}$ & $\mathrm{N}$ & $\mathrm{N}$ & $\mathrm{N}$ \\
\hline
\end{tabular}




\begin{tabular}{|c|c|c|c|c|c|c|c|c|}
\hline $\begin{array}{l}\text { Open-ended } \\
\text { survey } \\
\text { (Online } \\
\text { survey) } \\
\end{array}$ & $\mathrm{N}$ & $\mathrm{N}$ & $\mathrm{N}$ & $\mathrm{Y}$ & $\mathrm{Y}$ & $\mathrm{N}$ & $\mathrm{N}$ & $\mathrm{N}$ \\
\hline $\begin{array}{l}\text { Open ended } \\
\text { survey (paper } \\
\text { type) }\end{array}$ & $\mathrm{N}$ & $\mathrm{N}$ & $\mathrm{N}$ & $\mathrm{N}$ & $\mathrm{N}$ & $\mathrm{N}$ & Y & $\mathrm{Y}$ \\
\hline $\begin{array}{c}\text { Structured } \\
\text { questionnaire } \\
\text { (online } \\
\text { survey) } \\
\end{array}$ & Y & Y & $\mathrm{N}$ & $\mathrm{N}$ & $\mathrm{N}$ & $\mathrm{N}$ & $\mathrm{N}$ & $\mathrm{N}$ \\
\hline $\begin{array}{l}\text { Structured } \\
\text { questionnaire } \\
\text { (paper type) }\end{array}$ & $\mathrm{N}$ & $\mathrm{N}$ & $\mathrm{N}$ & $\mathrm{N}$ & $\mathrm{N}$ & $\mathrm{N}$ & $\mathrm{N}$ & $\mathrm{Y}$ \\
\hline $\begin{array}{c}\text { Paper } \\
\text { prototyping }\end{array}$ & $\mathrm{N}$ & $\mathrm{N}$ & $\mathrm{N}$ & $\mathrm{N}$ & $\mathrm{N}$ & $\mathrm{N}$ & $\mathrm{N}$ & $\mathrm{N}$ \\
\hline Focus groups & $\mathrm{N}$ & $\mathrm{N}$ & $\mathrm{N}$ & $\mathrm{N}$ & $\mathrm{N}$ & $Y$ & $\mathrm{~N}$ & $\mathrm{~N}$ \\
\hline $\begin{array}{l}\text { Open Card } \\
\text { sorting }\end{array}$ & $\mathrm{N}$ & $\mathrm{N}$ & $\mathrm{N}$ & $\mathrm{N}$ & $\mathrm{N}$ & $\mathrm{N}$ & $\mathrm{N}$ & $\mathrm{N}$ \\
\hline $\begin{array}{l}\text { Closed Card } \\
\text { sorting }\end{array}$ & $\mathrm{N}$ & $\mathrm{N}$ & $\mathrm{N}$ & $\mathrm{N}$ & $\mathrm{N}$ & $\mathrm{N}$ & $\mathrm{N}$ & $\mathrm{N}$ \\
\hline $\begin{array}{l}\text { Reverse card } \\
\text { sorting }\end{array}$ & $\mathrm{N}$ & $\mathrm{N}$ & $\mathrm{N}$ & $\mathrm{N}$ & $\mathrm{N}$ & $\mathrm{N}$ & $\mathrm{N}$ & $\mathrm{N}$ \\
\hline $\begin{array}{c}\text { Cultural } \\
\text { probe } \\
\text { (Camera) }\end{array}$ & $\mathrm{N}$ & $\mathrm{N}$ & $\mathrm{N}$ & $\mathrm{N}$ & $\mathrm{N}$ & $\mathrm{N}$ & $\mathrm{N}$ & $\mathrm{N}$ \\
\hline $\begin{array}{l}\text { Cultural } \\
\text { probe (Diary } \\
\text { recording) }\end{array}$ & $\mathrm{N}$ & $\mathrm{N}$ & $\mathrm{N}$ & $\mathrm{N}$ & $\mathrm{N}$ & $\mathrm{N}$ & $\mathrm{N}$ & $\mathrm{N}$ \\
\hline $\begin{array}{l}\text { Cultural } \\
\text { probe (Voice } \\
\text { recorder) }\end{array}$ & $\mathrm{N}$ & $\mathrm{N}$ & $\mathrm{N}$ & $\mathrm{N}$ & $\mathrm{N}$ & $\mathrm{N}$ & $\mathrm{N}$ & $\mathrm{N}$ \\
\hline $\begin{array}{l}\text { Think aloud } \\
\text { protocol }\end{array}$ & Y & $Y$ & $\mathrm{~N}$ & $Y$ & $Y$ & $\mathrm{Y}$ & Y & $\mathrm{N}$ \\
\hline $\begin{array}{l}\text { Think aloud } \\
\text { protocol (sign } \\
\text { language) }\end{array}$ & Y & $Y$ & Y & Y & Y & $\mathrm{Y}$ & Y & $\mathrm{N}$ \\
\hline $\begin{array}{l}\text { Retrospective } \\
\text { Think Aloud } \\
\text { protocol }\end{array}$ & Y & $\mathrm{Y}$ & $\mathrm{N}$ & $Y$ & $Y$ & $Y$ & $Y$ & $\mathrm{~N}$ \\
\hline
\end{tabular}




\begin{tabular}{|c|c|c|c|c|c|c|c|c|}
\hline $\begin{array}{c}\text { Mediated } \\
\text { workshop }\end{array}$ & $\mathrm{N}$ & $\mathrm{N}$ & $\mathrm{N}$ & $\mathrm{N}$ & $\mathrm{N}$ & $\mathrm{Y}$ & $\mathrm{Y}$ & $\mathrm{N}$ \\
\hline
\end{tabular}

\subsubsection{Discussion of survey study results}

As expected, methods such as focus groups seem easy for survey respondents to identify human capability demands as these are commonly used methods in many different disciplines. This may be because of the lower level of difficulty in conducting focus groups with older adults due to the availability of detailed guidelines (Krueger \& Casey, 2014; Morgan, 1997a, 1997b). In contrast, there are very few to no responses for card sorting and cultural probes because they are less commonly used/known methods among the UCD practitioners (Vredenburg et al., 2002).

Six methods including six variations of cultural probes and card sorting with no cell entries in Table 1 seem to be less well known or used even by experts; more than $60 \%$ of respondents did not know that these methods existed or had never used them although these methods may be appropriate for needs elicitation. This may be due to the increased effort to prepare the needs elicitation process (Thoring et al., 2013), challenges faced by participants due to limited physical abilities (Wherton et al., 2012a), or the lack of knowledge of these methods among researchers or designers (Magnúsdóttir, 2011).

From the survey, there are insignificant results for the face to face interviews for low vision and blind category. This is likely because even though the mode for all participants is "Not difficult" there were a sufficient quantity of survey participants who responded that it will be slightly difficult for people who are blind or low vision $(\mathrm{B} / \mathrm{LV})$ to participate in interviews to divide the results. It may be more difficult for $\mathrm{B} / \mathrm{LV}$ because nonverbal cues and gestures used in conversations by sighted people make conversations and interviews more effective as it allows 
interviewees and interviewers understand each other's emotions and mood (Fitzpatrick, Knapp, \& Miller, 1985). Moore (2002) suggested that researchers working with the B/LV participants could use verbal cues such as "uh huh", "um" to let the low vision or blind participants know that they are being heard. This approach has been shown to be effective because blind people have heightened abilities to interpret a person's emotions from the verbal tone (Sacks \& Wolffe, 2006).

Also, survey respondents disagreed on the level of difficulty in responses to open-ended online survey questions where survey participants responded moderately difficult for low vision participants and difficult for blind users. Although there are guidelines available on how to use the open-ended question effectively with low vision and blind users (Kaczmirek \& Wolff, 2007), there are very few examples showing that these guidelines have been used in actual research studies (Kim, 2010; Kim, Smith-Jackson, \& Kleiner, 2014). Even though screen readers such as Job Access With Speech (JAWS) are available it will be still difficult for blind participants to use the even well-established websites such as Facebook (Brinkley \& Tabrizi, 2017). This might be because most screen interface designers do not use W3C or Web Content Accessibility Guidelines (WCAG). To address these issues such as above, a gesture-based screen reader was developed (Kane et al., 2013). But there are no studies describing the wide-spread usage of this screen reader system.

\subsection{Populating the non-significant and blank cells in Table 1}

For UCNEM methods where there were fewer than five responses or statistically insignificant results, a focus group study was carried out to populate the missing cognitive, hearing and visual levels in the affected UCNEM methods. (see Appendix $\mathrm{J}$ for the REB application approval for the focus group study). 
A consensus approach (Powell \& Single, 1996; Sim, 1998) was used to ensure that all the participants agree on the same response to a focus group question. The focus group took place for two hours and was video and audio recorded. The video was transcribed and the qualitative data were analyzed. The responses were accepted into the database only if a consensus was reached.

\subsubsection{Participants}

Five expert participants from the design domain were recruited for the focus group study. The group comprised of experts in the field human factors, who have designed assistive products for older adults, who have developed new needs elicitation methods for disabled and elderly people or who have experience developing assistive technologies for Deaf participants. One of the participants was Deaf and hence, two interpreters were arranged to support the focus group conversation.

\subsubsection{Focus group study findings}

A consensus was eventually reached on determining the difficulty level for all the missing human capabilities in Table 1. There were initial disagreements in the following situations:

1. Level of difficulty faced by hard of hearing people when participating in a sign language interview.

2. Level of difficulty faced by participants with low vision in completing cultural probes with cameras.

3. Level of difficulty faced by participants with low vision in completing online surveys Based on the experience of the Deaf participant, hard of hearing people usually did not communicate with sign language. Other focus group participants disagreed suggesting that hard of hearing people could eventually learn sign language. After considerable discussion, everyone agreed with the Deaf participant, based on his/her years of personal experience and work 
experience with the Deaf community, that hard of hearing participants would not use sign language to communicate but rather use residual hearing, and speaking and/or gestures to communicate. It was finally agreed that people who are hard of hearing will have some difficulty participating in an interview involving sign language format. Although participants agreed that it will be somewhat difficult, it might become less difficult if the interviewer and participant knew sign language irrespective of the hearing capability.

The cultural probe camera study was originally intended to be used with sighted participants to take pictures of home environment and devices which they think has a design or functional problem (Gaver et al., 1999; Hemmings, Clarke, Rouncefield, Crabtree, \& Rodden, 2002) and is not developed with low vision and blind persons into consideration. During the focus group session there were initial disagreements on level of difficulty faced by participants with low vision in completing cultural probes with cameras. Two focus group participants disagreed that it was easy for participants with low vision to participate in data collection using the camera-based cultural probe method. They argued that the camera was the device taking the picture and no effort was required from the participant. Participants who agreed that it was moderately difficult for a person with low vision to participate in a camera-based cultural probe method said that people with vision loss would have trouble focusing the camera, and might not be able to determine where the buttons were located. This statement was agreed on by two other participants where they suggested that if a participant faces slight difficulty using an online survey on a mobile, they will definitely face the same level of difficulty using a camera in the cultural probe method. Since the focus group participants were not able to reach a consensus, the literature (Kutiyanawala et al., 2011; Vázquez \& Steinfeld, 2012) were used to make a decision. Evidence from literature indicates that although people with low to severe vision were not completely disabled to use a camera, they 
still face difficulties related to aiming/focusing/taking the correct pictures unless there is some assistance from others or a specialized assistance technology such as Tele-assistance (Kutiyanawala et al., 2011) or Assisted photography (Vázquez \& Steinfeld, 2012). Based on the literature available, it was decided that participants with low vision would face difficulty while engaging in a camera based cultural probe study.

In terms of using cultural probe camera study with blind people, one participant in the focus group argued that in a domestic environment where the blind person spends a significant amount of time they would recognize the position of the objects and would not experience difficulties taking pictures of the objects which they consider to have design flaws or not be usable. This might be because of the increased spatial knowledge and familiarity that blind people might develop after spending a significant amount of time in a static environment where placement of objects are not changed frequently (Corazzini, Tinti, Schmidt, Mirandola, \& Cornoldi, 2010). Added the participant also mentioned there were recent developments in mobile technology that help blind people to take pictures. This can be again related to applications such as Teleassistance (Kutiyanawala et al., 2011) and VizWiz (Bigham, Jayant, et al., 2010) that helps blind people take pictures and get help on what the picture is about. But there was no study identified, indicating the awareness and usage of these applications among blind users. Also, there is literature, where participants were given disposable cameras (Boehner et al., 2007; Wherton et al., 2012a), which does not have the inbuilt technology for blind people to take pictures. Considering there were no special technological assistance/accommodation for blind people to capture the right picture in most cases, the focus group participants came to a consensus that it will be difficult for blind people to participate in a camera based cultural probe study. 
As mentioned in the survey study results section 4.1.7, survey study responses did not yield statistically significant responses on the level of difficulty faced by low vision and blind people to participate in online survey study. The focus group study was used to fill this gap identified in survey study. Two focus group participants disagreed that implementing an online survey method with participants with low vision would not be difficult. The reasons provided were that people with low vision might use screen readers, and progressive websites and survey platforms were supposed to comply with Accessibility for Ontarians with Disabilities (AODA) rules and regulations to be accessible to users with disabilities including those with low vision. But, the rest of the focus group participants argued that not all low vision users use screen readers and not all web interfaces or survey platforms are built to comply with government standards/regulations. The focus groups participants then agreed that screen readers were rarely used by people with low vision, and in an the ideal situation the researchers might not be aware or do not use the guidelines on how to conduct online surveys with low vision and blind participants (Kaczmirek \& Wolff, 2007). In the focus group study, it was eventually decided that low vision and blind people will have moderate and high difficulty respectively to participate in an online survey study.

In terms of cognitive ability required needed to participate in online survey study, although the mode value of the responses suggested that people with moderate cognitive ability can participate in an online survey study, there were also survey respondents who reported only cognitively intact participants can participate in them. This distribution along with too few responses for this particular survey question ( 20 responses in total), may have resulted in an insignificant chi-square. Also due to the limited time in the focus group study, the focus group study participants were not able to discuss the acceptable cognitive ability to participate in the online survey study. Therefore, literature was used to address this gap. There were studies 
conducted showing that there was a high cognitive load required of the person finishing the survey if it was lengthy (Reynolds, 1979). Although open-ended questions are known to produce low levels of responsiveness (Sigelman et al., 1981), people with cognitive issues were able to respond to an open-ended survey, as long as the questions involved recalling past life events and complex scientific concepts were avoided (Finlay \& Lyons, 2001). Based on the findings from the literature combined with the mode value from the survey study response, it was decided the people with moderate cognitive ability can participate in online survey study.

With respect to telephone interviews, the Deaf focus group participant mentioned that a phone conversation will be not be highly difficult for a person who is hard of hearing but it would not be possible for a Deaf person. This maybe because, when a hard of hearing person uses the telephone, there are settings on hearing aids for use with telephones (Jemni, Ghoul, Yahia, \& Boulares, 2007, U.S. Patent No. 20040013279A1, 2004). The rest of the focus group participants agreed with the deaf participant's viewpoint and came to a consensus.

To translate these results into a decision support tool to assist researchers and designers in determining needs elicitation techniques that fit their target user abilities, a decision matrix (database) was developed. The matrix consisted of UCNEM in the rows and the physical, cognitive, visual and hearing abilities necessary to participate in the corresponding columns. Next, an algorithm was developed to map the demands required of the UCNEMs as indicated in the expert survey and focus group results with the estimated specification of particular participant's abilities and implemented in a software tool called NICKEL. 


\section{Chapter 5. NICKEL Development:}

\subsection{Vision of NICKEL (Needs Elicitation Methods Compatible with Key End User}

\section{Limitations)}

The aim of this chapter is to answer the second research question:

"How can the data gathered on the level of human capabilities in terms of visual and hearing abilities, motor skills and cognitive impairment from experts be used to develop a tool to be used as a criterion in the UCNEM determining process?"

The goal of NICKEL is to provide a simple way of helping novice designers, developers or researchers working with older adults and people with disability determine UCNEMs that are compatible with their potential participants based on their estimate of those participant's visual, hearing, motor and cognitive capabilities.

\subsection{Database creation for development of NICKEL}

Based on the data gathered from the survey and the focus group session, two databases to be used in NICKEL were developed. The first database contained data on the cognition and motor tasks required to participate in a particular UCNEM. The second database contained data on the level of difficulties faced by older and/or disabled adults of different visual and hearing abilities to participate in particular UCNEMs. Once the minimum capabilities required to participate in the different UCNEM's were determined in the survey in focus group study, the possible combinations of human capabilities with which a participant can be involved in each method were created. Details of the NICKEL databases are outlined in Appendix B.

\subsection{NICKEL Design}

Developing NICKEL for determining UCNEM means that designers can use human capabilities as criteria for determining a specific UCNEM along with other conventional factors 
such as inputs needed, process, problem and solutions domain, project domain, and types of results needed. The NICKEL interfaces asks users to select the levels of visual, hearing, cognitive and physical abilities, from three possible levels, that they believe their potential participants will have. Based on Tables 1 and 2 (as a database), NICKEL will produce a recommended set of UCNEM methods along with guidelines on how to use these methods and things to be considered when using these UCNEMs with older and/or disabled adults. A detailed explanation of how NICKEL works is provided in the next sections.

To make NICKEL more usable and compatible with all operating systems and web browsers it was developed in a google sheets platform. The user does not need to install any special software to use NICKEL. It can be used online by making a copy of the original worksheet. The URL to access the original NICKEL worksheet is at https://goo.gl/kcNrd1.

\subsection{NICKEL structure:}

Figure 2 shows the working flow of NICKEL. UCNEMs are provided as output by mapping the user input on their potential participant's human capabilities with the databases and algorithms created. Potential participant's visual, hearing, motor and cognitive abilities estimated by NICKEL's users comprise the input for NICKEL. The capabilities of the potential participants can be estimated using several possible techniques such as designer experience, target user specifications or methods such as creating scenarios (Blythe \& Dearden, 2009) or personas (Wöckl et al., 2012). For example, four different sample personas of older and disabled adults to evaluate NICKEL in the user study (see Appendix C) are used in order to generate human capability inputs for NICKEL.

The input portion of NICKEL's user interface consisted of four human capability sections, the level of cognition, vision, hearing and the different physical tasks (Zhou \& Salvendy, 2015) 
that can be performed by the participant. Figure 3 provides a screenshot of NICKEL's input screen. Outputs include the list of UCNEMs compatible with those selected capabilities and general instructions or guidelines on how to use those methods with older adults and people with disabilities as provided in Figure 4.

\begin{tabular}{|c|c|c|c|c|}
\hline $\begin{array}{l}\quad \frac{\text { Inputs }}{\text { Human }} \\
\quad \text { Capability } \\
\text { Level of: } \\
\text { Cognition } \\
\text { Hearing } \\
\text { Vision } \\
\text { Physical abilities }\end{array}$ & $\Longrightarrow$ & $\begin{array}{l}\text { Processing } \\
\text { Lookup and map } \\
\text { capabilities with } \\
\text { the database }\end{array}$ & $\Longrightarrow$ & $\begin{array}{c}\text { Outputs } \\
\text { UCNEM } \\
\text { Methods compatible with } \\
\text { input capabilities } \\
\text { Guidelines to use the } \\
\text { methods with older adult and } \\
\text { disabled people }\end{array}$ \\
\hline
\end{tabular}

Figure 2: Logic flow of NICKEL

\section{NICKEL - Needs Investigation methods Compatible with End user Limitations}

Cognitive ability What is the participant's level of cognitive ability?

What are the motor tasks/activities that the participants are

Motor ability capable of performing? (Please select Yes/No)

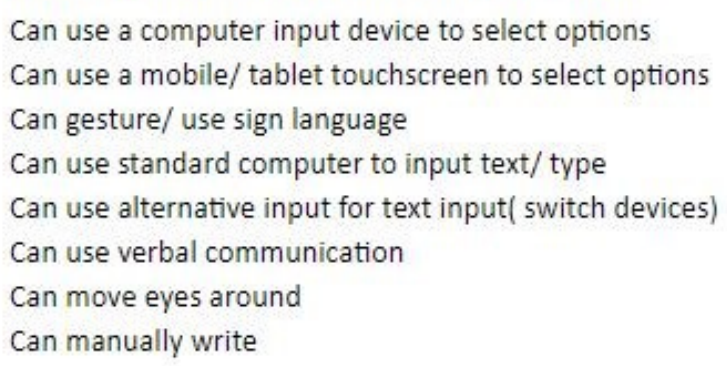

\begin{tabular}{|lc|}
\hline Yes & \\
\hline Yes & \\
\hline No & \\
\hline No & \\
\hline Yes & \\
\hline Yes & \\
\hline Yes & \\
\hline Yes & \\
\hline
\end{tabular}

Perceptual ability What is the participant's level of hearing ability?

What is the participant's visual ability?

Sighted $\quad-$

Figure 3: Screenshot of the NICKEL tool where inputs of potential participant's cognitive, hearing, visual and physical abilities are entered. 
List of methods that can be used with the participants

Face to Face interviews

Think Aloud protocol

Retrospective Think Aloud protocol

Face to Face Interviews:

1. Share your plan with the interviewee (eg. How long the interview lasts, why is the interview conducted)

2. Memorize/become familiar with the interview question before the session.

3. Conduct sample interviews and analyze data to determine if the expected data can be gathered with the interview question items.

4. It is necessary to have the interviewee review and sign a consent agreement if the interview data will be used in a research.

5. In order to produce valid and reliable results follow the rules below:
Think Aloud Protocol:

Think Aloud Protocol: Think-aloud protocols involve participants thinking aloud as they are performing a set of specified tasks. Participants are asked to say whatever comes into their mind as they complete the task. This might include what they are looking at, thinking, doing, and feeling. This gives observers insight into the participant's cognitive processes (rather than only their final product), to make thought processes as explicit as possible during task performance. In a formal research protocol, all verbalizations are transcribed and then analyzed.

Retrospective think aloud protocol: It's a form of think aloud protocol performed after the user testing session activities, instead of during them. Fairly often the retrospective protocol is stimulated by using a visual reminder such as a video replav. In writing studies, the visual

Figure 4: Screenshot of NICKEL outputs and below the outputs is the description of the UCNEM and general guidelines to be considered while conducting needs elicitation studies with older and disabled adults

\subsection{NICKEL Inputs}

To use NICKEL, users must enter their potential participant's human capabilities in terms of vision, cognition, hearing and physical/motor abilities. A detailed explanation on the different inputs related to the above mentioned HF components is provided below in section 6.5.1, 6.5.2, 6.5.3 and 6.5.4.

\subsubsection{Level of cognitive ability inputs}

Cognitive ability was classified into three categories: cognitively intact, moderate cognitive ability, and severe cognitive impairment. Designers and researchers may use one or more of cognitive level assessment scales described in Section 4.1.3 to determine the most appropriate category or they can make an informed estimate based on their experience or the descriptions provided in the NICKEL user manual on the characteristics of people with different cognitive levels and then estimate cognitive ability. 


\subsubsection{Level of visual ability inputs}

The level of vision was also allocated three levels: Sighted, Low vision, and Blind which are used to describe visual abilities (Jutai et al., 2005). The designer/developer/researcher can estimate the visual capabilities of their potential participants and input this selection into NICKEL (see Figure 3). As with estimating cognitive abilities, there are commonly used visual acuity scales such as the Snellen visual acuity scale (International Council of Ophthalmology, 1988). The user manual provides a mapping between the Snellen visual acuity scale ranges and the level of vision categories in NICKEL. It also includes a conversion chart for other visual acuity standards such as logMAR (Bailey \& Lovie, 1976) and the Jager standard (Holladay, 2004) (see Appendix N).

\subsubsection{Level of hearing ability inputs}

There are three different levels of hearing capability in NICKEL similar to cognition and vision: Hearing, Hard of Hearing and Deaf (Canadian Association of the Deaf, 2015). As with the other two input groups, hearing can be measured and mapped onto a standardized range in decibels

(dB) hearing loss of the person provided by the American Speech-Language-Hearing Association (Clark, 1981) or users can reference descriptions in NICKEL's user manual.

\subsubsection{Physical tasks input}

As described in section 5.1.6 of this thesis, after brainstorming session and with the help of the literature (e.g., U.S. Patent 8706920, 2014, U.S. Patent No. 7768499, 2013; Roberts \& Fels, 2006; Turpin et al., 2005) the physical task inputs for NICKEL were selected based on the different parameters that might affect a participant's ability to interact with another person, paper, computer or mobile tablet device. The different physical tasks used as input in NICKEL are:

1. Can use a mouse to select options

2. Can use a mobile/ tablet touchscreen to select options 
3. Can gesture/ use sign language

4. Can use keyboard to input text/ type

5. Can use alternative input for text input (switch devices)

6. Can use verbal communication

7. Can move eyes around

8. Can manually write

As seen in Figure 3, the user must select a yes or no answer for these tasks in the input section.

\subsection{NICKEL processing and outputs}

\subsubsection{NICKEL workflow}

NICKEL workflow diagram has been provided in Figure 5.

1. Once the human capability information has been entered by the user, the first step in the decision-making process involves finding an exact match with the first UCNEM database on the level of cognition and the different physical abilities that the participant can perform.

2. Once the relevant UCNEMs are retrieved, NICKEL proceeds to score each method (described in section 6.6.2) by the difficulty level for the participant's visual and hearing ability from the second UCNEM database. The reason for using scoring for the vision and hearing instead of the direct mapping unlike the cognition and physical tasks is because participants who are hard of hearing and/or low vision will be still be able to use the computer interface/camera/device or write in a diary/paper with some level of difficulty (Jacko et al., 2000).

3. NICKEL will then rank each relevant UCNEMs in descending order based on the scores. Users can view the list of UCNEMs as outputs (see Figure 4). The outputs are colour coded based on their rank with green as the most fit and highly recommended UCNEM, followed by slightly fit UCNEMs which are coded in yellow (can be used with some difficulty) and finally the least recommended methods are coded in red. 
4. NICKEL is primarily developed to help novice designers, developers and researchers who might lack knowledge of UCNEMs. Therefore, a list of general instructions and guidelines/tips on how to use these methods with older and/or disabled adult accompanies the list of UCNEM outputs. 


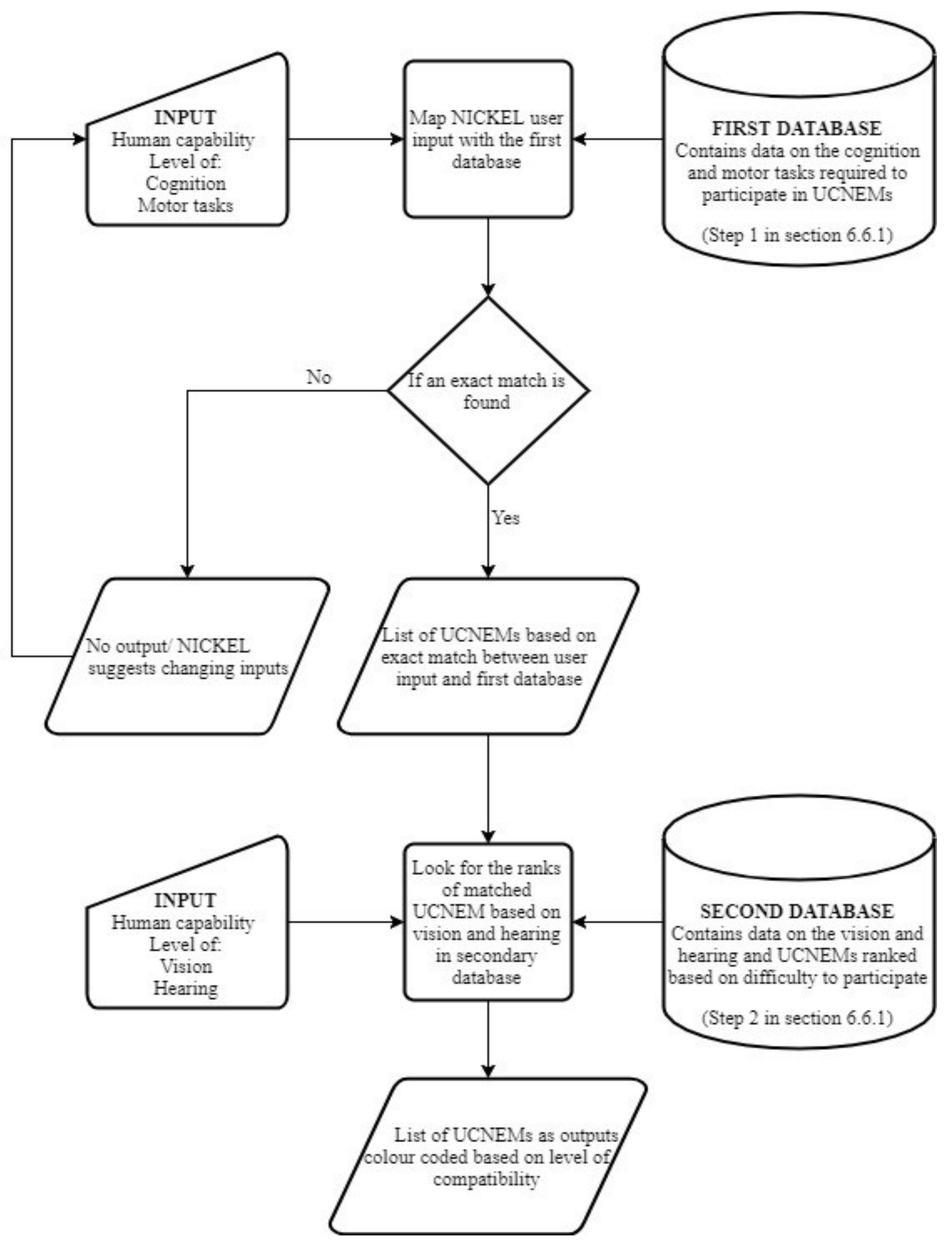

Figure 5: NICKEL decision flow 


\subsubsection{NICKEL scoring system for output}

As outlined in Chapter 4, expert designers and researchers were asked to rate the level of difficulty (not difficult, moderately difficult, very difficult) that would be experienced by an elderly participant with different level of vision and hearing while participating in the different UCNEMs. The resulting ratings were assigned numerical values for the level of difficulty of the different visual and hearing capabilities. The values were "0", "1", "2" for "not difficult", "moderately difficult" and "difficult" respectively (see Table 1). For example, Table 4 illustrates the values assigned to think aloud protocol (sign language) method for hearing and visual abilities.

Table 3: Scale used to determine difficulty to participate in UCNEM and their numerical values

\begin{tabular}{|c|c|}
\hline Level of difficulty & Numerical value \\
\hline Not difficult & 0 \\
\hline Moderately difficult & 1 \\
\hline Difficult & 2 \\
\hline
\end{tabular}

Table 4: Scoring of the level of difficulty to participate in UCNEM with different hearing and visual abilities

\begin{tabular}{|c|c|c|c|c|c|c|}
\hline \multirow{2}{*}{ UCNEM } & \multicolumn{2}{|c|}{$\begin{array}{c}\text { Level of difficulty for } \\
\text { different hearing abilities }\end{array}$} & \multicolumn{3}{c|}{$\begin{array}{c}\text { Level of difficulty for } \\
\text { different visual abilities }\end{array}$} \\
\cline { 2 - 7 } & Hearing & $\begin{array}{l}\text { Hard of } \\
\text { hearing }\end{array}$ & Deaf & Sighted & $\begin{array}{l}\text { Low } \\
\text { vision }\end{array}$ & Blind \\
\hline Think aloud protocol & 0 & 1 & 2 & 0 & 1 & 2 \\
\hline
\end{tabular}

1. Once the user selects their potential participant's hearing ability in NICKEL, the tool sums the difficulty values of the hearing ability given as input and difficulty value(s) of the next best hearing ability. This gives the hearing ability score of a potential participant. For example, when the user selects their participant capability as Deaf, the scoring sheet will add the numerical values corresponding Deaf, hard of hearing and hearing for each method. 
2. The same calculation applies to calculating the visual ability score.

3. The hearing and visual ability scores are then added to form a total score. Higher total scores represent higher difficulty the participant will face while participating in the corresponding method. This total scores for all UCNEMs are then ranked in an ascending order considering higher score meaning higher difficulty. The methods with the lowest difficulty score will appear first, or best fit, in NICKEL's recommendation listing.

As NICKEL is a decision support system where the values have been empirically derived. It is important that an evaluation be carried out to assess whether the outputs provided by NICKEL can satisfy the description of older and/or disabled adult needs provided as input. Section 5.7 provides a description of the user study, results and discussion. 


\subsection{User Evaluation}

This chapter is aimed at answering the final research question:

"Is NICKEL a useful and usable tool for novice designers, developers and researchers to determine UCNEM methods compatible with older/disabled participant's visual /hearing abilities, motor skills and cognitive impairment?"

The user study methodology, analysis of the user study data and the results is described in this chapter.

\subsubsection{Methodology}

A user study was carried out to evaluate NICKEL for usability and usefulness. Qualitative and quantitative data were collected using pre and post study questionnaire, and a think aloud protocol logging the interactions with NICKEL by participants. Quantitative and qualitative methods were also used to analyze the data with the level of significance set to $\mathrm{p}<0.05$ for statistical analyses.

Following Ryerson Research Ethics board approval (see Appendix G for the ethics approval letter) and signed consent participants were asked to complete a pre-study questionnaire, followed by a 30-minute session of using NICKEL with three different personas and then complete a post-study questionnaire. The personas were used to simulate descriptions of potential older adult participants in order for study participants to determine human capabilities and enter into them NICKEL. 


\subsubsection{Pre-study questionnaire}

The pre-study questionnaire consisted of five questions to capture data on gender, the primary area of interest or discipline, the years of experience in the area of design or research interest or discipline, and in conducting needs gathering studies (see Appendix K).

\subsubsection{Post-study questionnaire}

There were a total of 24 questions in the post study questionnaire divided into 8 sections (see Appendix L).

1. The first section captured the participant's ID (each participant were assigned a unique ID number at the beginning of the study).

2. The second section consisted of 10 questions that captured the usability characteristics of NICKEL using the standard system usability scale (SUS) (Brooke et al., 1996). Each question in the SUS used a 5-point Likert scale format. The usability characteristics included learnability, efficiency, memorability, errors and satisfaction, which were the five primary components of usability (Nielsen, 2012).

3. The third section of the questionnaire captured the user's reaction to using NICKEL using a 5-point Likert scale.

4. Sections 4 and 5 has two questions for participants to rate how helpful NICKEL was in determining UCNEM for older and disabled participants on 5-point Likert scales. Through the literature review (see section 3.7), it was identified that designers and engineers did not consider HF in determining which UCNEMs fit best with their participants. The NICKEL user study participants were thus asked to give their opinion on the importance of considering $\mathrm{HF}$ in determining a relevant UCNEM after using NICKEL in the user study. 
5. Section 6 has two questions, in which participants were asked whether they would use NICKEL in the future for their own work or research in a single question.

6. In section 7 , four questions were asked where participants were asked whether there was agreement between the classification of the visual, hearing, cognition and physical ability levels provided in the NICKEL user manual and the study participant's understanding of the levels of human capabilities.

7. Section 8 has four open ended questions which asks about the likes, dislikes of NICKEL, recommendation of any additional HF criteria to be added, and any recommendation in general.

\subsubsection{Think aloud protocol (TAP) study procedure}

A brief background of NICKEL and its functions was provided to each participant. As most of the participants were not familiar with many UCNEMs or the factors that are considered to decide on a specific UCD in the design process, a description of the existing usability planner tool (Ferre \& Bevan, 2011) and the challenges faced by elderly and disabled people to participate in UCNEM studies were provided. Participants were also provided with a training session for NICKEL, its components and a walkthrough of the manual. Training for NICKEL had the following steps:

1. Read a sample persona and highlight the important human capabilities or disability of a persona.

2. Compare the human capabilities from the persona with the instructions manual in NICKEL and determine the level of vision, hearing, cognition and the task that can be performed by the persona to participate in the UCNEM process.

3. Read instructions on how to interpret results. 
4. Enter the level of vision, hearing, cognition and the tasks the participant can perform into the NICKEL tool.

5. Read the output methods and guidelines on how to use the compatible methods.

6. Provide feedback on if the study participant agrees with the results provided by NICKEL.

Once the training was complete participants were given three personas with different human capability limitations (see Appendix C) and were asked to determine the appropriate UCNEMs for each persona using NICKEL while talking out loud. Participants were encouraged to use the tool and no support was provided unless there was a technical issue in the user study setup itself. Once they completed using NICKEL with all three personas provided, study participants were encouraged to create and describe their own personas based on any older or disabled participant they had encountered in their life. But, this task was optional. Following this task, participants were asked to complete the post study questionnaire. After the post study questionnaire was completed, participants were compensated with $\$ 20$ for their time.

\subsubsection{Participants}

Eighteen people (12-female, 6-male) participated in the NICKEL user study to evaluate the usefulness and usability of the software. The age range of the participants was not asked as it was not a relevant variable for the study.

All participants were currently working or had worked in the development of assistive technology or conducted research with older and/or disabled participants. They were primarily recruited from the Inclusive Media and Design Centre and Ryerson TETRA society. Six participants reported they were researchers, five participants reported themselves as engineers, three participants were designers. The rest of the study participants comprised of one computer 
science professional, one business administrator, one participant working in education and innovation domain and one participant working as a IT accessibility professional.

Of the 18 participants in the user study five people had less than 2 years of experience and seven people had 2 to 6 years of experience in the respective field or work domain who were classified as novice. These two participant groups were classified as novice and there were a total of 12 participants. Six participants had more than 6 years of experience and were classified as experts (Gladwell, 2008).

Of the 12 participants who were identified as novice in their area of expertise, nine participants have never conducted a needs gathering study in their career, two participants had less than 2 years of experience, one participant had 2 to 6 years of conducting user needs gathering study. Among the six participants identified as experts, two participants had less than 2 years and 2 to 6 years of experience conducting needs gathering study. But the rest four participants had more than 6 years of experience conducting needs gathering study.

\subsubsection{Data analysis methods}

All the quantitative questionnaire data in the post study questionnaire were subjected to non-parametric statistical analyses (chi square, Mann Whitney U tests) and descriptive analyses to assess the user responses for the usability and usefulness of NICKEL. A non-parametric chi square test was conducted on quantitative data to assess the agreement levels among the responses from the post study questionnaire and also evaluate which responses were significantly different from chance.

To analyze all the responses from the open ended questions and the audio comments provided during the study session a thematic analysis was used according the methodology 
outlined by Braun \& Clarke (2006). The themes were developed using open coding strategy (Pandit, 1996). Table 6 provides a list of all the themes and their corresponding definitions.

The qualitative data was coded in NOLDUS Observer ${ }^{\mathrm{TM}}$ for each theme. Two independent raters counted the occurrences of each theme in this data. The kappa coefficient in this study is $0.68>0.6$ indicating good inter rater reliability (McHugh, 2012). An intra-class correlation (ICC) coefficient was generated between the two raters and ICC $>0.64$ for all themes indicating a strong agreement between the two raters (see Table 5). The remaining data were coded by a single rater.

Table 5: ICC values for each theme

\begin{tabular}{|l|l|l|}
\hline Themes & ICC value & p-value \\
\hline Functionality & 0.688 & 0.000 \\
\hline Interaction with NICKEL & 0.658 & 0.000 \\
\hline Interaction with manual & 0.632 & 0.034 \\
\hline Interpretation from user manual & 0.776 & 0.000 \\
\hline Interpretation from persona & 0.674 & 0.001 \\
\hline Usability & 0.860 & 0.000 \\
\hline Recommendation & 1.000 & 0.000 \\
\hline
\end{tabular}

Table 6: Themes and definitions used for thematic analysis

\begin{tabular}{|l|l|l|}
\hline Themes & Definition- Examples & Examples \\
\hline $\begin{array}{l}\text { Interaction with } \\
\text { user manual and } \\
\text { NICKEL }\end{array}$ & $\begin{array}{l}\text { Interaction is the general use of the user } \\
\text { manual or NICKEL by a user. }\end{array}$ & $\begin{array}{l}\text { Example: } \\
\text { Interaction with manual } \\
\text { Modifiers: }\end{array}$ \\
$\begin{array}{l}\text { Positive: "I'm going to review the } \\
\text { criteria right now to check I did } \\
\text { not miss anything" } \\
\text { Negative: "Confusion } \\
\text { alternative input device" with } \\
\text { Interaction with NICKEL }\end{array}$ \\
\hline
\end{tabular}




\begin{tabular}{|c|c|c|}
\hline & & $\begin{array}{l}\text { Modifiers: } \\
\text { Positive: "I like when the tool } \\
\text { tells what's best" } \\
\text { Negative: "Lots of jargon" }\end{array}$ \\
\hline Usability & $\begin{array}{l}\text { The extent to which a product can be used } \\
\text { by specified users to achieve specified } \\
\text { goals with effectiveness, efficiency, and } \\
\text { satisfaction in a specified context of use }\end{array}$ & $\begin{array}{l}\text { Example: } \\
\text { Modifiers: } \\
\text { Positive: "Was easy to } \\
\text { understand and use." } \\
\text { Negative: "Confusing using the } \\
\text { tool interface" }\end{array}$ \\
\hline Functionality & $\begin{array}{l}\text { Functionality is the expression of system } \\
\text { capabilities, accuracy, completeness. }\end{array}$ & $\begin{array}{l}\text { Example: } \\
\text { Modifiers: } \\
\text { Positive: "It's pretty accurate" } \\
\text { Negative: "Disagree with results" }\end{array}$ \\
\hline Interpretation & $\begin{array}{l}\text { Interpretation is the action of } \\
\text { understanding and explaining the } \\
\text { meaning of the parameters in the persona, } \\
\text { user manual, and NICKEL }\end{array}$ & $\begin{array}{l}\text { Example: } \\
\text { Persona-Interpretation: } \\
\text { Modifiers: } \\
\text { Positive: "Based on activity } \\
\text { seems like she is cognitively } \\
\text { intact" } \\
\text { Negative: "Doesn't seem to } \\
\text { mention if the participant can use } \\
\text { a mobile phone" } \\
\text { User Manual-Interpretation: } \\
\text { Modifiers: } \\
\text { Positive: "It's 20/20, so he has } \\
\text { good vision" }\end{array}$ \\
\hline
\end{tabular}




\begin{tabular}{|l|l|l|}
\hline & & $\begin{array}{l}\text { Negative: "Participant } \\
\text { characteristics fits kinda both } \\
\text { cognitively intact and moderate } \\
\text { impairment. So It's hard to } \\
\text { decide" }\end{array}$ \\
\hline $\begin{array}{l}\text { Recommendation/ } \\
\text { Feedback }\end{array}$ & $\begin{array}{l}\text { A suggestion or proposal as to the best } \\
\text { course of action, especially one put } \\
\text { forward by an authoritative body. }\end{array}$ & $\begin{array}{l}\text { "Cognitive ability- refine into } \\
\text { abilities like the motor abilities" }\end{array}$ \\
\hline
\end{tabular}

\subsection{Results:}

\subsubsection{SUS questions}

There is a significant chi-square result for nine out of ten questions in the SUS scale with $\mathrm{p}<0.05$ (see Table 7). Also, the SUS scores from novice participants (mean SUS score $=77.5$, $\mathrm{SD}=20.9$ ) and expert participants (mean SUS score $=80.8, \mathrm{SD}=12.6$ ) (see Figure 6) were greater than 71.4, which according to Bangor, Kortum, \& Miller (2009) indicates that participants found NICKEL as a usable.

Table 7: Chi square results for SUS scale

\begin{tabular}{|l|l|l|l|l|l|l|}
\hline Q. No & SUS question & $\begin{array}{l}\text { Chi- } \\
\text { square } \\
\text { test }\end{array}$ & Mean & SD & $\begin{array}{l}\text { Mode value } \\
\text { (corresponding } \\
\text { response) }\end{array}$ & $\begin{array}{l}\text { p- } \\
\text { value }\end{array}$ \\
\hline 1 & $\begin{array}{l}\text { I think that I would like to use this } \\
\text { system frequently }\end{array}$ & 6.44 & 3.72 & 1.17 & 4 (Agree) & 0.168 \\
\hline 2 & $\begin{array}{l}\text { I found the system unnecessarily } \\
\text { complex }\end{array}$ & 20.88 & 1.72 & 1.12 & $\begin{array}{l}1 \text { (Strongly } \\
\text { disagree) }\end{array}$ & 0.000 \\
\hline 3 & $\begin{array}{l}\text { I thought the system was easy to } \\
\text { use }\end{array}$ & 14.22 & 4.11 & 1.13 & 5 (Strongly agree) & 0.007 \\
\hline 4 & $\begin{array}{l}\text { I think that I would need the } \\
\text { support of a technical person to } \\
\text { be able to use this system }\end{array}$ & 27.55 & 1.67 & 1.28 & $\begin{array}{l}1 \text { (Strongly } \\
\text { disagree) }\end{array}$ & 0.000 \\
\hline
\end{tabular}




\begin{tabular}{|l|l|l|l|l|l|l|}
\hline 5 & $\begin{array}{l}\text { I found the various functions in } \\
\text { this system were well integrated }\end{array}$ & 12.00 & 3.89 & 1.23 & 4 (Agree) & 0.017 \\
\hline 6 & $\begin{array}{l}\text { I thought there was too much } \\
\text { inconsistency in this system }\end{array}$ & 10.88 & 2.00 & 1.13 & $\begin{array}{l}1 \text { (Strongly } \\
\text { disagree) }\end{array}$ & 0.028 \\
\hline 7 & $\begin{array}{l}\text { I would imagine that most people } \\
\text { would learn to use this system } \\
\text { very quickly }\end{array}$ & 27.00 & 4.44 & 1.04 & 5 (Strongly agree) & 0.000 \\
\hline 8 & $\begin{array}{l}\text { I found the system very } \\
\text { cumbersome to use }\end{array}$ & 12.00 & 1.94 & 1.21 & $\begin{array}{l}1 \text { (Strongly } \\
\text { disagree) }\end{array}$ & 0.017 \\
\hline 9 & $\begin{array}{l}\text { I felt very confident using the } \\
\text { system }\end{array}$ & 23.66 & 4.50 & 0.61 & 5 (Strongly agree) & 0.000 \\
\hline 10 & $\begin{array}{l}\text { I needed to learn a lot of things } \\
\text { before I could get going with this } \\
\text { system }\end{array}$ & 19.77 & 1.89 & 1.41 & $\begin{array}{l}1 \text { (Strongly } \\
\text { disagree) }\end{array}$ & 0.001 \\
\hline
\end{tabular}

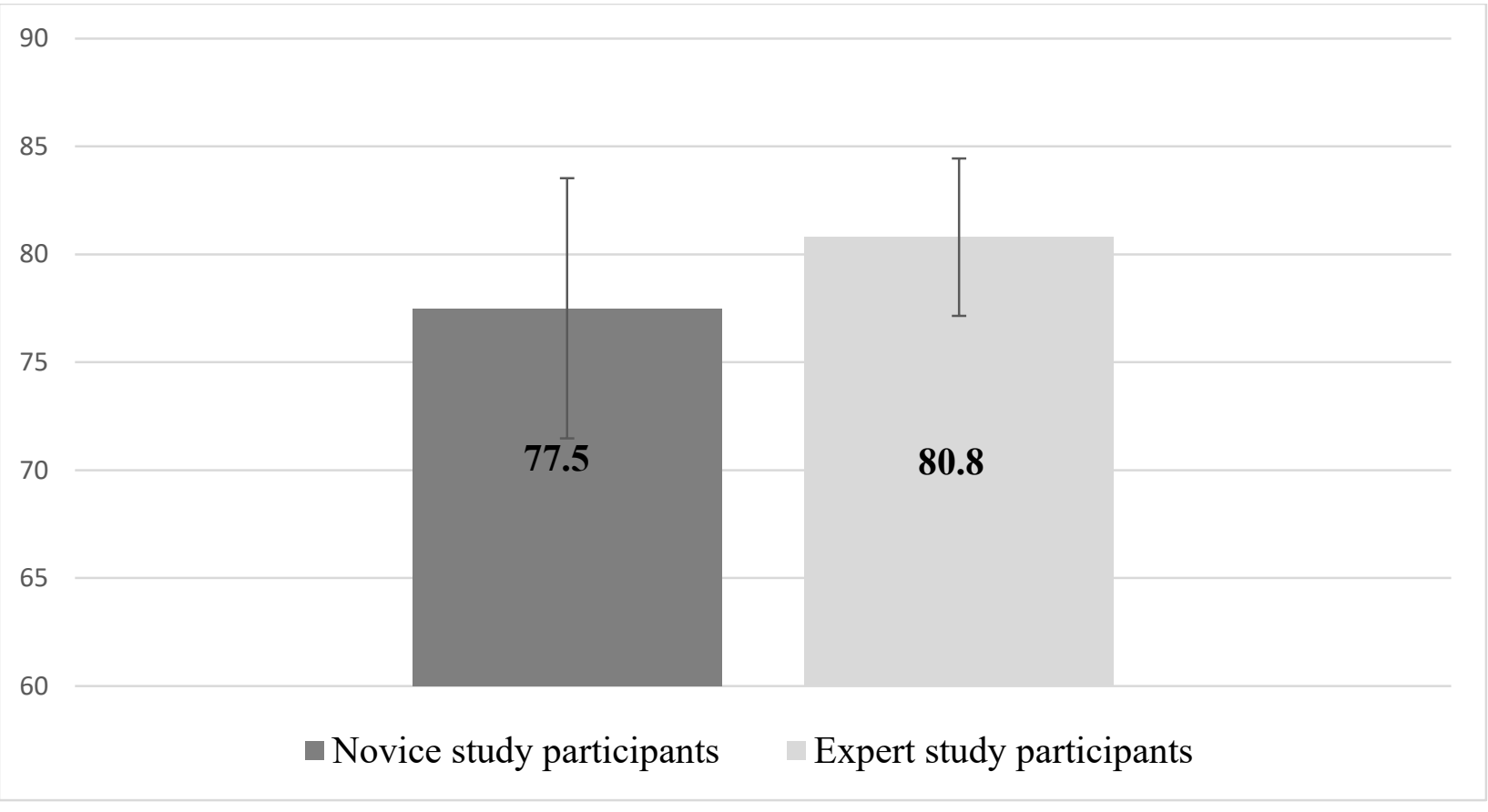

Figure 6: Mean SUS scores and standard deviation bars for novice and expert participants $>71.4$ indicating good usability (Bangor et al., 2009)

\subsubsection{Remaining questionnaire data}

There is a significant chi-square result between responses and chance $(p<0.05)$ for the forced choice questions in sections 4 to 7 as given in Table 8 . These questions capture the 
participant's agreement on the values and description provided on the different levels of vision, hearing, cognition, physical tasks. Also, it captures the participant's opinion on how helpful NICKEL is for selecting UCNEM for older and/or disabled participants and how important it is to consider HF in determining UCNEM.

Table 8: Significant chi square results for likert scale questions from Section 4 to 7 of the post study questionnaire

\begin{tabular}{|c|c|c|c|c|}
\hline Q.No & Questions & $\begin{array}{l}\text { Chi Square } \\
\text { value }\end{array}$ & Mode & p-value \\
\hline 1 & $\begin{array}{l}\text { My knowledge on the level of cognition is } \\
\text { similar to the description provided in } \\
\text { NICKEL }\end{array}$ & 10.88 & Agree & 0.028 \\
\hline 2 & $\begin{array}{l}\text { My knowledge on the level of hearing similar } \\
\text { to the description provided in NICKEL }\end{array}$ & 18.66 & Agree & 0.001 \\
\hline 3 & $\begin{array}{l}\text { My knowledge on the level of vision similar } \\
\text { to the description provided in NICKEL }\end{array}$ & 18.66 & Agree & 0.001 \\
\hline 4 & $\begin{array}{l}\text { It was difficult to understand the options } \\
\text { pertaining to physical tasks }\end{array}$ & 14.22 & Disagree & 0.007 \\
\hline 5 & $\begin{array}{l}\text { In your opinion how helpful is NICKEL for } \\
\text { novice designers to determine needs gathering } \\
\text { methods for older adult participants? }\end{array}$ & 11.44 & Very helpful & 0.022 \\
\hline 6 & $\begin{array}{l}\text { In your opinion how helpful is NICKEL for } \\
\text { novice designers to determine needs gathering } \\
\text { methods for disabled participants? }\end{array}$ & 13.66 & Very helpful & 0.008 \\
\hline 7 & $\begin{array}{l}\text { In your opinion, how important is to consider } \\
\text { human capabilities as a criteria while } \\
\text { designing the needs gathering process for } \\
\text { older adults and people with disabilities? }\end{array}$ & 33.66 & $\begin{array}{l}\text { Extremely } \\
\text { important }\end{array}$ & 0.000 \\
\hline
\end{tabular}

To identify the differences in responses between participants of different experience groups, a Mann Whitney U test was performed. The result showed that there was no significant difference $(p>0.05)$ between the responses from novice and expert participants for all questions. 


\subsubsection{Qualitative data}

All the responses from the participants in the open-ended questions in the post-study survey and the comments from the screen/audio recording of the TAP study were coded into the defined themes described in Table 6.

Although the SUS scale score indicates NICKEL to be usable, and 29 instances in thematic analysis relates to "Usability-Positive:" theme, there is still 19 instances which relate to "Usabilitynegative" theme (see Figure 7). A Mann Whitney U test between the responses in these two themes showed significant difference between these two themes $(U=129.5, p=0.024)$. Also, the percentage of comments from expert and novice participants for each theme is provided in Figure 8.

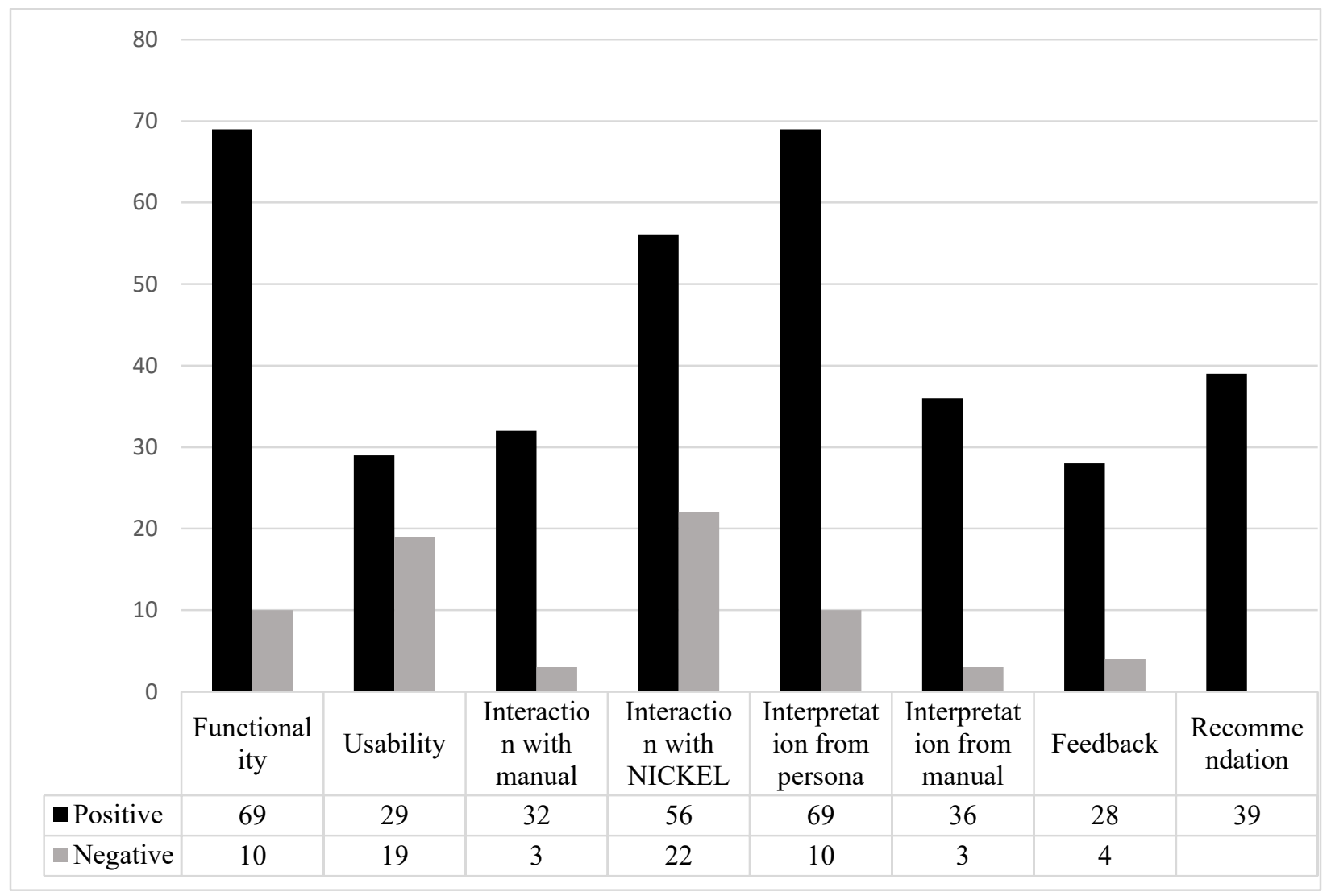

Figure 7:Frequency distribution of positive and negative comments from participants for each theme 


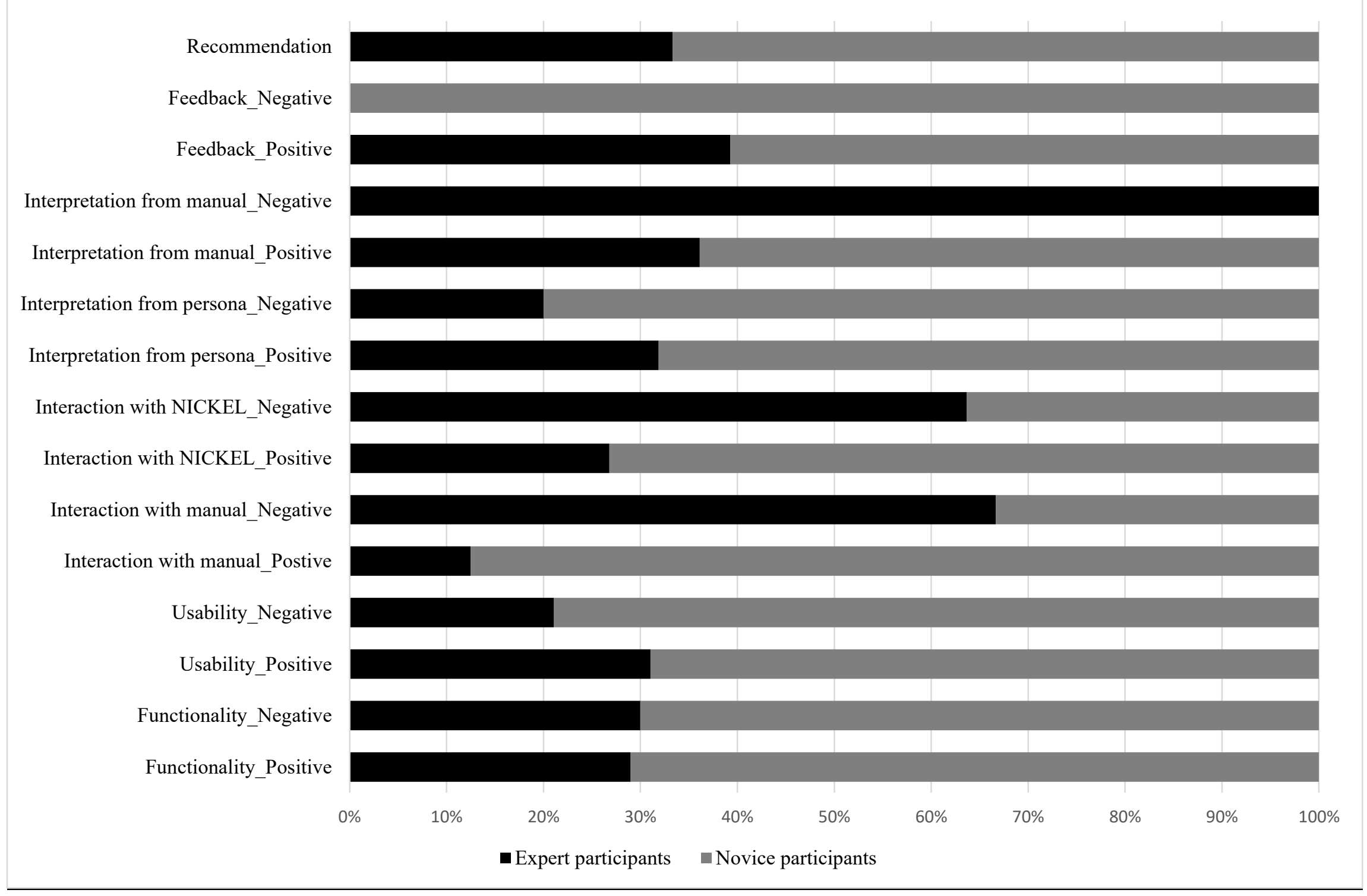

Figure 8: Percent of comments from expert and novice participants for each theme 


\subsection{Discussion}

\subsubsection{Usability of NICKEL}

One particular component of usability is ease of use (Bertoa \& Vallecillo, 2004). As seen in question \#3 of Table 7, in general user study participants thought that NICKEL is easy to use and not complex. These responses can be exemplified by the user comment in the TAP session:

$$
\text { "It's very easy to use" (Participant 9) }
$$

Complexity can also affect the usability of any system (Fang \& Holsapple, 2007). Note that ease of use is reported to be inversely proportional to the complexity of the system (Venkatesh \& Davis, 1996). Responses to question \#2 in the SUS questionnaire shows that participants "Strongly disagreed" that the system was unnecessarily complex. This might be because different human capability components were broken down as specific questions and common language modifiers such as e.g. sighted, low vision and blind were used to help novice users identify the various capabilities and provide rating estimates for those capabilities. For example, instead of asking users to enter the person's visual acuity level as a numeric value on a scale (e.g., as 20/100), participants were asked to assign a vision level using three commonly used labels (blind, low vision and sighted). For expert designers/researchers who were experienced enough to measure the potential participant's level of vision using a specific chart (e.g., Jaeger standard), conversion tables for a variety of scales were provided in the user manual. Conversion tables have also been provided for four cognition scales and visual abilities. By categorizing participant abilities into simple human ability categories, likely influenced NICKEL to be easy to use. This allowed NICKEL to be used by novice users without requiring specific measures or measurement instruments but also facilitating those who 
were familiar with using specific visual, hearing and cognition scales. Keates \& Clarkson (2003) and Naeini \& Mosaddad (2013) suggested that novice designers lack the in-depth knowledge on the different UCNEM and HF and that any interface should have simple and easy to understand text/terminologies to reduce complexity for the end user (Chilana, Wobbrock, \& Ko, 2010; Geissler, Zinkhan, \& Watson, 2001). The response to SUS scale on the low complexity of NICKEL is backed by comments provided by participants identified during the qualitative research. For example:

"I like that the tool provides categorization of disabilities" (Participant 6)

“Clarified and isolated User Experience (UE) factors” (Participant 15)

"The question really narrowed down on all abilities" (Participant 11)

Although NICKEL asks users to enter one of three possible discrete categories of human capabilities as an input such as "low vision", the scales used to measure the capabilities (e.g., the Snellen scale for vision or the dB scale for hearing) are continuous. If NICKEL suggests an online survey should be used with low vision participants and the participant's vision ranges from 20/100 to 20/160 on the Snellen scale, the survey administrators must ensure that the font size, screen contrast, types of alternative devices etc., are modified according to their participants' requirements. To determine the capabilities required by potential participants to engage in a UCNEM, the designer should understand their end user and study participants prior to using NICKEL. Although NICKEL provides general guidelines on how to use the methods with older and disabled adults, it does not provide customized instructions on how to modify the methods for specific participant abilities. 
The mode response to the SUS question \#5 indicated that the study participants "Agreed" that the system was well integrated. Although the mode value of the responses to SUS question \#1 indicate participants "Agreed" that they would like to use the system frequently, the chi square test showed these responses were not significant $(\mathrm{p}>0.05)$ (see Table 7 ). This may be because there were varied responses between the novice and expert participants. All 12 novice participants reported that they would use NICKEL frequently, but three out of six expert participants reported that they would not use the system frequently. As identified in the literature expert researchers tend to have less need of any specific tools to assist them in selecting needs elicitation methods (Hickey \& Davis, 2003a). This combined with the fact that all the expert participants recruited for my study had worked with older adults might be the reason why expert participants were not inclined to use NICKEL frequently in their own studies/research.

Another component in usability is learnability, which refers to how a product, tool or a software system enables the user to learn how to use it. Question \#4, \#7 and \#10 in the SUS related to learnability (see Table 7). The responses given by participants to these questions showed that the users found that NICKEL was easy to learn. However, there were instances where users were not able to understand how to translate the first persona into inputs. But, once the first persona was successfully used with NICKEL, the users found NICKEL easy to use for the remaining scenarios. Ngwenyama, Guergachi, \& McLaren (2007) suggest that there is a learning curve associated with every product which supports the difficulties encountered with the first persona. Some of the user comments related to learnability were:

"Initially I was confused for the first time. But from the second scenario, I knew what I wanted to do." (Participant 2) 
“NICKEL is a very user-friendly and easy-to-learn tool." (Participant 9)

Despite most participants finding NICKEL to be usable, there were some novice participants who found NICKEL to be more complex to understand and use. One such usability issue was the terminology used in NICKEL. Three novice participants found the terminology used in NICKEL to be complex and wanted simpler terms. Although there were only five of 19 comments related to terminology in the Usability-negative theme, it was treated as a major issue. Example comments from the participants in the TAP study included:

"Lots of jargon terminologies for me as a designer. If engineers or programmers use this tool it's one thing, but for me, it's hard to understand terminologies like cognitive impairment and stuff." (Participant 3)

"Designers didn't have to think about accessibility .....this is all new to them. So when you say cognitive ability give bullet points like motor skills. New designers will spend time just understanding what cognitive ability means" (Participant 3)

Upon further analysis, it was found that participants did not understand terminology related to alternative input devices and verbal communication. One participant mentioned:

"Are switch device and touchscreen the same? Confusion with terminologies" (Participant 11)

After this confusion was noticed with participant 11, the question in the tool was changed to "Can use alternative device for text input." After this was included participant 17 could not understand what alternative text input device meant, hence the question in the tool was again rephrased to "Can use alternative device for text input (switch devices)?" 
During the initial design of NICKEL, the physical abilities question "Can speak" was also rephrased to "Can use verbal communication." This was done in consideration of Deaf participants who consider ASL as their spoken language and who may enter "Yes" as the answer for the question "Can speak." Hence, they will enter "Yes" for questions "Can speak" and "Can use sign language." To avoid this confusion, the question "Can speak" was rephrased into "Can use verbal communication”. But, even after this rewording participant 12 asked "What do you mean by verbal communication. Does it mean talking?" Additional research is needed to find appropriate terminology/language that is easier for novice NICKEL users to understand. There may not be one term that is appropriate for one concept and that would be widely understood such as "alternative device" especially for domain specific concepts. Another solution then might be adding hyperlinks to definitions, images or websites so that novice users could learn specific terminology. Despite this feedback from three participants, the SUS scale scores indicate that NICKEL as a "easy to use" tool.

Another issue identified related to usability was the accessibility options for NICKEL. One participant who was an IT accessibility professional and had low vision neither agreed or disagreed that the system was complex. The participant had to use the accessible magnifier setting to use NICKEL. Because NICKEL was not optimized for a magnified view, he found NICKEL to be complex. Although the Google worksheet was magnified to 150 percent, the participant still faced issues navigating through NICKEL with the on-screen magnifier. Other accessibility barriers may also cause difficulties for users and negatively affect ease of use. For a future version of NICKEL, it is recommended that accessibility options are taken into consideration to make it easy to use for low vision and blind users. 


\subsubsection{Usefulness in research and design:}

This section will discuss the usefulness of NICKEL in the research and design process as indicated by the user study participants. One of the challenges that designers or researchers face while designing their project methodology is to find a UCNEM that fits their project from a pool of available methods (Goguen, 1996; Maiden \& Rugg, 1996). There are also studies showing that methods of data collection may not be compatible with people of different abilities (Lines \& Hone, 2002; Moore, 2002).

Response to the post study question \#5 and \#6 (see Table 8), show that study participants found NICKEL to be "Very helpful" to determine a UCNEM for potential older and/or disabled participants. This can be related to positive responses from participants in the think aloud protocol (TAP) on the satisfaction with the results and their willingness to use NICKEL in their future research shows that participants find it a useful and viable tool addressing the need to find a way to determine a UCNEM that fits with the older adult and/or disabled users as mentioned by Lines \& Hone (2002). Some example comments from the Think aloud protocol (TAP) study regarding NICKEL's usefulness are:

"It can assist me identifying the study design according to my population need." (Participant 5)

"It could help someone like me to analyze and think about what processes to use"

"For novice designers, it will be really helpful" (Participant 16)

Participants seemed to be satisfied with NICKEL and the UCNEM it provided as outputs. When asked "What was your reaction after using the NICKEL tool?", 11 out of 18 participants mentioned that they were satisfied with the outputs given by NICKEL. Also, 69 out of 79 (see Figure 7) instances in the functionality theme identified during thematic analysis of the Think aloud protocol (TAP) 
data were positive responses/instances indicating that participants were satisfied with the outputs of UCNEM and found it a useful tool. Positive comments provided by experts and novice participants with respect to "Functionality" theme:

Response from expert participants:

"It helped guide me and provided feedback to how to proceed"

"Both done online. That would work for him using his chin switch"

"This is so good. just going through the process and checklist" (Participant 15)

Response from novice participants:

$$
\begin{gathered}
\text { "I do agree with the results" (Participant 12) } \\
\text { "It's pretty accurate" (Participant 4) }
\end{gathered}
$$

At the same time, there were 10 negative instances during the qualitative data analysis with respect to the "Functionality" theme. There were participants who entered severe cognitive impairment in the cognitive ability section and did not receive any UCNEM as outputs, instead received an error message that there were no UCNEM available. This stems from the database created with the survey study in section 4.1.7 where the experts were not able to determine any UCNEM methods that were suitable for use with persons whose cognition are severely impaired. Therefore, more research is need to be conducted to develop UCNEMs to be used with people with severe cognitive impairment, so that NICKEL can be useful in identifying UCNEM for people having dementia etc., 
Also, some participants were not satisfied with the output UCNEMs after the entering human capabilities of Persona 4. Persona 4 used in the TAP study was a quadriplegic person, who could not move any part of the body, cannot use verbal communication and can use only a chin activated switch device to communicate (see Appendix C). Since the chin switch was the only method by which the persona can communicate/interact with computer or mobile devices, online based open and closed survey are the best UCNEM methods for this persona type despite the difficulty. Although all the participants received the same output from NICKEL (online based open and closed-ended survey), there were participants who were surprised as to why only these methods can be used with this persona. One participant mentioned "If he is quadraplegic, open-ended survey well that's not gonna work well with him. well, he can type with his chin switch, it's gonna be hard." Another novice participant (less than 2 years' experience in field of design) mentioned not knowing what quadriplegic means. This may be due to his/her limited knowledge and awareness of the different kinds of disability, or specifically physical disabilities (Fitchen, Hines, \& Amsel, 1985). Future versions of NICKEL could include help, hypertext links or other resources to help novice users find information on the different types of disabilities if needed.

Participants were also encouraged to create their own persona and try giving their persona's human capabilities as inputs. In this task 12 participants used NICKEL with their own persona and 9 participants were satisfied with the outputs they received, 1 participant was partially satisfied and 2 participants did not either get any results/disagreed with the UCNEM suggested as most compatible. For instance, a participant entered details about a person she knew, who was capable of all the HF components, but lacked interpersonal skills. NICKEL suggested a face-to-face interview as the best UCNEM option but the participant disagreed because the person she knew lacked interpersonal skills and an interview method would be ineffective. The participant commented: 
"Face to face interview will be best for her ability, but since her interpersonal skills are low, face to face will be very intimidating for her" (Participant 12)

The HF capabilities used with NICKEL were selected because they were identified as the primary capabilities (Carl \& Roger, 2004), to successfully determine UCNEM, however, it seems that other capabilities/skills are needed. Using the methodology outlined in this thesis, adding other capability factors, and finding and populating appropriate levels of these factors could occur.

Users also found the colour coding of the UCNEM based on compatibility to be helpful. An example comment was:

"I also like that it gave me various options for methods to use, with colours to identify which NICKEL thought was best for me." (Participant 2)

A benefit of having a list of possible UCNEM methods and their suitability rating is that can facilitate the integration of NICKEL with the other frameworks such as the usability planner tool (Ferre \& Bevan, 2011) so that human factors is used as a criteria along with other criteria such as cost, effort, type of data, etc.

When the outputs of the UCNEM are displayed, all the novice participants read the description, instruction, and guidelines provided on how to use the methods effectively in general and with older and disabled adults. The most common methods for which participants read these descriptions and instructions are for TAP, sign language TAP, retrospective TAP and cultural probes. This might be because they did not know how to use these different methods, particularly the lesser known methods such as cultural probes, card sorting, and other participatory design methods, effectively (Mao et al., 2005). Also, this might be because designers tend to use only the methods with which they are familiar and are most commonly used, and do not learn to use new UCNEMs despite the increased benefits, efficiency and rich data that can be collected. The instruction and guideline sections are also used by one expert participant. 
NICKEL not only provides a list of UCNEMs, but is also useful by providing instructions on how to use the UCNEMs. For example, one participant commented:

\section{"I didn't know what everything was. But the manual told what it was." (Participant 2)}

Two expert participants mentioned that NICKEL would be a good learning and teaching tool that could help novice designers. NICKEL could be deployed as a tool in classrooms which encompasses user engagement, or as a training tool in organizations which recruits novice researchers to work with older and/or disabled persons. Also, in the user study, participant 3, who was a novice designer with an arts background working in the field of assistive technology, mentioned that artists will be unfamiliar with these methods. He/she said:

"It would be great for people who are new such as art designers. It will help them think. Help them guide their thinking"

\section{(Participant 17)}

NICKEL is a simple and easy to understand decision support tool as indicated by the SUS score and participant's real-time comments. Although NICKEL is perceived to be easy to use and useful in determining UCNEMs, there are also a few drawbacks/limitations identified such as complex terminologies, no UCNEMs identified for people having severe cognitive impairment, only two methods available to be used with quadriplegic persons and people similar to persona 4 in the TAP study of this thesis. Therefore, future research is needed to address these drawbacks/limitations. 


\subsection{Limitations}

One of the main limitations of this research was the low number of participants. Only 18 participants were recruited due to very strict inclusion criteria to participate in the research study and limited availability of time. The small sample size limited the statistical analyses options and thereby the results had to be interpreted with caution and could not be generalized. There was also an uneven demographic distribution of the participants, particularly between novice and experts. Initially, a decision was made to recruit 22 participants with an equal number of novice and expert participants. But, the number of participants in each demographic was unequal because there are fewer experts with time to participate in research project or who had limited availability which again restricted the statistical analyses available and the reliability of any comparisons between the two groups. Based on the results generated from the data collected in my study there was a positive trend in usability for both demographic groups. Even though some expert participants who had experience conducting research studies with older and disabled adults mentioned NICKEL would not be much helpful in their own research, all expert participants thought it will be a very helpful tool for novice designers to learn about different UCNEMs and some considered using it as a teaching tool for non-designers in their own labs.

Another limitation is that NICKEL was designed to use a small set of human capabilities and there may be others worth adding. For example, participants suggested using interpersonal capabilities and technological adaptability which affects potential user's effective engagement and execution. Further research is needed to determine which new factors should be included and how to include them into NICKEL. However, this thesis has introduced a methodology using two assessment techniques (survey and focus group with 
experts) for how to assess and populate various capabilities for the different UCNEMs which could be followed when adding new factors.

Although NICKEL asks users to provide their potential participant's cognition, vision, hearing and physical abilities as inputs, it does not assist in assessing or measuring the human capabilities of the participant. The user of NICKEL must understand or assess their potential participant capabilities before starting to use NICKEL. If users are unsure of what some of the possible ways to understand/measure various capabilities, NICKEL's user manual provides descriptions of some of the common scales used to measure human capabilities that could be used as reference.

Since the duration of my user study was less than 1 hour including filling the questionnaire and doing the TAP session, there was only time to use 3 to 4 personas with NICKEL. Efforts were made to fit the maximum possible combinations of human capabilities into the three personas provided but more combination of inputs could have been provided in order to further evaluate NICKEL.

Another limitation to NICKEL is the limited number of methods used in the database as mentioned by some participants of the user study. There are two reasons for doing so in the development of NICKEL. As mentioned in the literature review and the results from survey study, most designers were unfamiliar with some of the standard UCNEMs which have been used in practice for several years. Considering the level of knowledge of the designers from the literature study, a decision was made, not to include the less common methods or customized methods developed for people with disabilities. Another reason is because creating an allencompassing database of UCNEMs was not the primary objective of this research. Rather, it was to create a prototype tool to 
demonstrate the concept of using a set of human capabilities as a way of determining which UCNEM fit a particular set of potential study participant characteristics, and evaluating whether designers and researchers could use that tool to support their needs elicitation methods process. Based on the user study results, participants were able to use NICKEL to obtain a set of UCNEMs that fits the personas used in the user study. Given this promising results NICKEL could be expanded to include more existing UCNEMS, enable the entry of new ones being design, and to add other capabilities. 


\section{Chapter 6. Conclusion, contribution and future work}

\subsection{Conclusions}

1. NICKEL seems to be a useful and usable tool for novice designers/developers and researchers to determine UCNEM for older and disabled adults. NICKEL uses four HF components: Motor abilities, Vision, Hearing and Cognition at three different levels in order to assist users in deciding on the best UCNEMs for their particular circumstances. Participants who evaluated NICKEL found it to be a quick and easy to use tool. The participants mentioned liking to how the questions asked in NICKEL classified the HF components and how it was easy to understand. Although participants found it difficult to use NICKEL initially for the first scenario, it became easy to use from the second scenario for which participants provided positive results to the ease of learning question in the SUS questionnaire. Overall, based on the user study results participants thought NICKEL provided expected outputs and could be used to determine UCNEMs that fit older and/or disabled adult's capabilities.

2. The survey generated data on the human capabilities needed by older and disabled adults for more commonly used methods such as surveys, interviews and focus groups. For six methods including variances of cultural probes and card sorting, limited/varied responses resulted in statistically insignificant responses on the different human capabilities needed by older adults and people with disability to participate in different UCNEM. This missing data was then captured using a focus group study with expert designers/researchers. From this process, a novel and extendable database has been created consisting of: 1) cognitive and motor dexterity demands required from older and/or disabled adults to participate in 18 UCNEMs; and 2) level of difficulty faced by people with different hearing and visual abilities to participate in 18 different UCNEMs. 


\subsection{Contributions:}

There are two main contributions from this thesis: 1) methodological; and 2) technical

1. According to literature, there were only a few references which considered developing UCNEMs for older and/or disabled adults but there was no structured framework/database which used human capabilities as a means to assess the applicability of a particular UCNEM for this population. As part of this thesis, databases were created which contained the cognitive, visual, hearing demands and the physical capabilities required to participate in 19 UCNEMs. A methodology was developed to specify the different capability levels required to successfully participate in these 19 UCNEMs. This methodology included first conducting a survey with experts to populate the acceptable levels of cognitive ability, visual and hearing abilities and the physical tasks required by older and/or disabled adults to participate in all 19 UCNEMs. Where there was either missing levels or no agreed upon level, a focus group study was conducted with experts in design and accessibility to come to a consensus on the most appropriate level. Databases, algorithms, and a user interface were created and drawn together as a decision-support tool, called NICKEL, for UCNEMs based on the data collected in the survey and focus group studies.

2. NICKEL was designed to assist designers and researchers in determining the UCNEMs that best fit a certain set of human capabilities that would characterize their potential user population. NICKEL allowed the user to input four human factors (HF) components: cognition, vision, hearing, and physical abilities. Once the user provided their input, NICKEL finds matches between the human capabilities given as input and the database containing the human capabilities required to participate in different UCNEMs. 
Once the list of UCNEMs matching the user inputs is determined, NICKEL ranks the list of up to five recommended UCNEMS in ascending order of difficulty to participate in different UCNEM. The NICKEL outputs are colour coded, where a UCNEM coded in green is the best fit for the participant capabilities specified, yellow is somewhat compatible but still recommended and red is the UCNEM least compatible and least recommended. A user manual is provided to explain how to determine the inputs for NICKEL and how to interpret the outputs. NICKEL assumes that users know about or can estimate their potential participant's capabilities and does not assist in the assessment of those capabilities.

NICKEL was evaluated with novice and expert designers/ researchers in order to assess the usability and usefulness of it. A majority of users found NICKEL as a useful and usable tool although a few issues such as complex terminologies, no UCNEMs identified for people having severe cognitive impairment exist which requires further research. NICKEL then is an applied and technical contribution of this thesis. 


\subsection{Future work}

Although the responses from the user study show promising results for NICKEL as a useful tool supporting the needs elicitation process, there are various limitations and negative comments identified in the user study. This opens room for various avenues to be explored in future research. To address the limitations and issues raised by participants during the user study sessions, the following improvements are recommended:

1. The user study analysis showed that one expert participant expected more methods to be added to the NICKEL database. Although this thesis did not concentrate on the number of methods used, it is the eventual goal of the NICKEL project to add other possible UCNEM methods available in practice and created through research. As mentioned in the limitation section this requires further research and a survey study might not be the most appropriate method to capture the human capability demands required by the UCNEM methods developed for very specific disabilities. This is because statistical validity can be difficult to achieve with small sample sizes. It can be difficult to find the participants who used these very specific methods in their research. Hence, using a focus group, similar to what was used in my thesis, or in-depth interview of researchers may assist in determine the levels and requirements for the various user capabilities for these more obscure or new methods.

2. As mentioned in the limitation section, the additional of additional human capabilities such as interpersonal skills as mentioned by one participant, may allow NICKEL to further support the decision making process and be more robust at recommending UCNEMs. Defining and validating those capabilities, and the various levels requires further systematic research involving the literature and consultation with experts. 
3. Another future direction is to convert NICKEL from google spreadsheet format into a more usable and downloadable toolset as a stand-alone app or web application so it could be made available for a wide audience.

4. NICKEL could be expanded to allow for new methods to be added as researchers develop them or as lesser known methods appear. However, lesser used methods that may be known by only by a few researchers working with persons with specific disabilities or new methods may not have human capability data available. Using the methodology developed in this thesis may not be possible or too onerous to gather human capability data for such particular UCNEMs. Other methods for accepting a new UCNEM into the NICKEL framework and populating the human capability levels may need to be used. Future researchers working with NICKEL need to add new UCNEM to NICKEL. An example alternative could be that a group of experts could moderate new UCNEM requests and approve them for NICKEL.

Other future work relates to the integration of NICKEL framework into Usability planner tool/Requirements elicitation framework created by Ferre \& Bevan (2011) and Ayalew (2006). 


\section{Appendices}

Appendix A:

This survey is aimed at gathering the experience and opinion of designers, engineers or researchers who have worked with older adults and User Centered Design needs analysis tools. Specifically, you will be asked about your opinion on the cognitive, motor and perceptual abilities you think are required from older adult participants. This survey takes 25 to 30 minutes to complete. Thank you in advance for your assistance.

1. What is your gender?

$$
\text { c Male }
$$

C Female

(c) Other

2. How would you classify your primary area of work related to work with older adults?

Novice Engineer/ Designer

$$
\begin{array}{|c|c|}
\hline \text { (around } 16000 \text { hours) } & \odot \text { Professional Engineer/ Designer } \\
& \varnothing \text { Clinical Psychologist }
\end{array}
$$


Research Psychologist

Other

3. How many years of experience do you have in your respective area of interest?

Less than 1 year

2 to 5 years

C 6 to 10 years

More than 10 years

4. How many years of experience do you have in conducting needs analysis study with older adults?

$C$ Less than 1 year

2 to 5 years

C 6 to 10 years

More than 10 years

5. How much experience do you have using the following User Centered Design (UCD) techniques?

\begin{tabular}{|c|c|c|c|c|c|}
\hline & $\begin{array}{l}\text { I am not } \\
\text { familiar with } \\
\text { this UCD } \\
\text { method }\end{array}$ & $\begin{array}{l}\text { Have } \\
\text { knowledge } \\
\text { about this } \\
\text { method, but I } \\
\text { have never } \\
\text { used it }\end{array}$ & $\begin{array}{l}\text { I have used this } \\
\text { method a few } \\
\text { times }\end{array}$ & $\begin{array}{l}\text { I have this } \\
\text { method } \\
\text { sometimes in } \\
\text { my research }\end{array}$ & $\begin{array}{l}\text { I often use } \\
\text { this } \\
\text { method in } \\
\text { my } \\
\text { research }\end{array}$ \\
\hline Interviews[?] & $c$ & $c$ & $c$ & $c$ & $c$ \\
\hline $\begin{array}{l}\text { Telephonic } \\
\text { Interview[?] }\end{array}$ & $C$ & $c$ & $C$ & $c$ & $c$ \\
\hline
\end{tabular}




\begin{tabular}{|c|c|c|c|c|c|}
\hline $\begin{array}{l}\text { Interviews } \\
\text { (with sign } \\
\text { language)[?] }\end{array}$ & 0 & 0 & 0 & 0 & 0 \\
\hline $\begin{array}{l}\text { Open ended } \\
\text { questionnaire } \\
\text { (online } \\
\text { survey)[?] }\end{array}$ & 0 & 0 & 0 & 0 & 0 \\
\hline $\begin{array}{l}\text { Open ended } \\
\text { questionnaire } \\
\text { (Paper type) }\end{array}$ & 0 & 0 & 0 & 0 & $c$ \\
\hline $\begin{array}{l}\text { Structured } \\
\text { questionnaire } \\
\text { (with } \\
\text { braille)[?] }\end{array}$ & 0 & 0 & 0 & 0 & 0 \\
\hline $\begin{array}{l}\text { Structured } \\
\text { questionnaire } \\
\text { (online } \\
\text { survey)[?] }\end{array}$ & 0 & 0 & 0 & 0 & 0 \\
\hline $\begin{array}{l}\text { Structured } \\
\text { questionnaire } \\
\text { (Paper type) }\end{array}$ & 0 & 0 & 0 & 0 & 0 \\
\hline $\begin{array}{l}\text { Paper } \\
\text { prototyping[?] }\end{array}$ & 0 & 0 & 0 & 0 & 0 \\
\hline $\begin{array}{l}\text { Focus } \\
\text { groups[?] }\end{array}$ & 0 & 0 & $c$ & 0 & 0 \\
\hline
\end{tabular}




\begin{tabular}{|c|c|c|c|c|c|}
\hline $\begin{array}{l}\text { Contextual } \\
\text { enquiry[?] }\end{array}$ & 0 & 0 & 0 & 0 & 0 \\
\hline $\begin{array}{l}\text { Open card } \\
\text { sorting[?] }\end{array}$ & c & c & 0 & o & c \\
\hline $\begin{array}{l}\text { Closed card } \\
\text { sorting[?] }\end{array}$ & 0 & $c$ & 0 & 0 & c \\
\hline $\begin{array}{l}\text { Reverse card } \\
\text { sorting }\end{array}$ & 0 & 0 & 0 & o & o \\
\hline $\begin{array}{l}\text { Cultural probe } \\
\text { (Camera)[?] }\end{array}$ & 0 & 0 & 0 & 0 & 0 \\
\hline $\begin{array}{l}\text { Cultural probe } \\
\text { (Diary } \\
\text { recording) }\end{array}$ & 0 & 0 & 0 & 0 & 0 \\
\hline $\begin{array}{l}\text { Cultural probe } \\
\text { (Voice } \\
\text { recorder) }\end{array}$ & o & o & 0 & 0 & o \\
\hline Living Labs[?] & o & c & o & o & c \\
\hline $\begin{array}{l}\text { Think Aloud } \\
\text { Protocol[?] }\end{array}$ & 0 & 0 & 0 & 0 & c \\
\hline $\begin{array}{l}\text { Gestural Think } \\
\text { Aloud } \\
\text { Protocol[?] }\end{array}$ & o & c & o & o & 0 \\
\hline
\end{tabular}




\begin{tabular}{|c|c|c|c|c|c|}
\hline $\begin{array}{l}\text { Retrospective } \\
\text { Think Aloud } \\
\text { Protocol[?] }\end{array}$ & $c$ & $C$ & 0 & $C$ & 0 \\
\hline $\begin{array}{l}\text { Mediated } \\
\text { workshop }\end{array}$ & $C$ & $\sigma$ & $c$ & $C$ & $c$ \\
\hline
\end{tabular}

6. In your opinion, what is the maximum level of cognitive impairment acceptable for using the following User Centered Design (UCD) methods to elicit needs from older adults?

Cognitively Intact - Participants have autonomy in daily activities, no subjective complains of cognitive deterioration, no history of neurological or psychiatric disorder.

Mild Cognitive impairment - Mild memory impairment such as forgetfulness in appointments, conversation and recent events, lack of reasoning and decision making ability, easy distraction, struggling to interpret object and judging distance.

Severe impairment - Severe lack of memory, severe impairment of judgement, Long term memory loss, unable to retain information on request

\begin{tabular}{|c|c|c|c|c|}
\hline & $\begin{array}{l}\text { I don't } \\
\text { know }\end{array}$ & $\begin{array}{l}\text { Cognitively } \\
\text { intact }\end{array}$ & $\begin{array}{l}\text { Moderate } \\
\text { cognitive } \\
\text { impairment }\end{array}$ & $\begin{array}{l}\text { Severe } \\
\text { cognitive } \\
\text { impairment }\end{array}$ \\
\hline Interviews & $\mathrm{C}$ & $\mathrm{C}$ & $\mathrm{C}$ & $\mathrm{C}$ \\
\hline Telephonic Interview & $\mathrm{C}$ & $\mathrm{C}$ & $\mathrm{C}$ & $\mathrm{C}$ \\
\hline Interviews (with sign language) & $\mathrm{c}$ & $\mathrm{c}$ & $\mathrm{O}$ & $c$ \\
\hline $\begin{array}{l}\text { Open ended questionnaire (online } \\
\text { survey) }\end{array}$ & $c$ & $\mathrm{c}$ & $\mathrm{c}$ & $\mathrm{c}$ \\
\hline
\end{tabular}




\begin{tabular}{|c|c|c|c|c|}
\hline Open ended questionnaire (Paper type) & $\mathrm{c}$ & 0 & 0 & 0 \\
\hline Structured questionnaire (with braille) & 0 & 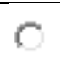 & 0 & 0 \\
\hline $\begin{array}{l}\text { Structured questionnaire (online } \\
\text { survey) }\end{array}$ & 0 & $c$ & c & 0 \\
\hline Structured questionnaire (Paper type) & $\mathrm{o}$ & 0 & 0 & $\mathrm{o}$ \\
\hline Paper prototyping & 0 & 0 & 0 & 0 \\
\hline Focus groups & o & 0 & c & o \\
\hline Contextual enquiry & $\mathrm{c}$ & 0 & c & 0 \\
\hline Open card sorting & 0 & 0 & $\mathrm{c}$ & 0 \\
\hline Closed card sorting & 0 & o & 0 & 0 \\
\hline Reverse card sorting & $\mathrm{o}$ & $\mathrm{c}$ & 0 & $\mathrm{o}$ \\
\hline Cultural probe (Camera) & $\mathrm{c}$ & 0 & c & $\mathrm{c}$ \\
\hline Cultural probe (Diary recording) & 0 & $\mathrm{c}$ & $\mathrm{c}$ & 0 \\
\hline Cultural probe (Voice recorder) & 0 & 0 & o & 0 \\
\hline Living Labs & 0 & 0 & c & 0 \\
\hline Think Aloud Protocol & 0 & 0 & o & 0 \\
\hline
\end{tabular}




\begin{tabular}{|c|c|c|c|c|}
\hline Gestural Think Aloud Protocol & $\mathrm{C}$ & $c$ & $\mathrm{C}$ & $\mathrm{c}$ \\
\hline Retrospective Think Aloud Protocol & $\mathrm{C}$ & $\mathrm{C}$ & $\mathrm{C}$ & $\mathrm{c}$ \\
\hline Mediated workshop & $c$ & $c$ & $c$ & 0 \\
\hline
\end{tabular}

7. In your opinion, what are the motor skills required to successfully accomplish needs analysis tasks using following User Centered Design (UCD) methods? (Please check all that applies)

\begin{tabular}{|c|c|c|c|c|c|c|c|c|}
\hline & $\begin{array}{l}\text { Ability to } \\
\text { use a } \\
\text { computer } \\
\text { input } \\
\text { device to } \\
\underline{\text { select }} \\
\text { options } \\
\text { (e.g, } \\
\text { keyboard, } \\
\text { mouse) }\end{array}$ & $\begin{array}{l}\text { Ability to } \\
\text { use a } \\
\text { mobile/ } \\
\text { tablet } \\
\text { touchscreen } \\
\text { to select } \\
\text { options } \\
\text { (e.g., } \\
\text { tapping, } \\
\text { swiping, } \\
\text { dragging) }\end{array}$ & $\begin{array}{l}\text { Ability to } \\
\text { use } \\
\text { gesture } \\
\text { (e.g., Sign } \\
\text { language,) } \\
\text { orient a } \\
\text { mobile } \\
\text { device) }\end{array}$ & $\begin{array}{l}\text { Ability to } \\
\text { use } \\
\text { standard } \\
\text { computer } \\
\text { input } \\
\text { devices } \\
\text { for text } \\
\underline{\text { input }} \\
\text { (e.g., } \\
\text { writing, } \\
\text { keyboard, } \\
\text { touchscre } \\
\text { en) }\end{array}$ & $\begin{array}{l}\text { Ability to } \\
\text { alternative } \\
\text { input for text } \\
\text { input (e.g., } \\
\text { switch } \\
\text { devices, } \\
\text { joystick, voice } \\
\text { recognition) }\end{array}$ & $\begin{array}{l}\text { Ability } \\
\text { to } \\
\text { speak }\end{array}$ & $\begin{array}{l}\text { Ability to } \\
\text { move } \\
\text { eyes } \\
\text { around } \\
\text { (e.g., } \\
\text { look at } \\
\text { different } \\
\text { areas) }\end{array}$ & $\begin{array}{l}\text { Ability to } \\
\text { manually } \\
\text { write }\end{array}$ \\
\hline Interviews & $\Gamma$ & $\Gamma$ & $\Gamma$ & $\Gamma$ & $\Gamma$ & $\Gamma$ & $\Gamma$ & $\Gamma$ \\
\hline $\begin{array}{l}\text { Telephonic } \\
\text { Interview }\end{array}$ & $\Gamma$ & $\Gamma$ & $\Gamma$ & $\Gamma$ & $\Gamma$ & $\Gamma$ & $\Gamma$ & $\Gamma$ \\
\hline $\begin{array}{l}\text { Interviews (with } \\
\text { sign language) }\end{array}$ & Г & Г & $\Gamma$ & $\Gamma$ & $\Gamma$ & Г & $\Gamma$ & $\Gamma$ \\
\hline
\end{tabular}




\begin{tabular}{|c|c|c|c|c|c|c|c|c|}
\hline $\begin{array}{l}\text { Open ended } \\
\text { questionnaire } \\
\text { (online survey) }\end{array}$ & $\Gamma$ & $\Gamma$ & $\Gamma$ & г & \ulcorner & $\Gamma$ & $\Gamma$ & $\Gamma$ \\
\hline $\begin{array}{l}\text { Open ended } \\
\text { questionnaire } \\
\text { (Paper type) }\end{array}$ & $\Gamma$ & $\Gamma$ & $\Gamma$ & г & $\Gamma$ & $\Gamma$ & $\Gamma$ & $\Gamma$ \\
\hline $\begin{array}{l}\text { Structured } \\
\text { questionnaire } \\
\text { (with braille) }\end{array}$ & $\Gamma$ & г & $\Gamma$ & $\Gamma$ & $\Gamma$ & $\Gamma$ & $\Gamma$ & $\Gamma$ \\
\hline $\begin{array}{l}\text { Structured } \\
\text { questionnaire } \\
\text { (online survey) }\end{array}$ & $\Gamma$ & г & $\Gamma$ & $\Gamma$ & $\Gamma$ & $\Gamma$ & $\Gamma$ & $\Gamma$ \\
\hline $\begin{array}{l}\text { Structured } \\
\text { questionnaire } \\
\text { (Paper type) }\end{array}$ & $\Gamma$ & $\Gamma$ & $\Gamma$ & $\Gamma$ & \ulcorner & $\Gamma$ & $\Gamma$ & $\Gamma$ \\
\hline $\begin{array}{l}\text { Paper } \\
\text { prototyping }\end{array}$ & $\Gamma$ & $\Gamma$ & $\Gamma$ & $\Gamma$ & $\Gamma$ & \ulcorner & $\Gamma$ & $\Gamma$ \\
\hline Focus groups & $\Gamma$ & \ulcorner & \ulcorner & \ulcorner & \ulcorner & \ulcorner & $\Gamma$ & $\Gamma$ \\
\hline $\begin{array}{l}\text { Contextual } \\
\text { enquiry }\end{array}$ & $\Gamma$ & $\Gamma$ & $\Gamma$ & \ulcorner & \ulcorner & $\Gamma$ & $\Gamma$ & $\Gamma$ \\
\hline $\begin{array}{l}\text { Open card } \\
\text { sorting }\end{array}$ & $\Gamma$ & $\Gamma$ & $\Gamma$ & $\Gamma$ & $\Gamma$ & \ulcorner & $\Gamma$ & \ulcorner \\
\hline $\begin{array}{l}\text { Closed card } \\
\text { sorting }\end{array}$ & $\Gamma$ & $\Gamma$ & $\Gamma$ & $\Gamma$ & $\Gamma$ & \ulcorner & \ulcorner & $\Gamma$ \\
\hline
\end{tabular}




\begin{tabular}{|c|c|c|c|c|c|c|c|c|}
\hline $\begin{array}{l}\text { Reverse card } \\
\text { sorting }\end{array}$ & \ulcorner & $\Gamma$ & \ulcorner & $\Gamma$ & $\Gamma$ & \ulcorner & \ulcorner & $\Gamma$ \\
\hline $\begin{array}{l}\text { Cultural probe } \\
\text { (Camera) }\end{array}$ & $\Gamma$ & $\Gamma$ & \ulcorner & $\Gamma$ & $\Gamma$ & \ulcorner & $\Gamma$ & \ulcorner \\
\hline $\begin{array}{l}\text { Cultural probe } \\
\text { (Diary } \\
\text { recording) }\end{array}$ & \ulcorner & $\Gamma$ & \ulcorner & $\Gamma$ & $\Gamma$ & \ulcorner & \ulcorner & $\Gamma$ \\
\hline $\begin{array}{l}\text { Cultural probe } \\
\text { (Voice recorder) }\end{array}$ & \ulcorner & \ulcorner & $\Gamma$ & \ulcorner & $\Gamma$ & $\Gamma$ & $\Gamma$ & \ulcorner \\
\hline Living Labs & \ulcorner & $\Gamma$ & \ulcorner & $\Gamma$ & $\Gamma$ & $\Gamma$ & \ulcorner & \ulcorner \\
\hline $\begin{array}{l}\text { Think Aloud } \\
\text { Protocol }\end{array}$ & \ulcorner & $\Gamma$ & \ulcorner & $\Gamma$ & \ulcorner & $\Gamma$ & $\Gamma$ & $\Gamma$ \\
\hline $\begin{array}{l}\text { Gestural Think } \\
\text { Aloud Protocol }\end{array}$ & $\Gamma$ & $\Gamma$ & $\Gamma$ & \ulcorner & $\Gamma$ & $\Gamma$ & $\Gamma$ & $\Gamma$ \\
\hline $\begin{array}{l}\text { Retrospective } \\
\text { Think Aloud } \\
\text { Protocol }\end{array}$ & \ulcorner & \ulcorner & \ulcorner & $\Gamma$ & \ulcorner & $\Gamma$ & \ulcorner & \ulcorner \\
\hline $\begin{array}{l}\text { Retrospective } \\
\text { Think Aloud } \\
\text { Protocol }\end{array}$ & \ulcorner & г & $\Gamma$ & $\Gamma$ & \ulcorner & \ulcorner & \ulcorner & \ulcorner \\
\hline $\begin{array}{l}\text { Mediated } \\
\text { workshop }\end{array}$ & \ulcorner & \ulcorner & \ulcorner & $\Gamma$ & $\Gamma$ & $\Gamma$ & $\Gamma$ & $\Gamma$ \\
\hline
\end{tabular}


7. What is the level of difficulty experienced by older participants when participating in needs gathering processes with respect to perception? (Please check all that apply)

Visual ability:

Normal vision: $20 / 20$ to $20 / 60$

Low vision: $20 / 70$ to $20 / 160$

Blind: 20/200 and more

Hearing ability:

Normal hearing -10 to $25 \mathrm{~dB}$ hearing loss

Moderately impaired: 26 to $70 \mathrm{~dB}$ hearing loss

Severely impaired: Greater than $70 \mathrm{~dB}$ hearing loss

\begin{tabular}{|c|c|c|c|c|c|c|c|c|c|}
\hline & & \multicolumn{3}{|c|}{ Ability to hear } & \multicolumn{3}{|c|}{ Ability to see } & \multirow{2}{*}{$\begin{array}{l}\text { Ability } \\
\text { to } \\
\text { speak }\end{array}$} & \multirow{2}{*}{$\begin{array}{l}\text { Ability } \\
\text { to touch }\end{array}$} \\
\hline & & Normal & $\begin{array}{l}\text { Moderately } \\
\text { impaired }\end{array}$ & $\begin{array}{l}\text { Severely } \\
\text { impaired }\end{array}$ & $\begin{array}{l}\text { Normal } \\
\text { Vision }\end{array}$ & $\begin{array}{l}\text { Low } \\
\text { vision }\end{array}$ & Blind & & \\
\hline \multirow[t]{3}{*}{ Interviews } & Not difficult & Г & Г & Г & Г & Г & Г & Г & Г \\
\hline & Moderately difficult & Г & Г & Г & Г & Г & Г & Г & Г \\
\hline & Difficult & Г & Г & Г & Г & $\Gamma$ & Г & Г & $\Gamma$ \\
\hline
\end{tabular}




\begin{tabular}{|c|c|c|c|c|c|c|c|c|c|}
\hline \multirow{3}{*}{$\begin{array}{l}\text { Telephonic } \\
\text { Interview }\end{array}$} & Not difficult & $\Gamma$ & $\Gamma$ & $\Gamma$ & $\Gamma$ & $\Gamma$ & $\Gamma$ & г & $\Gamma$ \\
\hline & Moderately difficult & $\Gamma$ & $\Gamma$ & $\Gamma$ & $\Gamma$ & $\Gamma$ & $\Gamma$ & $\Gamma$ & $\Gamma$ \\
\hline & Difficult & $\Gamma$ & г & $\Gamma$ & $\Gamma$ & $\Gamma$ & $\Gamma$ & $\Gamma$ & $\Gamma$ \\
\hline \multirow{3}{*}{$\begin{array}{l}\text { Interviews (with } \\
\text { sign language) }\end{array}$} & Not difficult & $\Gamma$ & Г & $\Gamma$ & $\Gamma$ & г & $\Gamma$ & $\Gamma$ & $\Gamma$ \\
\hline & Moderately difficult & $\Gamma$ & Г & $\Gamma$ & $\Gamma$ & $\Gamma$ & $\Gamma$ & г & \ulcorner \\
\hline & Difficult & $\Gamma$ & $\Gamma$ & \ulcorner & $\Gamma$ & $\Gamma$ & $\Gamma$ & $\Gamma$ & $\Gamma$ \\
\hline \multirow{4}{*}{$\begin{array}{l}\text { Open ended } \\
\text { questionnaire } \\
\text { (online survey) }\end{array}$} & Not difficult & $\Gamma$ & г & г & $\Gamma$ & $\Gamma$ & $\Gamma$ & $\Gamma$ & $\Gamma$ \\
\hline & Moderately difficult & $\Gamma$ & Г & г & $\Gamma$ & $\Gamma$ & $\Gamma$ & $\Gamma$ & $\Gamma$ \\
\hline & Difficult & $\Gamma$ & $\Gamma$ & $\Gamma$ & $\Gamma$ & $\Gamma$ & $\Gamma$ & $\Gamma$ & \ulcorner \\
\hline & Not difficult & $\Gamma$ & $\Gamma$ & г & Г & Г & $\Gamma$ & г & $\Gamma$ \\
\hline
\end{tabular}




\begin{tabular}{|c|c|c|c|c|c|c|c|c|c|c|}
\hline \multirow{2}{*}{$\begin{array}{l}\text { Open ended } \\
\text { questionnaire } \\
\text { (Paper type) }\end{array}$} & Moderately difficult & $\Gamma$ & $\Gamma$ & $\Gamma$ & $\Gamma$ & $\Gamma$ & Г & $\Gamma$ & $\Gamma$ & \\
\hline & Difficult & $\Gamma$ & $\Gamma$ & $\Gamma$ & $\Gamma$ & $\Gamma$ & $\Gamma$ & $\Gamma$ & $\Gamma$ & \\
\hline \multirow{3}{*}{$\begin{array}{l}\text { Structured } \\
\text { questionnaire (with } \\
\text { braille) }\end{array}$} & Not difficult & $\Gamma$ & $\Gamma$ & & $\Gamma$ & $\Gamma$ & $\Gamma$ & $\Gamma$ & $\Gamma$ & Г \\
\hline & Moderately difficult & $\Gamma$ & $\Gamma$ & & $\Gamma$ & $\Gamma$ & $\Gamma$ & $\Gamma$ & $\Gamma$ & Г \\
\hline & Difficult & $\Gamma$ & $\Gamma$ & & $\Gamma$ & \ulcorner & $\Gamma$ & $\Gamma$ & \ulcorner & Г \\
\hline \multirow{3}{*}{$\begin{array}{l}\text { Structured } \\
\text { questionnaire } \\
\text { (online survey) }\end{array}$} & Not difficult & $\Gamma$ & $\Gamma$ & & $\Gamma$ & $\Gamma$ & \ulcorner & $\Gamma$ & \ulcorner & Г \\
\hline & Moderately difficult & $\Gamma$ & $\Gamma$ & & $\Gamma$ & \ulcorner & $\Gamma$ & $\Gamma$ & $\Gamma$ & $\Gamma$ \\
\hline & Difficult & $\Gamma$ & $\Gamma$ & & $\Gamma$ & \ulcorner & $\Gamma$ & $\Gamma$ & \ulcorner & Г \\
\hline \multirow{2}{*}{$\begin{array}{l}\text { Structured } \\
\text { questionnaire } \\
\text { (Paper type) }\end{array}$} & Not difficult & $\Gamma$ & $\Gamma$ & & $\Gamma$ & \ulcorner & $\Gamma$ & $\Gamma$ & \ulcorner & Г \\
\hline & Moderately difficult & $\Gamma$ & $\Gamma$ & & $\Gamma$ & \ulcorner & $\Gamma$ & $\Gamma$ & $\Gamma$ & Г \\
\hline
\end{tabular}




\begin{tabular}{|c|c|c|c|c|c|c|c|c|c|}
\hline & Difficult & $\Gamma$ & $\Gamma$ & $\Gamma$ & \ulcorner & \ulcorner & $\Gamma$ & $\Gamma$ & $\Gamma$ \\
\hline \multirow[t]{3}{*}{ Paper prototyping } & Not difficult & $\Gamma$ & \ulcorner & $\Gamma$ & \ulcorner & \ulcorner & \ulcorner & \ulcorner & $\Gamma$ \\
\hline & Moderately difficult & $\Gamma$ & \ulcorner & $\Gamma$ & $\Gamma$ & $\Gamma$ & $\Gamma$ & \ulcorner & Г \\
\hline & Difficult & $\Gamma$ & $\Gamma$ & $\Gamma$ & $\Gamma$ & $\Gamma$ & $\Gamma$ & $\Gamma$ & $\Gamma$ \\
\hline \multirow[t]{3}{*}{ Focus groups } & Not difficult & $\Gamma$ & $\Gamma$ & $\Gamma$ & $\Gamma$ & $\Gamma$ & \ulcorner & $\Gamma$ & $\Gamma$ \\
\hline & Moderately difficult & \ulcorner & $\Gamma$ & $\Gamma$ & \ulcorner & \ulcorner & г & \ulcorner & Г \\
\hline & Difficult & $\Gamma$ & $\Gamma$ & $\Gamma$ & $\Gamma$ & $\Gamma$ & $\Gamma$ & $\Gamma$ & $\Gamma$ \\
\hline \multirow[t]{3}{*}{ Contextual enquiry } & Not difficult & $\Gamma$ & \ulcorner & $\Gamma$ & $\Gamma$ & \ulcorner & \ulcorner & \ulcorner & $\Gamma$ \\
\hline & Moderately difficult & $\Gamma$ & $\Gamma$ & $\Gamma$ & \ulcorner & $\Gamma$ & 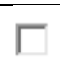 & $\Gamma$ & $\Gamma$ \\
\hline & Difficult & \ulcorner & \ulcorner & $\Gamma$ & г & \ulcorner & $\Gamma$ & \ulcorner & Г \\
\hline
\end{tabular}




\begin{tabular}{|c|c|c|c|c|c|c|c|c|c|}
\hline \multirow[t]{3}{*}{ Open card sorting } & Not difficult & $\Gamma$ & $\Gamma$ & $\Gamma$ & $\Gamma$ & $\Gamma$ & $\Gamma$ & $\Gamma$ & $\Gamma$ \\
\hline & Moderately difficult & $\Gamma$ & $\Gamma$ & $\Gamma$ & $\Gamma$ & $\Gamma$ & $\Gamma$ & $\Gamma$ & Г \\
\hline & Difficult & $\Gamma$ & $\Gamma$ & $\Gamma$ & $\Gamma$ & $\Gamma$ & $\Gamma$ & $\Gamma$ & Г \\
\hline \multirow[t]{3}{*}{ Closed card sorting } & Not difficult & $\Gamma$ & $\Gamma$ & $\Gamma$ & $\Gamma$ & $\Gamma$ & $\Gamma$ & $\Gamma$ & $\Gamma$ \\
\hline & Moderately difficult & $\Gamma$ & $\Gamma$ & $\Gamma$ & $\Gamma$ & $\Gamma$ & $\Gamma$ & $\Gamma$ & Г \\
\hline & Difficult & $\Gamma$ & $\Gamma$ & $\Gamma$ & $\Gamma$ & $\Gamma$ & \ulcorner & $\Gamma$ & $\Gamma$ \\
\hline \multirow{4}{*}{$\begin{array}{l}\text { Reverse card } \\
\text { sorting }\end{array}$} & Not difficult & $\Gamma$ & $\Gamma$ & \ulcorner & $\Gamma$ & \ulcorner & $\Gamma$ & $\Gamma$ & $\Gamma$ \\
\hline & Moderately difficult & $\Gamma$ & $\Gamma$ & $\Gamma$ & $\Gamma$ & $\Gamma$ & $\Gamma$ & $\Gamma$ & Г \\
\hline & Difficult & \ulcorner & $\Gamma$ & $\Gamma$ & $\Gamma$ & $\Gamma$ & $\Gamma$ & $\Gamma$ & $\Gamma$ \\
\hline & Not difficult & г & $\Gamma$ & \ulcorner & г & \ulcorner & $\Gamma$ & $\Gamma$ & $\Gamma$ \\
\hline
\end{tabular}




\begin{tabular}{|c|c|c|c|c|c|c|c|c|c|}
\hline \multirow[t]{2}{*}{$\begin{array}{l}\text { Cultural probe } \\
\text { (Camera) }\end{array}$} & Moderately difficult & $\Gamma$ & г & \ulcorner & $\Gamma$ & $\Gamma$ & $\Gamma$ & $\Gamma$ & Г \\
\hline & Difficult & $\Gamma$ & $\Gamma$ & $\Gamma$ & $\Gamma$ & \ulcorner & \ulcorner & $\Gamma$ & $\Gamma$ \\
\hline \multirow{3}{*}{$\begin{array}{l}\text { Cultural probe } \\
\text { (Diary recording) }\end{array}$} & Not difficult & $\Gamma$ & $\Gamma$ & $\Gamma$ & $\Gamma$ & \ulcorner & $\Gamma$ & $\Gamma$ & $\Gamma$ \\
\hline & Moderately difficult & $\Gamma$ & $\Gamma$ & $\Gamma$ & $\Gamma$ & $\Gamma$ & $\Gamma$ & $\Gamma$ & $\Gamma$ \\
\hline & Difficult & $\Gamma$ & $\Gamma$ & $\Gamma$ & $\Gamma$ & $\Gamma$ & $\Gamma$ & $\Gamma$ & Г \\
\hline \multirow{3}{*}{$\begin{array}{l}\text { Cultural probe } \\
\text { (Voice recorder) }\end{array}$} & Not difficult & $\Gamma$ & $\Gamma$ & $\Gamma$ & $\Gamma$ & \ulcorner & $\Gamma$ & \ulcorner & $\Gamma$ \\
\hline & Moderately difficult & $\Gamma$ & $\Gamma$ & г & $\Gamma$ & $\Gamma$ & $\Gamma$ & $\Gamma$ & $\Gamma$ \\
\hline & Difficult & $\Gamma$ & $\Gamma$ & $\Gamma$ & $\Gamma$ & $\Gamma$ & $\Gamma$ & $\Gamma$ & $\Gamma$ \\
\hline \multirow[t]{2}{*}{ Living Labs } & Not difficult & $\Gamma$ & $\Gamma$ & $\Gamma$ & \ulcorner & $\Gamma$ & \ulcorner & $\Gamma$ & Г \\
\hline & Moderately difficult & $\Gamma$ & $\Gamma$ & $\Gamma$ & $\Gamma$ & \ulcorner & $\Gamma$ & $\Gamma$ & Г \\
\hline
\end{tabular}




\begin{tabular}{|c|c|c|c|c|c|c|c|c|c|}
\hline & Difficult & $\Gamma$ & г & $\Gamma$ & $\Gamma$ & $\Gamma$ & $\Gamma$ & $\Gamma$ & $\Gamma$ \\
\hline \multirow{3}{*}{$\begin{array}{l}\text { Think Aloud } \\
\text { Protocol }\end{array}$} & Not difficult & $\Gamma$ & $\Gamma$ & $\Gamma$ & $\Gamma$ & \ulcorner & \ulcorner & $\Gamma$ & Г \\
\hline & Moderately difficult & $\Gamma$ & $\Gamma$ & $\Gamma$ & $\Gamma$ & $\Gamma$ & $\Gamma$ & $\Gamma$ & $\Gamma$ \\
\hline & Difficult & $\Gamma$ & $\Gamma$ & $\Gamma$ & $\Gamma$ & $\Gamma$ & $\Gamma$ & $\Gamma$ & $\Gamma$ \\
\hline \multirow{3}{*}{$\begin{array}{l}\text { Gestural Think } \\
\text { Aloud Protocol }\end{array}$} & Not difficult & $\Gamma$ & \ulcorner & $\Gamma$ & $\Gamma$ & \ulcorner & $\Gamma$ & $\Gamma$ & $\Gamma$ \\
\hline & Moderately difficult & $\Gamma$ & г & $\Gamma$ & $\Gamma$ & $\Gamma$ & \ulcorner & $\Gamma$ & $\Gamma$ \\
\hline & Difficult & $\Gamma$ & $\Gamma$ & $\Gamma$ & $\Gamma$ & $\Gamma$ & $\Gamma$ & $\Gamma$ & $\Gamma$ \\
\hline \multirow{3}{*}{$\begin{array}{l}\text { Retrospective } \\
\text { Think Aloud } \\
\text { Protocol }\end{array}$} & Not difficult & $\Gamma$ & $\Gamma$ & $\Gamma$ & $\Gamma$ & $\Gamma$ & $\Gamma$ & $\Gamma$ & $\Gamma$ \\
\hline & Moderately difficult & $\Gamma$ & $\Gamma$ & $\Gamma$ & $\Gamma$ & $\Gamma$ & \ulcorner & $\Gamma$ & $\Gamma$ \\
\hline & Difficult & $\Gamma$ & $\Gamma$ & $\Gamma$ & $\Gamma$ & \ulcorner & $\Gamma$ & \ulcorner & Г \\
\hline
\end{tabular}




\begin{tabular}{|c|c|c|c|c|c|c|c|c|c|}
\hline \multirow[t]{3}{*}{ Mediated workshop } & Not difficult & $\Gamma$ & $\Gamma$ & $\Gamma$ & $\Gamma$ & $\Gamma$ & $\Gamma$ & $\Gamma$ & $\Gamma$ \\
\hline & Moderately difficult & $\Gamma$ & $\Gamma$ & $\Gamma$ & $\Gamma$ & $\Gamma$ & $\Gamma$ & $\Gamma$ & $\Gamma$ \\
\hline & Difficult & $\Gamma$ & $\Gamma$ & $\Gamma$ & $\Gamma$ & $\Gamma$ & $\Gamma$ & $\Gamma$ & $\Gamma$ \\
\hline
\end{tabular}

9. In your experience what are the challenges faced by researchers when using various needs gathering methods with older or frail participants?

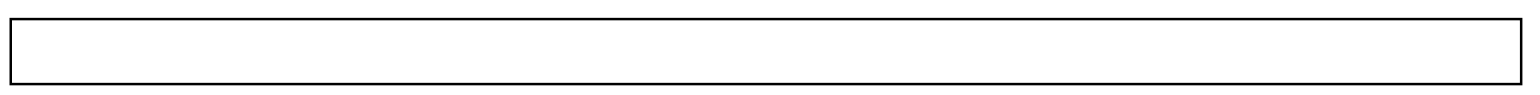

10. In your experience what are the successes faced by researchers when using these needs gathering methods with older or frail participants?

11. Do you know of any needs gathering method being used with older adults or disabled participants other than the ones mentioned in this survey?

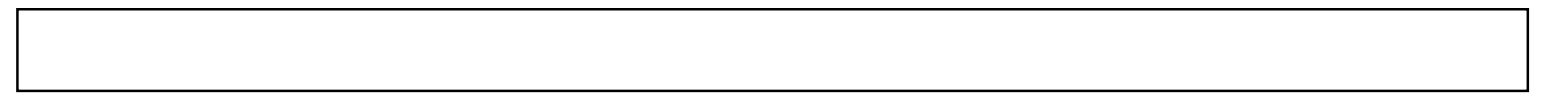

12. Please provide your e-mail address if you would like to be contacted for further details about the new method you have mentioned in Question 11. 


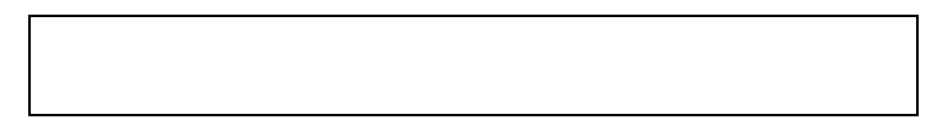




\begin{tabular}{|c|c|c|c|c|c|c|c|}
\hline \multirow[t]{2}{*}{ UCNEM } & \multirow{2}{*}{$\begin{array}{c}\text { Acceptable } \\
\text { cognitive } \\
\text { impairment }\end{array}$} & \multicolumn{3}{|c|}{ Difficulty for different hearing abilities } & \multicolumn{3}{|c|}{ Difficulty for different vision abilities } \\
\hline & & Hearing & $\begin{array}{l}\text { Hard of } \\
\text { hearing }\end{array}$ & Deaf & Sighted & Low vision & Blind \\
\hline $\begin{array}{c}\text { Face to Face } \\
\text { interviews }\end{array}$ & $\begin{array}{l}\text { Moderate } \\
\text { impairment }\end{array}$ & $\begin{array}{c}\text { Not } \\
\text { difficult }\end{array}$ & $\begin{array}{l}\text { Moderate } \\
\text { difficulty }\end{array}$ & Difficult & $\begin{array}{c}\text { Not } \\
\text { difficult }\end{array}$ & Not difficult & $\begin{array}{c}\text { Not } \\
\text { difficult }\end{array}$ \\
\hline $\begin{array}{l}\text { Telephonic } \\
\text { interview }\end{array}$ & $\begin{array}{c}\text { Cognitively } \\
\text { intact }\end{array}$ & $\begin{array}{c}\text { Not } \\
\text { difficult }\end{array}$ & $\begin{array}{l}\text { Moderate } \\
\text { difficulty }\end{array}$ & Difficult & $\begin{array}{c}\text { Not } \\
\text { difficult }\end{array}$ & Not difficult & $\begin{array}{c}\text { Not } \\
\text { difficult }\end{array}$ \\
\hline $\begin{array}{l}\text { Interview } \\
\text { (Sign } \\
\text { language) }\end{array}$ & $\begin{array}{c}\text { Cognitively } \\
\text { intact }\end{array}$ & Difficult & $\begin{array}{l}\text { Moderate } \\
\text { difficulty }\end{array}$ & $\begin{array}{c}\text { Not } \\
\text { difficult }\end{array}$ & $\begin{array}{c}\text { Not } \\
\text { difficult }\end{array}$ & $\begin{array}{l}\text { Moderate } \\
\text { difficulty }\end{array}$ & Difficult \\
\hline $\begin{array}{c}\text { Open ended } \\
\text { survey } \\
\text { (Online } \\
\text { survey) } \\
\end{array}$ & $\begin{array}{l}\text { Moderate } \\
\text { impairment }\end{array}$ & $\begin{array}{c}\text { Not } \\
\text { difficult }\end{array}$ & Not difficult & $\begin{array}{c}\text { Not } \\
\text { difficult }\end{array}$ & $\begin{array}{c}\text { Not } \\
\text { difficult }\end{array}$ & $\begin{array}{l}\text { Moderate } \\
\text { difficulty }\end{array}$ & Difficult \\
\hline $\begin{array}{l}\text { Open ended } \\
\text { survey (paper } \\
\text { type) }\end{array}$ & $\begin{array}{l}\text { Moderate } \\
\text { impairment }\end{array}$ & $\begin{array}{c}\text { Not } \\
\text { difficult }\end{array}$ & Not difficult & $\begin{array}{c}\text { Not } \\
\text { difficult }\end{array}$ & $\begin{array}{c}\text { Not } \\
\text { difficult }\end{array}$ & $\begin{array}{l}\text { Moderate } \\
\text { difficulty }\end{array}$ & Difficult \\
\hline $\begin{array}{c}\text { Structured } \\
\text { questionnaire } \\
\text { (online } \\
\text { survey) } \\
\end{array}$ & $\begin{array}{l}\text { Moderate } \\
\text { impairment }\end{array}$ & $\begin{array}{c}\text { Not } \\
\text { difficult }\end{array}$ & Not difficult & $\begin{array}{c}\text { Not } \\
\text { difficult }\end{array}$ & $\begin{array}{c}\text { Not } \\
\text { difficult }\end{array}$ & $\begin{array}{l}\text { Moderate } \\
\text { difficulty }\end{array}$ & Difficult \\
\hline $\begin{array}{l}\text { Structured } \\
\text { questionnaire } \\
\text { (paper type) }\end{array}$ & $\begin{array}{l}\text { Moderate } \\
\text { impairment }\end{array}$ & $\begin{array}{c}\text { Not } \\
\text { difficult }\end{array}$ & Not difficult & $\begin{array}{c}\text { Not } \\
\text { difficult }\end{array}$ & $\begin{array}{c}\text { Not } \\
\text { difficult }\end{array}$ & $\begin{array}{l}\text { Moderate } \\
\text { difficulty }\end{array}$ & Difficult \\
\hline $\begin{array}{c}\text { Paper } \\
\text { prototyping }\end{array}$ & $\begin{array}{l}\text { Moderate } \\
\text { impairment }\end{array}$ & $\begin{array}{c}\text { Not } \\
\text { difficult }\end{array}$ & Not difficult & $\begin{array}{c}\text { Not } \\
\text { difficult }\end{array}$ & $\begin{array}{c}\text { Not } \\
\text { difficult }\end{array}$ & $\begin{array}{l}\text { Moderate } \\
\text { difficulty }\end{array}$ & Difficult \\
\hline Focus groups & $\begin{array}{l}\text { Moderate } \\
\text { impairment }\end{array}$ & $\begin{array}{c}\text { Not } \\
\text { difficult }\end{array}$ & $\begin{array}{l}\text { Moderate } \\
\text { difficulty }\end{array}$ & Difficult & $\begin{array}{c}\text { Not } \\
\text { difficult }\end{array}$ & Not difficult & $\begin{array}{c}\text { Not } \\
\text { difficult }\end{array}$ \\
\hline $\begin{array}{l}\text { Open Card } \\
\text { sorting }\end{array}$ & $\begin{array}{l}\text { Moderate } \\
\text { impairment }\end{array}$ & $\begin{array}{c}\text { Not } \\
\text { difficult }\end{array}$ & Not difficult & $\begin{array}{c}\text { Not } \\
\text { difficult }\end{array}$ & $\begin{array}{c}\text { Not } \\
\text { difficult }\end{array}$ & $\begin{array}{c}\text { Moderately } \\
\text { difficult }\end{array}$ & Difficult \\
\hline $\begin{array}{c}\text { Closed Card } \\
\text { sorting }\end{array}$ & $\begin{array}{l}\text { Moderate } \\
\text { impairment }\end{array}$ & $\begin{array}{c}\text { Not } \\
\text { difficult }\end{array}$ & Not difficult & $\begin{array}{c}\text { Not } \\
\text { difficult }\end{array}$ & $\begin{array}{c}\text { Not } \\
\text { difficult }\end{array}$ & $\begin{array}{c}\text { Moderately } \\
\text { difficult }\end{array}$ & Difficult \\
\hline $\begin{array}{l}\text { Reverse card } \\
\text { sorting }\end{array}$ & $\begin{array}{l}\text { Moderate } \\
\text { impairment }\end{array}$ & $\begin{array}{c}\text { Not } \\
\text { difficult }\end{array}$ & Not difficult & $\begin{array}{c}\text { Not } \\
\text { difficult }\end{array}$ & $\begin{array}{c}\text { Not } \\
\text { difficult }\end{array}$ & $\begin{array}{c}\text { Moderately } \\
\text { difficult }\end{array}$ & Difficult \\
\hline $\begin{array}{c}\text { Cultural } \\
\text { probe } \\
\text { (Camera) }\end{array}$ & $\begin{array}{c}\text { Cognitively } \\
\text { intact }\end{array}$ & $\begin{array}{c}\text { Not } \\
\text { difficult }\end{array}$ & Not difficult & $\begin{array}{c}\text { Not } \\
\text { difficult }\end{array}$ & $\begin{array}{c}\text { Not } \\
\text { difficult }\end{array}$ & $\begin{array}{l}\text { Moderate } \\
\text { difficulty }\end{array}$ & Difficult \\
\hline $\begin{array}{l}\text { Cultural } \\
\text { probe (Diary } \\
\text { recording) }\end{array}$ & $\begin{array}{l}\text { Moderate } \\
\text { impairment }\end{array}$ & $\begin{array}{c}\text { Not } \\
\text { difficult }\end{array}$ & Not difficult & $\begin{array}{c}\text { Not } \\
\text { difficult }\end{array}$ & $\begin{array}{c}\text { Not } \\
\text { difficult }\end{array}$ & Not difficult & Difficult \\
\hline
\end{tabular}




\begin{tabular}{|c|c|c|c|c|c|c|c|}
\hline $\begin{array}{c}\text { Cultural } \\
\text { probe (Voice } \\
\text { recorder) }\end{array}$ & $\begin{array}{c}\text { Cognitively } \\
\text { intact }\end{array}$ & $\begin{array}{c}\text { Not } \\
\text { difficult }\end{array}$ & Not difficult & $\begin{array}{c}\text { Not } \\
\text { difficult }\end{array}$ & Not difficult & $\begin{array}{c}\text { Not } \\
\text { difficult }\end{array}$ \\
\hline $\begin{array}{c}\text { Think aloud } \\
\text { protocol }\end{array}$ & $\begin{array}{c}\text { Moderate } \\
\text { impairment }\end{array}$ & $\begin{array}{c}\text { Not } \\
\text { difficult }\end{array}$ & $\begin{array}{c}\text { Moderate } \\
\text { difficulty }\end{array}$ & Difficult & $\begin{array}{c}\text { Not } \\
\text { difficult }\end{array}$ & $\begin{array}{c}\text { Moderate } \\
\text { difficulty }\end{array}$ & Difficult \\
\hline $\begin{array}{c}\text { Think aloud } \\
\text { protocol (sign } \\
\text { language) }\end{array}$ & $\begin{array}{c}\text { Moderate } \\
\text { impairment }\end{array}$ & Difficult & Not difficult & $\begin{array}{c}\text { Not } \\
\text { difficult }\end{array}$ & $\begin{array}{c}\text { Not } \\
\text { difficult }\end{array}$ & $\begin{array}{c}\text { Moderate } \\
\text { difficulty }\end{array}$ & Difficult \\
\hline $\begin{array}{c}\text { Retrospective } \\
\text { Think Aloud } \\
\text { protocol }\end{array}$ & $\begin{array}{c}\text { Moderate } \\
\text { impairment }\end{array}$ & $\begin{array}{c}\text { Not } \\
\text { difficult }\end{array}$ & $\begin{array}{c}\text { Moderate } \\
\text { difficulty }\end{array}$ & $\begin{array}{c}\text { Difficult } \\
\text { difficult }\end{array}$ & $\begin{array}{c}\text { Moderate } \\
\text { difficulty }\end{array}$ & Difficult \\
\hline $\begin{array}{c}\text { Mediated } \\
\text { workshop }\end{array}$ & $\begin{array}{c}\text { Moderate } \\
\text { impairment }\end{array}$ & $\begin{array}{c}\text { Not } \\
\text { difficult }\end{array}$ & Not difficult & $\begin{array}{c}\text { Not } \\
\text { difficult }\end{array}$ & $\begin{array}{c}\text { Not } \\
\text { difficult }\end{array}$ & Not difficult & $\begin{array}{c}\text { Not } \\
\text { difficult }\end{array}$ \\
\hline
\end{tabular}

\begin{tabular}{|c|c|c|c|c|c|c|c|c|}
\hline UCNEM & $\begin{array}{c}\text { Use a } \\
\text { computer } \\
\text { input } \\
\text { device to } \\
\text { select } \\
\text { options }\end{array}$ & $\begin{array}{c}\text { Use a } \\
\text { mobile/ } \\
\text { tablet } \\
\text { touchscre } \\
\text { en } \\
\text { to select } \\
\text { options } \\
\end{array}$ & $\begin{array}{c}\text { Gesture/ } \\
\text { use sign } \\
\text { language }\end{array}$ & $\begin{array}{c}\text { Use } \\
\text { standard } \\
\text { computer } \\
\text { to input } \\
\text { text/type }\end{array}$ & $\begin{array}{c}\text { Use } \\
\text { alternative } \\
\text { input for } \\
\text { text input } \\
\text { (switch } \\
\text { devices) }\end{array}$ & $\begin{array}{c}\text { Verbal } \\
\text { comm } \\
\text { unicati } \\
\text { on }\end{array}$ & $\begin{array}{c}\text { Move } \\
\text { eyes } \\
\text { around }\end{array}$ & $\begin{array}{c}\text { Manually } \\
\text { Write }\end{array}$ \\
\hline $\begin{array}{c}\text { Face to Face } \\
\text { interviews }\end{array}$ & $\mathrm{N}$ & $\mathrm{N}$ & $\mathrm{N}$ & $\mathrm{N}$ & $\mathrm{N}$ & $\mathrm{Y}$ & $\mathrm{N}$ & $\mathrm{N}$ \\
\hline $\begin{array}{l}\text { Telephonic } \\
\text { interview }\end{array}$ & $\mathrm{N}$ & $\mathrm{N}$ & $\mathrm{N}$ & $\mathrm{N}$ & $\mathrm{N}$ & $\mathrm{Y}$ & $\mathrm{N}$ & $\mathrm{N}$ \\
\hline $\begin{array}{l}\text { Interview } \\
\quad \text { (Sign } \\
\text { language) }\end{array}$ & $\mathrm{N}$ & $\mathrm{N}$ & $\mathrm{Y}$ & $\mathrm{N}$ & $\mathrm{N}$ & $\mathrm{N}$ & $\mathrm{N}$ & $\mathrm{N}$ \\
\hline $\begin{array}{c}\text { Open ended } \\
\text { survey } \\
\text { (Online } \\
\text { survey) } \\
\end{array}$ & $\mathrm{N}$ & $\mathrm{N}$ & $\mathrm{N}$ & $\mathrm{Y}$ & Y & $\mathrm{N}$ & $\mathrm{N}$ & $\mathrm{N}$ \\
\hline $\begin{array}{l}\text { Open ended } \\
\text { survey (paper } \\
\text { type) }\end{array}$ & $\mathrm{N}$ & $\mathrm{N}$ & $\mathrm{N}$ & $\mathrm{N}$ & $\mathrm{N}$ & $\mathrm{N}$ & $\mathrm{Y}$ & $\mathrm{Y}$ \\
\hline $\begin{array}{c}\text { Structured } \\
\text { questionnaire } \\
\text { (online } \\
\text { survey) }\end{array}$ & $\mathrm{Y}$ & $\mathrm{Y}$ & $\mathrm{N}$ & $\mathrm{N}$ & $\mathrm{N}$ & $\mathrm{N}$ & $\mathrm{N}$ & $\mathrm{N}$ \\
\hline $\begin{array}{c}\text { Structured } \\
\text { questionnaire } \\
\text { (paper type) }\end{array}$ & $\mathrm{N}$ & $\mathrm{N}$ & $\mathrm{N}$ & $\mathrm{N}$ & $\mathrm{N}$ & $\mathrm{N}$ & $\mathrm{N}$ & $\mathrm{Y}$ \\
\hline $\begin{array}{c}\text { Paper } \\
\text { prototyping }\end{array}$ & $\mathrm{N}$ & $\mathrm{N}$ & $\mathrm{N}$ & $\mathrm{N}$ & $\mathrm{N}$ & $\mathrm{N}$ & $\mathrm{N}$ & $\mathrm{N}$ \\
\hline Focus groups & $\mathrm{N}$ & $\mathrm{N}$ & $\mathrm{N}$ & $\mathrm{N}$ & $\mathrm{N}$ & $\mathrm{Y}$ & $\mathrm{N}$ & $\mathrm{N}$ \\
\hline
\end{tabular}




\begin{tabular}{|c|c|c|c|c|c|c|c|c|}
\hline $\begin{array}{c}\text { Open Card } \\
\text { sorting }\end{array}$ & $\mathrm{N}$ & $\mathrm{N}$ & $\mathrm{N}$ & $\mathrm{N}$ & $\mathrm{N}$ & $\mathrm{N}$ & $\mathrm{N}$ & $\mathrm{N}$ \\
\hline $\begin{array}{c}\text { Closed Card } \\
\text { sorting }\end{array}$ & $\mathrm{N}$ & $\mathrm{N}$ & $\mathrm{N}$ & $\mathrm{N}$ & $\mathrm{N}$ & $\mathrm{N}$ & $\mathrm{N}$ & $\mathrm{N}$ \\
\hline $\begin{array}{c}\text { Reverse card } \\
\text { sorting }\end{array}$ & $\mathrm{N}$ & $\mathrm{N}$ & $\mathrm{N}$ & $\mathrm{N}$ & $\mathrm{N}$ & $\mathrm{N}$ & $\mathrm{N}$ & $\mathrm{N}$ \\
\hline $\begin{array}{c}\text { Cultural } \\
\text { probe } \\
\text { (Camera) }\end{array}$ & $\mathrm{N}$ & $\mathrm{N}$ & $\mathrm{N}$ & $\mathrm{N}$ & $\mathrm{N}$ & $\mathrm{N}$ & $\mathrm{N}$ & $\mathrm{N}$ \\
\hline $\begin{array}{c}\text { Cultural } \\
\text { probe (Diary } \\
\text { recording) }\end{array}$ & $\mathrm{N}$ & $\mathrm{N}$ & $\mathrm{N}$ & $\mathrm{N}$ & $\mathrm{N}$ & $\mathrm{N}$ & $\mathrm{N}$ & $\mathrm{N}$ \\
\hline $\begin{array}{c}\text { Cultural } \\
\text { probe (Voice } \\
\text { recorder) }\end{array}$ & $\mathrm{N}$ & $\mathrm{N}$ & $\mathrm{N}$ & $\mathrm{N}$ & $\mathrm{N}$ & $\mathrm{N}$ & $\mathrm{N}$ & $\mathrm{N}$ \\
\hline $\begin{array}{c}\text { Think aloud } \\
\text { protocol }\end{array}$ & $\mathrm{Y}$ & $\mathrm{Y}$ & $\mathrm{N}$ & $\mathrm{Y}$ & $\mathrm{Y}$ & $\mathrm{Y}$ & $\mathrm{Y}$ & $\mathrm{N}$ \\
\hline $\begin{array}{c}\text { Think aloud } \\
\text { protocol (sign } \\
\text { language) }\end{array}$ & $\mathrm{Y}$ & $\mathrm{Y}$ & $\mathrm{Y}$ & $\mathrm{Y}$ & $\mathrm{Y}$ & $\mathrm{Y}$ & $\mathrm{Y}$ & $\mathrm{N}$ \\
\hline $\begin{array}{c}\text { Retrospective } \\
\text { Think Aloud } \\
\text { protocol }\end{array}$ & $\mathrm{Y}$ & $\mathrm{Y}$ & $\mathrm{N}$ & $\mathrm{Y}$ & $\mathrm{Y}$ & $\mathrm{Y}$ & $\mathrm{Y}$ & $\mathrm{N}$ \\
\hline $\begin{array}{c}\text { Mediated } \\
\text { workshop }\end{array}$ & $\mathrm{N}$ & $\mathrm{N}$ & $\mathrm{N}$ & $\mathrm{N}$ & $\mathrm{N}$ & $\mathrm{Y}$ & $\mathrm{Y}$ & $\mathrm{N}$ \\
\hline
\end{tabular}


Appendix C: Personas provided to participants in the think aloud protocol session in user study

\section{Persona 2:}

The Accessibility for Ontarians with Disabilities Act committee is planning on designing a new online mandatory course on awareness and integration of disability in the workplace which needs to be completed by every employee. The agency is looking for advocates, and prominent disability rights activists in the city to use the draft version of the online course.

Eighty-five-year-old Raisa has a master's degree in Electrical engineering and had a forty-year career as an engineer and as an advocate for rights of the deaf community. She is congenitally deaf and cannot use verbal communication and hence uses American Sign Language (ASL) and e-mail as her primary method of communication.

She still has a good memory and continues to advise Disability Rights Association in California. Although she uses social networking to communicate with her peers, she still prefers to meet people and educate them on the importance of integration of disabled adults into workplace through sign language. She has no problem with her hand dexterity, can use the mouse and keyboard, write and does not need any alternative text input devices to use the computer. Her vision level remains at 20/20. She refrains from using her mobile phone. Raisa sometimes gets frustrated and wishes technology were easier to use.

\section{Persona 3:}

A group of scientists are trying to get feedback on a mobile application which helps patients with PTSD provide mental health assessment and send the results directly to the doctor as an e-mail. The researchers are planning to collect feedback based on the experiences of elderly individuals who had PTSD and have recovered. You want to select the most appropriate needs analysis method(s) using the NICKEL software using the following persona. 
Seventy-year old Mark was a line worker in a steel manufacturing company. He lost both his hands in a workplace accident and has been physically challenged since the accident. As a result, he cannot write, use a computer or mobile phone but still wishes to do so in order to "keep up with the times." He uses head switch as an alternative input device to use his computer or mobile phone. The incident also caused severe mental health problems which included PTSD and memory problems but he recovered back to normal after two years. Mark has excellent vision and hearing. He is active in delivering motivational talks for workers and soldiers who have been severely injured during work or military service.

\section{Persona 4:}

We are testing an ebook reader Apple application using a chin activated single switch with Mohammed. We need to find out what Mohammed's needs are for accessing ebooks (e.g., library, bookstore, online ebook services, etc.) to determine the best ways to group the e-reader functionality into logical groupings to allow him to efficiently access all of his prefered functions.

Mohammed is sixty years old and living in a long term health care facility. He loves to read and still remembers the books he read thirty years ago. He is quadriplegic and has been bedridden for

three years. He cannot speak or move any of his body except for his eyes and head, and has learned to use a computer, mobile or tablet with a chin switch as an alternative input device. Mohammed has $20 / 20$ vision and full hearing functions. He is also able to use his cell phone with a chin switch. 
Appendix D: Chi square values for the survey results on the final version (Cells not color codedResponses significant from chance, Cells highlighted - Survey results which were insignificant but were still considered because of number of responses, Empty cells - Insignificant due to less than 5 responses)

\begin{tabular}{|c|c|c|c|c|c|c|c|}
\hline \multirow[t]{2}{*}{ UCNEM } & \multirow{2}{*}{$\begin{array}{c}\text { Acceptable } \\
\text { cognitive } \\
\text { impairment }\end{array}$} & \multicolumn{3}{|c|}{ Difficulty for different hearing abilities } & \multicolumn{3}{|c|}{ Difficulty for different vision abilities } \\
\hline & & Hearing & $\begin{array}{l}\text { Hard of } \\
\text { hearing }\end{array}$ & Deaf & Sighted & Low vision & Blind \\
\hline $\begin{array}{c}\text { Face to Face } \\
\text { interviews }\end{array}$ & 0.04 & 0.007 & 0.007 & 0 & 0.03 & 0.17 & 0.26 \\
\hline $\begin{array}{l}\text { Telephonic } \\
\text { interview }\end{array}$ & 0.17 & 0.03 & 0.36 & 0.059 & 0.10 & 0.41 & 0.41 \\
\hline $\begin{array}{l}\text { Interview } \\
\text { (Sign } \\
\text { language) }\end{array}$ & 0.81 & 0.31 & 1.00 & 0.31 & 0.31 & 0.31 & 0.77 \\
\hline $\begin{array}{c}\text { Open ended } \\
\text { survey } \\
\text { (Online } \\
\text { survey) } \\
\end{array}$ & 0.25 & 0.034 & 0.059 & 0.059 & 0.034 & 0.36 & 0.60 \\
\hline $\begin{array}{l}\text { Open ended } \\
\text { survey (paper } \\
\text { type) }\end{array}$ & 0.015 & 0 & 0.034 & 0.034 & 0 & 0.19 & 0.034 \\
\hline $\begin{array}{c}\text { Structured } \\
\text { questionnaire } \\
\text { (online } \\
\text { survey) } \\
\end{array}$ & 0.05 & 0.02 & 0.034 & 0.034 & 0.05 & 0.71 & 0.36 \\
\hline $\begin{array}{l}\text { Structured } \\
\text { questionnaire } \\
\text { (paper type) }\end{array}$ & 0.002 & 0.02 & 0.15 & 0.15 & 0.02 & 0.04 & 0.04 \\
\hline $\begin{array}{c}\text { Paper } \\
\text { prototyping }\end{array}$ & 0.838 & 0 & 0 & 0 & 0.102 & 0.102 & 0.102 \\
\hline Focus groups & 0.039 & 0 & 0 & 0 & 0.102 & 0.102 & 0.102 \\
\hline $\begin{array}{l}\text { Open Card } \\
\text { sorting }\end{array}$ & 0.039 & & & & & & \\
\hline $\begin{array}{l}\text { Closed Card } \\
\text { sorting }\end{array}$ & & & & & & & \\
\hline $\begin{array}{l}\text { Reverse card } \\
\text { sorting }\end{array}$ & 0 & & & & & & \\
\hline
\end{tabular}




\begin{tabular}{|c|c|c|c|c|c|c|c|}
\hline $\begin{array}{c}\text { Cultural } \\
\text { probe } \\
\text { (Camera) }\end{array}$ & 0.01 & 0.02 & 0.15 & 0.70 & 0.02 & 0.25 & 0.36 \\
\hline $\begin{array}{c}\text { Cultural } \\
\text { probe (Diary } \\
\text { recording) }\end{array}$ & 0.076 & 0 & 0.05 & 0.04 & 0.01 & 0.05 & 0.368 \\
\hline $\begin{array}{c}\text { Cultural } \\
\text { probe (Voice } \\
\text { recorder) }\end{array}$ & 0.003 & 0.018 & 0.70 & 0.36 & 0.25 & 0.25 & 0.56 \\
\hline $\begin{array}{c}\text { Think aloud } \\
\text { protocol }\end{array}$ & 0.009 & 0.02 & 1 & 1 & 0 & 1 & 0.41 \\
\hline $\begin{array}{c}\text { Think aloud } \\
\text { protocol (sign } \\
\text { language) }\end{array}$ & 0.009 & 0.02 & 0.157 & 0.368 & 0 & 1 & 0.607 \\
\hline $\begin{array}{c}\text { Retrospective } \\
\text { Think Aloud } \\
\text { protocol }\end{array}$ & 0.57 & 0.05 & 0.34 & 0.71 & 0.007 & 0.6 & 0.6 \\
\hline $\begin{array}{c}\text { Mediated } \\
\text { workshop }\end{array}$ & 0.05 & & 0.607 \\
\hline
\end{tabular}




\section{Ryerson}

University

\section{Consent to Participate in Research}

\begin{abstract}
Project Title A User Centered Design(UCD) framework - a human factors approach for UCD methods selection for frail elderly and disabled participants

Principal

Investigator

Joash Sujan Samuel Roy, Graduate Research Student, Department of Industrial Engineering, Ryerson University. 6479391140 or joash.sujan@,ryerson.ca
\end{abstract}

Co Investigators

Deborah Fels, P.Eng., Ph.D., Professor at Ryerson and Director at the Inclusive Media and Design Centre (IMDC)

(416) 979-5000x7619 or dfels@ryerson.ca

W. Patrick Neumann., Ph.D., Professor at Ryerson and Principal investigator at Human Factors Engineering (HFE) lab

(416) 979-5000x7738 or pneumann@ryerson.ca

You are being asked to participate in a research study. Before you give your consent to be a volunteer, it is important that you read the following information and ask as many questions as necessary to be sure you understand what you will be asked to do.

\section{Introduction and Purpose:}

My name is Joash Sujan Samuel Roy and I am a graduate student at Ryerson University working with Dr. Deborah Fels from the Ted Rogers School of Management and Dr. W. Patrick Neumann form the Department of Industrial Engineering at Ryerson University. The purpose of this study is to better understand the cognitive, motor and perceptual abilities needed by older adults when participating in various types of user centered design (UCD) needs analysis methods such as questionnaires, workshops and cultural probes. I am also interested in any modifications done to existing methods or new ones that researchers have invented or tried. Specifically, we are interested in the UCD methods that you are using in your research. You will be asked to complete 12 questions related to this topic using an online survey. 


\section{What you are being asked to do:}

You are being asked to voluntarily complete an online survey. First, you will be requested to read the consent and click the button labelled "Accept and Continue" if you agree to participate. The survey will take about 15 to 20 minutes. The survey will ask you for some background information on your experience working with older adults. More specific questions will follow on the cognitive, physical and perceptual abilities and demands placed on older adult participants in needs assessment process. When you are finished with the survey, you will be asked to submit it using the "Submit Survey" button. By submitting your survey, you consent to participation. If you do not want to participate at this point, you can cancel the submission using the "Cancel" button.

\section{Potential Benefits:}

There is no direct benefit to you in participating in this study, however the data you contribute will be used to develop a participant selection framework for future researchers and designers in order to better understand older adult user's needs.

\section{What are the potential risks to you?}

The risks associated with the study are considered minimal. You may experience some mental fatigue while doing the survey. Since the survey is not timed, you can take a break at any time and resume your session later without having to sign back into the survey or reenter responses. Some of the survey questions pertaining to the demographic data may make you uncomfortable or upset or you may simply wish not to answer some questions. You are free to decline to answer any questions you do not wish to answer, or stop participating at any time by closing your browser. If you close your browser before getting to the end of the survey and do not confirm your consent to participate at the end of the survey by clicking the 'Submit' button your information will not be used. You may contact the researchers in this study if you are having trouble accessing or completing the survey. Please note, if you contact the researchers, your identity will be known to 
them. Please print this page or write down the contact information in case you want to access this information once you complete the survey. Only members of the project team will have access to all the data, which will be stored in encrypted folders in the Inclusive design and media center (IMDC) lab server at Ryerson.

\section{Voluntary Nature of Participation}

Participation in this study is voluntary. Your choice of whether or not to participate will not influence your future relations with Ryerson University or any of the agencies or organizations through which you were recruited. If you decide not to participate, you are free to withdraw your consent and to stop your participation at any time without penalty. At any particular point in the study, you may refuse to answer any particular question or stop participation altogether. If you stop participating in the study your written data will not be used in the research and will be deleted.

\section{Your identity will be confidential:}

The survey has a question which allows you to provide your email identification if you are willing to share any new needs gathering methods you have developed or modified and which have not been mentioned in the survey. Please note that it is not mandatory for you to provide the email address. If you choose to provide your email address it will be accessed only by the research investigators listed. Your Internet Protocol (IP) address will not be collected during the survey process. All the data including the participant responses and email addresses will be encrypted and saved in a secure folder on a password protected server in the locked IMDC lab at the Ryerson University. When the research is completed, the researcher/s will keep the data for up to five years after the study is over and then it will be destroyed by a research staff member. Consent forms will be stored separately from all other data to avoid linking names with participants and destroyed after five years by a staff member. 


\section{How your information will be protected and stored?}

This survey uses Qualtrics which is an American (USA) company. Consequently, USA authorities under the provisions of the Patriot Act, may access the survey data. If you would rather participate with an email or paper based survey, please contact the researchers. Please note email or paper based surveys may allow your identity to be known to the researcher/s but if you select this option your information will be kept confidential. To further protect your information, data stored by the researcher will be password protected and encrypted. Only the researcher/s named in this study will have access to the data as collected. Any future publications will include collective information (i.e. aggregate data). Your individual responses (i.e. raw data) will not be shared with anyone outside of the research team. The results of the study and data analysis will be presented at academic venues and in a master's thesis. Results will only be published in summary form; no one individual will be identified. If you are interested in the results of the study, you will be able to find links to them on the IMDC website (www.imdc.ca).

\section{Incentive for participation:}

You will not be paid for taking part in this study.

\section{Your rights as a research participant:}

Participation in research is completely voluntary and you can withdraw your consent at any point up to clicking the submit button at the end of the survey. The survey is anonymous, unless you are willing to provide your email address to be contacted by the researchers. Unless you provide your email address, once you click the submit button at the end of the survey the researchers will not be able to determine which survey answers belong to you so your information cannot be withdrawn after that point. Please note that by clicking submit at the end of the study you are providing your consent to participate. By consenting to participate you are not waiving any of your legal rights as 


\section{Questions about the Study:}

If you have any questions or concerns, please do not hesitate to call Joash Sujan Samuel Roy, Dr.

Deborah Fels or Dr. W. Patrick Neumann at the contact information provided below. In addition, if you have any questions about your rights or treatment as a research participant in this study, please contact the Ryerson University Research Ethics Board at rebchair@ryerson.ca (416) 9795042.

\begin{tabular}{|c|c|}
\hline Project Title & $\begin{array}{l}\text { A User Centered Design(UCD) framework - a human factors approach } \\
\text { for UCD methods selection for frail elderly and disabled participants }\end{array}$ \\
\hline $\begin{array}{l}\text { Principal } \\
\text { Investigator }\end{array}$ & $\begin{array}{l}\text { Joash Sujan Samuel Roy, Graduate Research Student, } \\
\text { Department of Industrial Engineering, Ryerson University. } \\
6479391140 \text { or joash.sujan@ryerson.ca }\end{array}$ \\
\hline Co Investigators & $\begin{array}{l}\text { Deborah Fels, P.Eng., Ph.D., Professor at Ryerson and Director at the } \\
\text { Inclusive Media and Design Centre (IMDC) } \\
\text { (416) } 979-5000 \times 7619 \text { or dfels@,ryerson.ca }\end{array}$ \\
\hline & $\begin{array}{l}\text { W. Patrick Neumann., Ph.D., Professor at Ryerson and Principal } \\
\text { investigator at Human Factors Engineering (HFE) lab } \\
\text { (416) 979-5000 ext } 7738 \text { or pneumann@,ryerson.ca }\end{array}$ \\
\hline
\end{tabular}

Please print a copy of this page for your future reference.

START SURVEY < start survey button>

By clicking SUBMIT I am consenting to participate in this study. 
Appendix F: Consent form used in Focus group study

\section{Ryerson \\ University}

Ryerson University

Consent Agreement

You are being invited to participate in a research study. Please read this consent form so that you understand what your participation will involve. Before you consent to participate, please ask any questions to be sure you understand what your participation will involve.

\begin{tabular}{|l|l|}
\hline Project Title & $\begin{array}{l}\text { Developing a framework to assist designers in selecting User Centered } \\
\text { Design methods for assessing needs of older adults }\end{array}$ \\
\hline $\begin{array}{l}\text { Principal } \\
\text { Investigator }\end{array}$ & $\begin{array}{l}\text { Joash Sujan Samuel Roy, Graduate Research Student, } \\
\text { Department of Industrial Engineering, Ryerson University. } \\
\text { 6479391140 or joash.sujan@,ryerson.ca }\end{array}$ \\
\hline Co Investigators & $\begin{array}{l}\text { Deborah I. Fels, P.Eng., Ph.D., Professor at Ryerson and Director at the } \\
\text { Inclusive Media and Design Centre (IMDC) } \\
\text { (416) 979-5000 x7619 or dfels@ryerson.ca } \\
\text { W. Patrick Neumann., Ph.D., Professor at Ryerson and Principal } \\
\text { investigator at Human Factors Engineering (HFE) lab } \\
\text { (416) 979-5000 x7738 or pneumann@,ryerson.ca }\end{array}$ \\
\hline
\end{tabular}

PURPOSE OF THE STUDY: My name is Joash Sujan Samuel Roy and I am a graduate student at Ryerson University working with Dr. Deborah Fels from the Ted Rogers School of Management and Dr. W. Patrick Neumann form the Department of Industrial Engineering at Ryerson University. The purpose of this study is to better understand the level of difficulty faced older adults when participating in various types of user-centered design (UCD) needs analysis methods such as questionnaires, workshops and cultural probes based on their hearing and visual abilities. I am also interested in any modifications done to existing methods or new ones that researchers have invented or tried. Specifically, we are interested in the user centered design (UCD) methods that you are using in your research. You will be asked to 1 question asking the level of difficulty for 21 user-centered design (UCD) methods with respect to hearing abilities and 1 question asking the level of difficulty for 21 user-centered design (UCD) methods with respect to visual abilities and each question will be open for discussion among the participants in the focus group session. 


\section{WHAT YOU WILL BE ASKED TO DO [OR] WHAT PARTICIPATION MEANS:}

You are being asked to voluntarily participate in a focus group session. First you will be briefed about the research, how the study benefits the research and requested to sign this consent form. The focus group session will take about 2 to 3 hours. More specific questions will follow during the focus group session to record the level of difficulty faced by older adults and disabled people having different hearing and visual levels/ abilities to participate in the various user-centered design (UCD) needs gathering methods. Please note that the focus group session will be audio recorded. By signing this consent form in page 4 you agree to participate in the focus group study and agree that the data recorded can be used for research purpose as mentioned in the "Purpose of study section".

POTENTIAL BENEFITS: There is no direct benefit to you in participating in this study, however the data you contribute will be used to develop a method selection framework for future researchers and designers in order to better understand older adult user's needs.

\section{WHAT ARE THE POTENTIAL RISKS TO YOU AS A PARTICIPANT?}

The risks associated with the study are considered minimal. You may experience some mental fatigue during the focus group session. Participants will have timed break of 10 minutes during the session for every one hour. If you provide your name or the name of your workplace/organization during the focus group session, the participant should be aware that the other participants in the session will know your details. In this case the moderator/investigators will make sure that the participant's personal details are stored in the IMDC secure folder and will not be used as a research data. However, if the personal details mentioned above is made available to the public through the other participants in the focus group session, the moderator and investigators of the research project are not responsible in this case. You are free to decline to answer any focus group questions you do not wish to answer, or stop participating at any time during the session. Only 
members of the project team will have access to all the data, which will be stored in encrypted folders in the Inclusive design and media center (IMDC) lab server at Ryerson.

\section{CONFIDENTIALITY:}

All the data including the audio recording of the participant responses in the focus group session and pre-study questionnaire responses will be encrypted and saved in a secure folder on a password protected server in the locked IMDC lab at the Ryerson University. When the research is completed, the researcher/s will keep the data for up to five years after the study is over and then it will be destroyed by a research staff member in the IMDC lab. Consent forms will be stored separately from all other data to avoid linking names with participants and destroyed after five years by a IMDC lab staff member at the Ryerson University.

\section{INCENTIVES FOR PARTICIPATION:}

You will not be paid for taking part in this study.

\section{COSTS TO PARTICIPATION:}

Travel cost will be compensated for participants travelling from within the Greater Toronto, Halton, Peel, York and Durham region. Travel cost include TTC, Go Transit, Mileage and parking charges at the Ryerson University. For participants travelling to the focus group location in a car, Ryerson will compensate 50 cents for every kilometer for the fuel charge and will also cover the parking charges at the Ryerson University. Please note that participants need to provide appropriate travel receipts to be reimbursed. For participants travelling by car, need to submit the gas receipt, the parking receipt and also provide the distance of travel. For participants using public transportation need to submit their ticket purchasing receipts.

Ryerson mileage policy: http://www.ryerson.ca/financialservices/about/services/

Ryerson parking rates and location: http://www.ryerson.ca/ubs/parking/vehicle/rates/ 


\section{VOLUNTARY PARTICIPATION AND WITHDRAWAL:}

Participation in this study is completely voluntary. You can choose whether to be in this study or not. If any question makes you uncomfortable, you can skip that question. You may stop participating at any time and you will still be provided with the reimbursements described above. If you choose to stop participating, you may also choose to not have your data included in the study. Your choice of whether or not to participate will not influence your future relations with Ryerson University or the investigators Joash Sujan Samuel Roy, Dr. Deborah. I. Fels \& Dr. W. Patrick Neumann involved in the research.

\section{QUESTIONS ABOUT THE STUDY:}

If you have any questions or concerns, please do not hesitate to call Joash Sujan Samuel Roy, Dr. Deborah Fels or Dr. W. Patrick Neumann at the contact information provided below. In addition, if you have any questions about your rights or treatment as a research participant in this study, please contact the Ryerson University Research Ethics Board at rebchair@,ryerson.ca (416) 9795042. This study has been reviewed by the Ryerson University Research Ethics Board. If you have questions regarding your rights as a participant in this study, please contact:

Research Ethics Board c/o Office of the Vice President, Research and Innovation Ryerson University 350 Victoria Street Toronto, ON M5B 2K3 416-979-5042 rebchair@ryerson.ca 
Developing a framework to assist designers in selecting User Centered Design methods for assessing needs of older adults

\section{CONFIRMATION OF AGREEMENT:}

Your signature below indicates that you have read the information in this agreement and have had a chance to ask any questions you have about the study. Your signature also indicates that you agree to participate in the study and have been told that you can change your mind and withdraw your consent to participate at any time. You have been given a copy of this agreement.

You have been told that by signing this consent agreement you are not giving up any of your legal rights.

Name of Participant

Date

I agree to be audio and video-recorded for the purposes of this study. I understand how these recordings will be stored and destroyed. 
Appendix G: Consent form used in User study

\section{Ryerson \\ University \\ Ryerson University \\ Consent Agreement}

You are being invited to participate in a research study. Please read this consent form so that you understand what your participation will involve. Before you consent to participate, please ask any questions to be sure you understand what your participation will involve.

\begin{tabular}{|l|l|}
\hline Project Title & $\begin{array}{l}\text { NICKEL 1.0 - A tool to assist designers in selecting User Centered } \\
\text { Design methods for assessing needs of older adults }\end{array}$ \\
\hline $\begin{array}{l}\text { Principal } \\
\text { Investigator }\end{array}$ & $\begin{array}{l}\text { Joash Sujan Samuel Roy, Graduate Research Student, } \\
\text { Department of Industrial Engineering, Ryerson University. } \\
+1-6479391140 \text { or joash.sujan@,ryerson.ca }\end{array}$ \\
\hline Co Investigators & $\begin{array}{l}\text { Deborah I. Fels, P.Eng., Ph.D., Professor at Ryerson and Director at the } \\
\text { Inclusive Media and Design Centre (IMDC) } \\
\text { (416) 979-5000 x7619 or dfels@,ryerson.ca } \\
\text { W. Patrick Neumann., Ph.D., Professor at Ryerson and Principal } \\
\text { investigator at Human Factors Engineering (HFE) lab } \\
\text { (416) 979-5000 x7738 or pneumann@ryerson.ca }\end{array}$ \\
\hline
\end{tabular}

PURPOSE OF THE STUDY: My name is Joash Sujan Samuel Roy and I am a graduate student at Ryerson University working under the supervision of Dr. Deborah Fels from the Ted Rogers School of Management and Dr. W. Patrick Neumann form the Department of Industrial Engineering at Ryerson University. The NICKEL 1.0 is an excel based tool which has been developed to assist designers/ developers of assistive technology to determine the right user centered design (UCD) needs gathering methods based on the participant's capabilities. The purpose of this study is to determine whether or not the tool is viable with a high degree of usefulness and usability in helping designers/ developers determine the right UCD method based on participant capability. This study is conducted in the partial fulfillment of Master of Applied sciences in Industrial engineering. The project is funded by Age-Well NCE Inc through Dr. Deborah Fels's research grant. 


\section{WHAT YOU WILL BE ASKED TO DO [OR] WHAT PARTICIPATION MEANS:}

You are being asked to voluntarily participate in this study. First, you will be asked to complete a pre-study questionnaire to collect some background information. Once it is completed, there will be a short description of the tool. Then you will be asked to work on the tool. You will be asked to speak out loud what you do, and what you see and think during the study. You will be videotaped when you are using NICKEL 1.0 so that we can record any commentary you make during the study and analyze it later. Lastly, you will be asked to complete a post-study questionnaire on your general opinion and overall impressions of NICKEL 1.0. The study will be approximately 1 hour in length including 10 minutes of pre-study questionnaire, about 25-30 minute of video recording while you are using NICKEL 1.0 and a 20-25 minute of post-study questionnaire.

POTENTIAL BENEFITS: There is no direct benefit to you in participating in this study, however the data you contribute will be used to make revisions in the future versions of the tool.

\section{WHAT ARE THE POTENTIAL RISKS TO YOU AS A PARTICIPANT?}

The risks associated with the study are considered minimal. You might feel uncomfortable or fatigued while responding to the individual questions, questionnaires or while using NICKEL 1.0. If you feel tired or uncomfortable, you may take a break to rest or discontinue participation in the study either temporarily or permanently. You may feel uncomfortable being videotaped. We will turn on the camera during the pre-study questionnaire so that you can become use to it being on. If that does not help, then we can either finish the study without camera recording or stop the whole study. If you provide your name or the name of your workplace/organization during the session, the participant should be aware that the investigators of the recorded data will know your details. Only members of the project team will have access to all the data, which will be stored in encrypted folders in the Inclusive Media and Design (IMDC) lab server at Ryerson. 


\section{CONFIDENTIALITY:}

All data will remain confidential; will be secured at the IMDC at Ryerson University and destroyed after five years. Furthermore, only the principal investigator and faculty supervisor of this study will have access to the data for analysis purposes. Data will only be presented in summary form and no one individual will be identified unless you mention your name in the recorded session. Number codes will be used to link data with personal information. We will also be recording the study on video. We will not use this footage in any public setting, and the footage will be stored on our password protected lab servers located at Ryerson University. You have all the right to review/edit the recordings or transcripts as well.

\section{INCENTIVES FOR PARTICIPATION:}

You will be compensated with $\$ 20.00$ in cash for completing the entire study. If you choose not to finish the study, you will still be given the incentive for your participation.

\section{COSTS TO PARTICIPATION:}

Travel cost will be compensated for participants travelling from within the Greater Toronto, Halton, Peel, York and Durham region. Travel cost include TTC, Go Transit, Mileage and parking charges at the Ryerson University. For participants travelling to the study location in a car, Ryerson will compensate $\$ .50$ for every kilometer for the fuel charge and will also cover the parking charges at the Ryerson University. Please note that participants need to provide appropriate travel receipts to be reimbursed. For participants travelling by car, need to submit the gas receipt, the parking receipt and also provide the distance of travel. For participants using public transportation need to submit their ticket purchasing receipts.

Ryerson mileage policy: http:/www.ryerson.ca/financialservices/about/services/ Ryerson parking rates and location: http://www.ryerson.ca/ubs/parking/vehicle/rates/ 


\section{VOLUNTARY PARTICIPATION AND WITHDRAWAL:}

Participation in this study is completely voluntary. You can choose whether to be in this study or not. If any question makes you uncomfortable, you can skip that question. You may stop participating at any time and you will still be provided with the reimbursements described above. If you choose to stop participating, you may also choose to not have your data included in the study. Your choice of whether or not to participate will not influence your future relations with Ryerson University or the investigators Joash Sujan Samuel Roy, Dr. Deborah. I. Fels \& Dr. W. Patrick Neumann involved in the research.

\section{QUESTIONS ABOUT THE STUDY:}

If you have any questions or concerns, please do not hesitate to call Joash Sujan Samuel Roy, Dr. Deborah Fels or Dr. W. Patrick Neumann at the contact information provided below. In addition, if you have any questions about your rights or treatment as a research participant in this study, please contact the Ryerson University Research Ethics Board at rebchair@ryerson.ca (416) 9795042.

This study has been reviewed by the Ryerson University Research Ethics Board. If you have questions regarding your rights as a participant in this study please contact:

Research Ethics Board c/o Office of the Vice President, Research and Innovation Ryerson University 350 Victoria Street

Toronto, ON M5B 2K3

416-979-5042

rebchair@ryerson.ca 


\section{A tool to assist designers in selecting User Centered Design methods for assessing needs of older adults CONFIRMATION OF AGREEMENT:}

Your signature below indicates that you have read the information in this agreement and have had a chance to ask any questions you have about the study. Your signature also indicates that you agree to participate in the study and have been told that you can change your mind and withdraw your consent to participate at any time. You have been given a copy of this agreement.

You have been told that by signing this consent agreement you are not giving up any of your legal rights.

Name of Participant

Date

I agree to be audio and video-recorded for the purposes of this study. I understand how these recordings will be stored and destroyed. 
Appendix H: Compensation receipt used in user study:

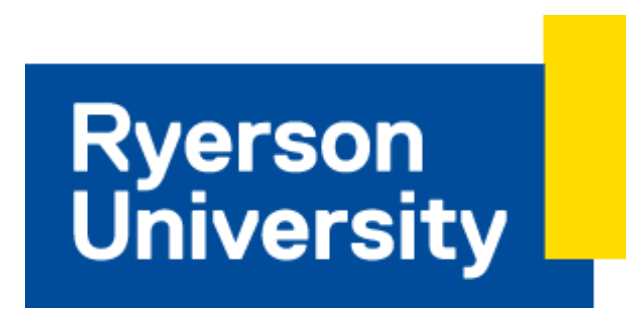

Ryerson University is required to maintain the confidentiality of information about research study participants while still complying with recordkeeping requirements of the Ryerson University. This form serves as documentation of receipt of compensation by individuals participating in research studies conducted by Ryerson University personnel and is used to obtain information to comply with Ryerson University reporting requirements.

$\mathrm{I}$, have received a compensation of CAD20 for my participation in research study and CAD for my travel expenses as cash.

- I am not requesting any compensation for my travel expenses

- I have received compensation for my travel expenses and have provided the original/ photocopy of the original travel receipts to Mr. Joash Sujan Samuel Roy.

Research Participant's Signature $\overline{\text { Date (DD/MM/YYYY) }}$ 
Appendix I: Survey study REB application approval

Ryerson

University

Ryerson Home > Online Ethics Submission and Review System > Protocol View

Email sent to applicant on September 26, 2016 09:41:06 AM

From: rebchaireryerson,ca

Tot joash.sujan@ryerson.ca, ,margot. whitfield @ryerson,ca,dfelseryerson.ca, pneumann@ryerson,ca, ,dfeiseryerson.ca, pneumanneryerson.ca

Cc: rebchairøryerson,ca

Subject: REB 2016-310 Status

Date: September 26, 2016 09:41:06 AM

REB 2016-310

Project Title: Developing a framework to assist designers in selecting User Centred Design methods for assessing needs of older adults

Dear Joash Sujan Samuel Roy,

The Research Ethics Board has completed the review of your submission. Your research project is now approved for a one year period as of Sep 26, 2016. The approval letter is attached in Adobe Acrobat (PDF) format.

Congratulations and best of luck with the project.

Please note that this approval is for one year only and will expire on September 26, 2017. Shortly before the expiry date a request to complete an annual report will be automatically sent to you. Completion of the annual report takes only a few minutes, enables the collection of information required by federal guidelines and when processed will allow the protocol to remain active for another year.

Please note that REB approval policies require that you adhere strictly to the protocol as last reviewed by the REB. Any modifications must be approved by the Board before they are implemented. Adverse or unexpected events must be reported to the REB as soon as possible with an indication from the Principal Investigator as to how, in the view of the Principal Investigator, these events affect the continuation of the protocol.

Please quote your REB file number (REB 2016-310) on future correspondence.

If you have any questions regarding your submission or the review process, please do not hesitate to get in touch with the Research Ethics Board (contact information below).

No research involving humans shall begin without the prior approval of the Research Ethics Board.

This is part of the permanent record respecting or associated with a research ethics application submitted to Ryerson University.

NOTE: This email account (rebchair@ryerson.ca) is monitored by multiple individuals. If you wish to contact a specific member of the Research Ethics Board, please do so directly.

Yours sincerely,

Toni Fletcher, MA 
Appendix J: Focus group REB application approval

Ryerson

University

Ryerson Home > Online Ethics Submission and Review System > Protocol View

Email sent to applicant on February 06, 2017 01:47:12 PM

From: rebchaireryerson.ca

To: joash.sujan@ryerson.ca, ,margot. whitfield@ryerson.ca,dfelseryerson.ca,pneumann@ryerson.ca, ,dfeis@ryerson.ca, pneumannêryerson.ca

Cc: rebchair@iryerson.ca

Subject: REB 2016-310 Status

Date: February 06, 2017 01:47:12 PM

REB 2016-310

Project Title: Developing a framework to assist designers in selecting User Centred Design methods for assessing needs of older adults

Dear Joash Sujan Samuel Roy,

Thank you very much for the submission of amendments for the above project. The Research Ethics Board has completed the review of your resubmission and the proposed amendments have been approved. This does not change the approval status nor the original approval date of the project.

The Research Ethics Board did notice a few typos on the Consent Forms (E.g., "from the Department of... " and not "form the Department of.") As such, the Research Ethics Board requests that you please proofread all Consent Forms before you begin further recruitment.

Congratulations and best of luck with the project.

Please quote your REB file number (REB 2016-310) on future correspondence.

If you have any questions regarding your submission or the review process, please do not hesitate to get in touch with the Research Ethics Board (contact information below).

No research involving humans shall begin without the prior approval of the Research Ethics Board.

This is part of the permanent record respecting or associated with a research ethics application submitted to Ryerson University.

NOTE: This email account (rebchair@ryerson.ca) is monitored by multiple individuals. If you wish to contact a specific member of the Research Ethics Board, please do so directly.

Yours sincerely,

Jeff D'Souza,

Research Ethics Coordinator

on behalf of:

Dr. Nancy Walton, PhD

Co-Chair

Ryerson Research Ethics Board

416-212-4952

nwalton@ryerson.ca

AND 
Appendix K: User evaluation: pre-study questionnaire

\section{Pre-Study Questionnaire}

The purpose of these questions is to collect general information about you and your general experience in needs gathering process. It should take less than 10 minutes to complete this questionnaire. Thank you in advance.

" Required

1. Please write your participant number *

2. What is your gender?*

Mark only one oval.

Male

Female

Prefer not to say

Other.

3. What is your primary area of interest/discipline? *

Mark only one oval.

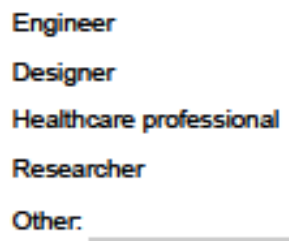

Other.

4. How many years of experience do you have in the respective area of interest? * Mark only one oval.
Less than 2 years
2 to 6 years
More than 6 years

5. How many years of experience do you have in conducting user needs analysis studies? * Mark only one oval.

None
Less than two years
2 to 6 years
More than 6 years


Appendix L: User evaluation: post-study questionnaire

\section{Post-Study Questionnaire}

The purpose of this questionnaire is to understand the usability and viability of the NICKEL 1.0 tool and to understand overall experience of yours. The questionnaire will take about 20-25 minutes.

Part A is for general and overall usability of the system and Part B asked specification questions about "the tool" and your impressions of how it helped you choose a needs analysis method.

* Required

1. Please write your participant number*

\section{Part A- System Usability}

2. I think that I would like to use this system frequently * Mark only one oval.

$\begin{array}{lllll}1 & 2 & 3 & 4 & 5\end{array}$

Strongly disgaree $\square \square \square \square$ Strongly agree

3. I found the system unnecessarily complex * Mark only one oval.

$\begin{array}{llllllll} & 1 & 2 & 3 & 4 & 5 & \\ \text { Strongly disgaree } & \square & & & & \\ & & & & \end{array}$

4. I thought the system was easy to use * Mark only one oval.

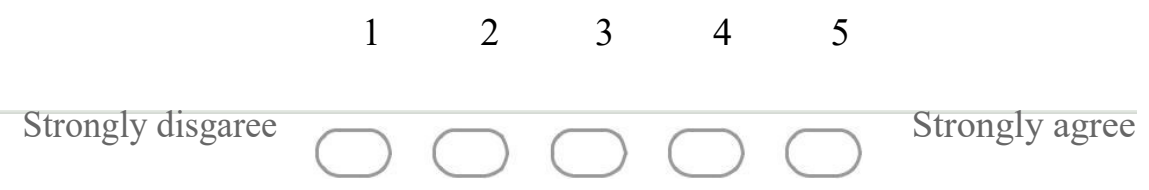

5. I think that I would need the support of a technical person to be able to use this system * Mark only one oval.

$$
\begin{array}{lllll}
1 & 2 & 3 & 4 & 5
\end{array}
$$

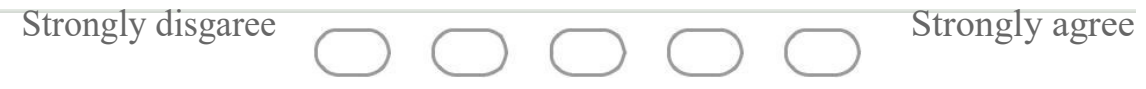


6. I found the various functions in this system were well integrated * Mark only one oval.

$\begin{array}{lllll}1 & 2 & 3 & 4 & 5\end{array}$

Strongly disgaree $\square \square \square$ Strongly agree

7. I thought there was too much inconsistency in this system * Mark only one oval.

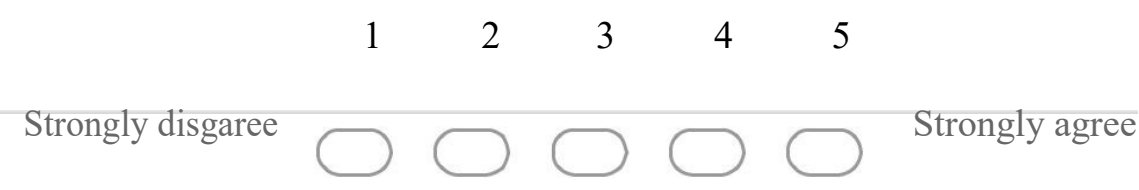

8. I would imagine that most people would learn to use this system very quickly * Mark only one oval.

$$
\begin{array}{lllll}
1 & 2 & 3 & 4 & 5
\end{array}
$$

Strongly disgaree

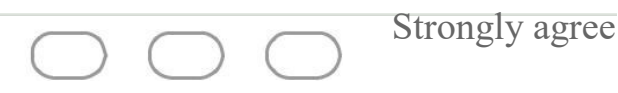

9. I found the system very cumbersome to use * Mark only one oval.

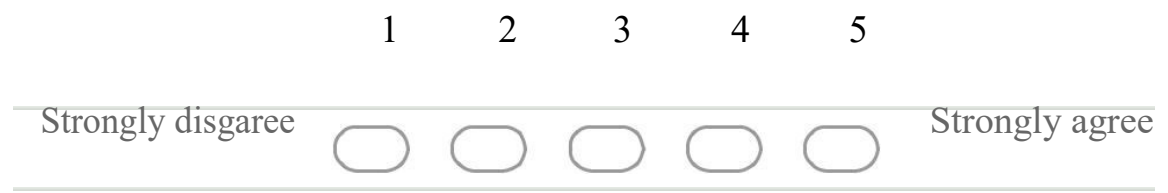

10. I feel confident using the system* Mark only one oval.

$\begin{array}{lllll}1 & 2 & 3 & 4 & 5\end{array}$

Strongly disgaree $\square \square \square \square\left(\square+\infty{ }^{\text {Strongly agree }}\right.$

10. I needed to learn a lot of things before I could get going with this system * Mark only one oval.

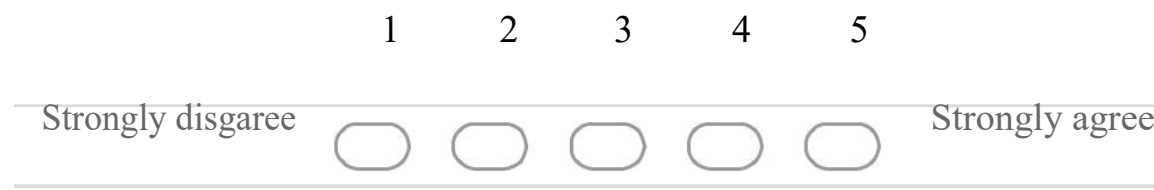




\section{Part B}

11. What was your reaction after using the NICKEL tool? (Please check all that applies) * Check all that apply.

Interested in further using the tool

Satisfied with the results provided by the tool

Confident in using the tool

$\square$ Dissatisfied with the results provided by the tool

Other:

12. In your opinion how helpful is NICKEL for novice designers to determine needs gathering methods for older adult participants? *

Mark only one oval.
Not helpful
Slightly helpful
$\bigcirc$ Moderately helpful
$\bigcirc$ Very helpful
$\bigcirc$ Extremely helpful

13. In your opinion how helpful is NICKEL for novice designers to determine needs gathering methods for disabled participants? *

Mark only one oval.
$\bigcirc$ Not helpful
$\bigcirc$ Slightly helpful
$\Longrightarrow$ Moderately helpful
$\bigcirc$ Very helpful
$\bigcirc$ Extremely helpful

14. In your opinion, how important is to consider human capabilities as a criteria while designing the needs gathering process for older adults and people with disabilities? ${ }^{*}$

Mark only one oval.

Not important

Slightly important

Moderately important

Very important

$\bigcirc$ Extremely important 
15. How do you see using NICKEL in your own research?

16. My knowledge on the level of cognition similar to the description provided in NICKEL? * Mark only one oval.

Have never heard about level of cognition before

Disagree

Neither agree nor disagree

Agree

Strongly agree

17. My knowledge on the level of hearing similar to the description provided in NICKEL? * Mark only one oval.

Have never heard about level of hearing before

Disagree

Neither agree nor disagree

Agree

Strongly agree

18. My knowledge on the level of vision similar to the description provided in NICKEL? * Mark only one oval.

Have never heard about level of vision before

Disagree

Neither agree nor disagree

Agree

Strongly agree

19. It was difficult to understand the options pertaining to physical tasks? * Mark only one oval.

Strongly disagree

Disagree

Neither agree nor disagree

Agree

Strongly agree

20. What did you like about NICKEL?

21. What did you not like about NICKEL? 
22. What other human capability factors do you think should be added to NICKEL?

23. Do you have any recommendation that can be added to NICKEL 
Appendix M: Persona used during the NICKEL demonstration in the user study

\section{Persona 1:}

You are designing a revised version of an existing computer application that will include older adults and would like gather new needs from the participants on the tool. To gather new needs, the participant must use the existing application, provide feedback and suggest ideas for possible expanded future functionality or features.

Ninety-three-year-old Rose was a stay-at-home mother and raised two children. She now suffers from arthritis, diabetes, tremor, osteoporosis and decline in vision due to macular degeneration but has an impeccable hearing. She can speak and hence does not use sign language to communicate.

Because she has a lot of free time and has few visitors, Rose finds different ways to keep herself busy. She is learning to use a computer and this has been more difficult than she expected. Unfortunately, her arthritis limits her ability to control the mouse, use a mobile phone and write. Also, her low vision makes it difficult for her to follow a standard mouse pointer. Learning new tasks is not as easy as it used to be but Rose is still positive about learning. Although she easily understands the explanation of how to manipulate the mouse, she tends to forget what she has learned. Although she has difficulty using the mouse she still continues to use it and the keyboard, and refuses to try alternative devices to interact with computer. Her reaction time when trying to time mouse clicks is sometimes off. She has difficulty sitting for a complete 20minute training session. Rose often complains of pain in her hands and back when using the computer, despite having an "ergonomic" keyboard and chair. Also, she no longer writes, signs papers or uses mobile phone due to the occasional severe tremors she faces. 
Appendix N: Visual acuity conversion chart

\begin{tabular}{|c|c|c|c|c|c|c|c|c|c|c|c|c|c|}
\hline \multirow[b]{3}{*}{$\begin{array}{l}\text { Line } \\
\text { Number }\end{array}$} & \multirow{3}{*}{$\begin{array}{l}\text { Visual } \\
\text { Angle } \\
\text { (min) }\end{array}$} & \multirow{3}{*}{$\begin{array}{l}\text { Spatial } \\
\text { Frequency } \\
\text { (Cyc/deg) }\end{array}$} & \multirow{3}{*}{ LogMAR } & \multicolumn{4}{|c|}{ Distance } & \multicolumn{6}{|c|}{ Near } \\
\hline & & & & \multirow{2}{*}{$\begin{array}{l}\% \text { Central } \\
\text { Visual } \\
\text { Efficiency }\end{array}$} & \multicolumn{2}{|c|}{ Snellen Equivalent } & \multirow{2}{*}{ Decimal } & \multirow{2}{*}{$\begin{array}{l}\% \text { Central } \\
\text { Visual } \\
\text { Efficienty }\end{array}$} & \multirow{2}{*}{$\begin{array}{c}\text { Inches } \\
(14 /)\end{array}$} & \multirow[b]{2}{*}{$\begin{array}{c}\text { Centimeters } \\
(35 /)\end{array}$} & \multirow{2}{*}{$\begin{array}{c}\text { Revised } \\
\text { Jaeger } \\
\text { Standard }\end{array}$} & \multirow{2}{*}{$\begin{array}{c}\text { American } \\
\text { Point-Type }\end{array}$} & \multirow[b]{2}{*}{$\begin{array}{c}\text { "M" } \\
\text { Notation }\end{array}$} \\
\hline & & & & & $\begin{array}{c}\text { Feet } \\
20 /\end{array}$ & $\begin{array}{c}\text { Meter } \\
6 /\end{array}$ & & & & & & & \\
\hline-3 & 0.50 & 60.00 & 0.30 & 100 & 10 & 3.0 & 2.00 & 100 & 7.0 & 17.5 & - & - & 0.20 \\
\hline-2 & 0.63 & 48.00 & 0.20 & 100 & 12.5 & 3.8 & 1.60 & 100 & 8.8 & 21.9 & - & - & 0.25 \\
\hline-1 & 0.80 & 37.50 & 0.10 & 100 & 16 & 4.8 & 1.25 & 100 & 11.2 & 28.0 & - & - & 0.32 \\
\hline 0 & 1.00 & 30.00 & 0.00 & 100 & 20 & 6.0 & 1.00 & 100 & 14.0 & 35.0 & 1 & 3 & 0.40 \\
\hline 1 & 1.25 & 24.00 & -0.10 & 95 & 25 & 7.5 & 0.80 & 100 & 17.5 & 43.8 & 2 & 4 & 0.50 \\
\hline - & 1.50 & 20.00 & -0.18 & 91 & 30 & 9.0 & 0.67 & 95 & 21.0 & 52.5 & 3 & 5 & 0.60 \\
\hline 2 & 1.60 & 18.75 & -0.20 & 90 & 32 & 9.6 & 0.63 & 94 & 22.4 & 56.0 & 4 & 6 & 0.64 \\
\hline 3 & 2.00 & 15.00 & -0.30 & 85 & 40 & 12.0 & 0.50 & 90 & 28.0 & 70.0 & 5 & 7 & 0.80 \\
\hline 4 & 2.50 & 12.00 & -0.40 & 75 & 50 & 15.0 & 0.40 & 50 & 35.0 & 87.5 & 6 & 8 & 1.0 \\
\hline- & 3.00 & 10.00 & -0.48 & 67 & 60 & 18.0 & 0.33 & 42 & 42.0 & 105.0 & 7 & 9 & 1.2 \\
\hline 5 & 3.15 & 9.52 & -0.50 & 65 & 63 & 18.9 & 0.32 & 40 & 44.1 & 110.3 & 8 & 10 & 1.3 \\
\hline- & 3.50 & 8.57 & -0.54 & 63 & 70 & 21.0 & 0.29 & 32 & 49.0 & 122.5 & - & - & 1.4 \\
\hline 6 & 4.00 & 7.50 & -0.60 & 60 & 80 & 24.0 & 0.25 & 20 & 56.0 & 140.0 & 9 & 11 & 1.6 \\
\hline 7 & 5.00 & 6.00 & -0.70 & 50 & 100 & 30.0 & 0.20 & 15 & 70.0 & 175.0 & 10 & 12 & 2.0 \\
\hline - & 5.70 & 5.26 & -0.76 & 44 & 114 & 34.2 & 0.18 & 12 & 79.8 & 199.5 & 11 & 13 & 2.3 \\
\hline 8 & 6.25 & 4.80 & -0.80 & 40 & 125 & 37.5 & 0.16 & 10 & 87.5 & 218.8 & 12 & 14 & 2.5 \\
\hline- & 7.50 & 4.00 & -0.88 & 32 & 150 & 45.0 & 0.13 & 6 & 105.0 & 262.5 & - & - & 3.0 \\
\hline 9 & 8.00 & 3.75 & -0.90 & 30 & 160 & 48.0 & 0.13 & 5 & 112.0 & 280.0 & 13 & 21 & 3.2 \\
\hline 10 & 10.00 & 3.00 & -1.00 & 20 & 200 & 60.0 & 0.10 & 2 & 140.0 & 350.0 & 14 & 23 & 4.0 \\
\hline 11 & 12.50 & 2.40 & -1.10 & 17 & 250 & 75.0 & 0.08 & 0 & 175.0 & 437.5 & - & - & 5.0 \\
\hline- & 15.00 & 2.00 & -1.18 & 16 & 300 & 90.0 & 0.07 & 0 & 210.0 & 525.0 & - & - & 6.0 \\
\hline 12 & 16.00 & 1.88 & -1.20 & 15 & 320 & 96.0 & 0.06 & 0 & 224.0 & 560.0 & - & - & 6.4 \\
\hline 13 & 20.00 & 1.50 & -1.30 & 10 & 400 & 120.0 & 0.05 & 0 & 280.0 & 700.0 & - & - & 8.0 \\
\hline 16 & 40.00 & 0.75 & -1.60 & 5 & 800 & 240.0 & 0.03 & 0 & 560.0 & 1400.0 & - & - & 16.0 \\
\hline 20 & 100.00 & 0.30 & -2.00 & 0 & $2000^{\circ}$ & 600.0 & 0.01 & 0 & 1400.0 & 3500.0 & - & - & 40.0 \\
\hline 30 & 1000.00 & 0.03 & -3.00 & 0 & $20000^{\circ}$ & 6000.0 & 0.001 & 0 & 14000.0 & 35000.0 & - & - & 400.0 \\
\hline
\end{tabular}

Bold values are standard logMAR progression.

LogMAR = logarithm of the minimum angle of resolution

-20/2000 is equivalent to counting fingers 12 feet

${ }^{2} 20 / 20000$ is equivalent to hand motion (2) 2 feet 


\section{References}

Abras, C., Maloney-Krichmar, D., \& Preece, J. (2004). User-centered design. Encyclopedia of Human-Computer Interaction, 37(4), 445-456. https://doi.org/10.3233/WOR-2010-1109

Alabdulkader, B., \& Leat, S. J. (2010). Reading in children with low vision. Journal of Optometry, 3(2), 68-73. https://doi.org/10.1016/S1888-4296(10)70010-8

Allen, D. N. (2011). Brief Cognitive Rating Scale. In J. Kreutzer, J. DeLuca, \& B. Caplan (Eds.), Encyclopedia of Clinical Neuropsychology (1st ed., pp. 446-447). Springer-Verlag New York. https://doi.org/https://doi.org/10.1007/978-0-387-79948-3_168

Angelo Jennifer. (2000). Factors affecting the use of a single switch with assistive technology devices. Journal of Rehabilitation Research and Development, 37(5), 591-598.

Arsand, E., \& Demiris, G. (2008). User-centered methods for designing patient-centric self-help tools. Informatics for Health \& Social Care, 33(3), 158-169.

https://doi.org/10.1080/17538150802457562

Astell, A., Alm, N., Gowans, G., Ellis, M., Dye, R., \& Vaughan, P. (2009). Involving older people with dementia and their careers in designing computer based support systems: some methodological considerations. Universal Access in the Information Society, 8(1), 49-58. https://doi.org/10.1007/s10209-008-0129-9

Ayalew, Y. (2006). A Framework for requirements elicitation. 15th International Conference on Software Engineering and Data Engineering, 1-6. Retrieved from http://www.gjms.co.in/index.php/gjms/article/view/195

Ayres, L. (2008). Semi-structured interview. In L. M. Given (Ed.), The SAGE encyclopedia of qualitative research methods (pp. 810-813). SAGE Publications. 
https://doi.org/http://dx.doi.org/10.4135/9781412963909.n420

Bailey, I. L., \& Lovie, J. E. (1976). New Design Principles for Visual Acuity Letter Charts*. American Journal of Optomery \& Physiological Optics, 53(11), 740-745.

Bangor, A., Kortum, P., \& Miller, J. (2009). Determining what individual SUS scores mean: Adding an adjective rating scale. Journal of Usability Studies, 4(3), 114-123. https://doi.org/66.39.39.113

Baroudi, J. J., Olson, M. H., \& Ives, B. (1986). An Empirical Study of the Impact of User Involvement on System Usage and Information Satisfaction. Communications of the ACM The MIT Press Scientific Computation Series, 29(3), 232-238. https://doi.org/10.1145/5666.5669

Bernard, M., Liao, C. H., \& Mills, M. (2001). The effects of font type and size on the legibility and reading time of online text by older adults. In CHI '01 extended abstracts on Human factors in computer systems - CHI '01 (p. 175). https://doi.org/10.1145/634164.634173

Bertoa, M., \& Vallecillo, A. (2004). Usability metrics for software components. In 8th international workshop on quantitative approaches in object-oriented software engineering (QAOOSE'2004) (pp. 1-10). Oslo, Norway. https://doi.org/§

Better Hearing Institute. (2018). Types and Degrees of Hearing Loss. Retrieved from http://www.betterhearing.org/hearingpedia/types-hearing-loss

Bhidayasiri, R., \& Tarsy, D. (2012). Primary Writing Tremor. In In: Movement Disorders: A Video Atlas. Current Clinical Neurology (pp. 62-63). Totowa, NJ: Humana Press. https://doi.org/10.1007/978-1-60327-426-5_29

Bigham, J. P., Jayant, C., Ji, H., Little, G., Miller, A., Miller, R. C., .. Yeh, T. (2010). VizWiz: Nearly Real-Time Answers to Visual Questions. In UIST’10 (pp. 333-342). New York 
City. https://doi.org/10.1145/1866029.1866080

Bigham, J. P., Robert, C., White, S., Jayant, C., Ji, H., Little, G., .. Yeh, T. (2010). VizWiz: nearly real-time answers to visual questions. In Proceedings of the 23nd annual ACM symposium on User interface software and technology (pp. 333-342). New York, New York, USA: ACM. https://doi.org/10.1145/1866029.1866080

Blackstien-Adler, S., Shein, F., Quintal, J., Birch, S., \& Weiss, P. L. T. (2004). Mouse Manipulation Through Single-Switch Scanning. Assistive Technology, 16(1), 28-42. https://doi.org/10.1080/10400435.2004.10132072

Blythe, M., \& Dearden, A. (2009). Representing older people: Towards meaningful images of the user in design scenarios. Universal Access in the Information Society, 8(1), 21-32. https://doi.org/10.1007/s10209-008-0128-x

Boehner, K., Vertesi, J., Sengers, P., \& Dourish, P. (2007). How HCI interprets the probes. In Proceedings of the SIGCHI conference on Human factors in computing systems - CHI '07 (pp. 1077-1086). San Jose, California: ACM. https://doi.org/10.1145/1240624.1240789

Brandimonte, M. A., Bruno, N., \& Collina, S. (2006). Cognition. Psychological Concepts: An International Historical Perspective. Hove, UK: Psychology Press.

Braun, V., \& Clarke, V. (2006). Using thematic analysis in psychology. Qualitative Research in Psychology, 3(2), 77-101. https://doi.org/10.1191/1478088706qp063oa

Brinkley, J., \& Tabrizi, N. (2017). A Desktop Usability Evaluation of the Facebook Mobile Interface using the JAWS Screen Reader with Blind Users. In Proceedings of the Human Factors and Ergonomics Society 2017 Annual Meeting (Vol. 61, pp. 828-832). Austin, Texas: Sage publications. https://doi.org/10.1177/1541931213601699

Brooke, J., Jordan, P. W., Thomas, B., Weerdmeester, B. A., \& McClelland, I. L. (1996). SUS: A 
quick and dirty usability scale. In P. W. Jordan, B. Thomas, B. A. Weerdmeester, \& I. L. McClelland (Eds.), Usability Evaluation In Industry (pp. 189-194). Reading,UK: Taylor \& Francis. https://doi.org/10.1002/hbm.20701

Brown, M., Tsai, A., Baurley, S., Koppe, T., Lawson, G., Martin, J., ... Arunachalam, U. (2014). Using cultural probes to inform the design of assistive technologies. In International Conference on Human-Computer Interaction (pp. 35-46). Cham: Springer. https://doi.org/10.1007/978-3-319-07233-3_4

Buzzi, M. C., Buzzi, M., Leporini, B., Mori, G., \& Penichet, V. M. . (2010). Accessing google docs via screen reader. In International Conference on Computers for Handicapped Persons (Vol. 6179 LNCS, pp. 92-99). Berlin, Heidelberg: Springer. https://doi.org/10.1007/978-3642-14097-6_17

Caleb-Solly, P., Flind, A., \& Vargheese, J. P. (2011). Cameras as cultural probes in requirements gathering - Exploring their potential in supporting the design of assistive technology. In Proceedings - IEEE Symposium on Computer-Based Medical Systems (pp. 1-6). https://doi.org/10.1109/CBMS.2011.5999158

Canadian Association of the Deaf. (2015). Terminology. Retrieved from http://cad.ca/resourceslinks/terminology/

Carl, S., \& Roger, H. S. (2004). Humans: skills, capabilities and limitation. In Human factors for engineers (pp. 38-44). London, UK: Institution of Electrical Engineers.

Chandrashekar, S., Stockman, T., Fels, D., \& Benedyk, R. (2006). Using think aloud protocol with blind users:: a case for inclusive usability evaluation methods. In Proceedings of the 8th international ACM SIGACCESS conference on Computers and accessibility (pp. 251252). Portland, Oregon: Association for Computing Macinery. 
Charters, E. (2003). The use of think-aloud methods in qualitative research an introduction to think-aloud methods. Brock Education Journal, 12(2), 68-82.

https://doi.org/10.1080/02602938.2010.496532

Chawla, B., \& Singh, R. (2017). Definition of blindness under National Programme for Control of Blindness: Do we need to revise it? Indian J Ophthalmol, 65(2), 133-139. https://doi.org/10.4103/ijo.IJO

Cheek, P., Nikpour, L., \& Nowlin, H. D. (2005). Aging well with smart technology. Nursing Administration Quarterly, 29(4), 329-338. https://doi.org/00006216-200510000-00007 [pii]

Chilana, P. K., Wobbrock, J. O., \& Ko, A. J. (2010). Understanding usability practices in complex domains. In Proceedings of the 28th international conference on Human factors in computing systems - CHI '10 (pp. 2337-2346). https://doi.org/10.1145/1753326.1753678

Chung, J., Chaudhuri, S., Le, T., Chi, N.-C., Thompson, H. J., \& Demiris, G. (2015). The use of think-aloud to evaluate a navigation structure for a multimedia health and wellness application for older adults and their caregivers. Educational Gerontology, 41(12), 916929. https://doi.org/10.1080/03601277.2015.1071586

City of Toronto. (2004). City of Toronto accessibility design guidelines. Retrieved from www.toronto.ca/diversity/accessibilityplan2003

Claes, R., \& Heymans, M. (2008). HR professionals' views on work motivation and retention of older workers: a focus group study. Career Development International, 13(2), 95-111. https://doi.org/10.1108/13620430810860521

Clark, J. G. (1981). Uses and abuses of hearing loss. Asha: A Journal of the American SpeechLanguage-Hearing Association, 23(7), 493-500.

Clarkson, J., Coleman, R., Hosking, I., \& Waller, S. (2007). Inclusive design toolkit. University 
of Cambridge. Retrieved from https://www-edc.eng.cam.ac.uk/downloads/idtoolkit.pdf

Cohen, D., \& Crabtree, B. (2006). Qualitative Research Guidelines Project: Structured Interviews. Retrieved from http://www.qualres.org/HomeStru-3628.html

Cooper, A. (2004). The Inmates Are Running the Asylum: Why High Tech Products Drive Us Crazy and How to Restore the Sanity (2nd ed.). Indianapolis,IN: Sams Publishing.

Corazzini, L. L., Tinti, C., Schmidt, S., Mirandola, C., \& Cornoldi, C. (2010). Developing Spatial Knowledge in the Absence of Vision: Allocentric and Egocentric Representations Generated by Blind People When Supported by Auditory Cues. Psychologica Belgica, 50(3-4), 327. https://doi.org/10.5334/pb-50-3-4-327

Crilly, N., \& Clarkson, P. J. (2006). the Influence of Consumer Research on Product Aesthetics. In International Design Conference (pp. 689-696). Dubrovnik, Croatia.

Cullen, B., O’Neill, B., Evans, J. J., Coen, R. F., \& Lawlor, B. A. (2007). A review of screening tests for cognitive impairment. Journal of Neurology, Neurosurgery, and Psychiatry, 78(8), 790-9. https://doi.org/10.1136/jnnp.2006.095414

Davidson, E. . (1999). Joint application design (JAD) in practice. Journal of Systems and Software, 45(3), 215-223. https://doi.org/10.1016/S0164-1212(98)10080-8

Davis, A. . M., \& Zowghi, D. (2006). Good requirements practices are neither necessary nor sufficient. Requirements Engineering, 11(1), 1-3. https://doi.org/10.1007/s00766-004-02064

de Joode, E., van Heugten, C., Verhey, F., \& van Boxtel, M. (2010). Efficacy and usability of assistive technology for patients with cognitive deficits: a systematic review. Clinical Rehabilitation, 24(8), 701-714. https://doi.org/10.1177/0269215510367551

Den Oudsten, B. L., Lucas-Carrasco, R., \& Green, A. M. (2011). Perceptions of persons with 
Parkinson's disease, family and professionals on quality of life: an international focus group study. Disability and Rehabilitation, 33(25-26), 2490-2508.

https://doi.org/10.3109/09638288.2011.575527

Denno, S., Isle, B. A., Ju, G., Koch, C. G., Metz, S. V, Penner, R., ... Ward, J. (1992). Human Factors Design Guidelines for the Elderly and People with Disabilities. Technical Report SSDC-SYS/AI-C92-009, Honeywell. Minneapolis.

Dong, H., Keates, S., Clarkson, P. J., \& Cassim, J. (2002). Implementing Inclusive Design: The Discrepancy between Theory and Practice. In Carbonell N., Stephanidis C. (eds) Universal Access Theoretical Perspectives, Practice, and Experience (pp. 106-117). Berlin, Heidelberg: Springer International Publishing.

Donker, A., \& Markopoulos, P. (2002). Comparison of Think-Aloud, Questionnaires and Interviews for Testing Usability With Children. In People and Computers XVI - Memorable Yet Invisible, Proceedings HCI 2002 (pp. 305-316).

https://doi.org/10.1145/1017833.1017848

Eason, K. D. (2005). Information technology and organisational change. Taylor \& Francis. Retrieved from https://books.google.ca/books?hl=en\&lr=\&id=7BaH07ob6zQC\&oi=fnd\&pg=PP1\&dq=Info rmation+technology + and + organisational + change \&ots=qAB8WGRrgS\&sig=p3m60MWJQr zqNOSuVa6tup6GzcQ\#v=onepage\&q=Information technology and organisational change $\& \mathrm{f}=$ false

Eisma, R., Dickinson, A., Goodman, J., Mival, O., Syme, A., \& Tiwari, L. (2003). Mutual inspiration in the development of new technology for older people. In Include 2003 (Vol. 7, pp. 252-259). London, UK. 
Eisma, R., Dickinson, a., Goodman, J., Syme, a., Tiwari, L., \& Newell, a. F. (2004). Early user involvement in the development of information technology-related products for older people. Universal Access in the Information Society, 3(2), 131-140.

https://doi.org/10.1007/s10209-004-0092-z

Ellis, T. J., \& Levy, Y. (2010). A Guide for Novice Researchers: Design and Development Research Methods. In Proceedings of Informing Science \& IT Education Conference (InSITE) (pp. 107-118). Retrieved from http://proceedings.informingscience.org/InSITE2010/InSITE10p107-118Ellis725.pdf

Falkenstein, I. A., Cochran, D. E., Azen, S. P., Dustin, L., Tammewar, A. M., Kozak, I., \& Freeman, W. R. (2008). Comparison of Visual Acuity in Macular Degeneration Patients Measured with Snellen and Early Treatment Diabetic Retinopathy Study Charts. Ophthalmology, 115(2), 319-323. https://doi.org/10.1016/j.ophtha.2007.05.028.Comparison Fang, X., \& Holsapple, C. W. (2007). An empirical study of web site navigation structures' impacts on web site usability. Decision Support Systems, 43(2), 476-491. https://doi.org/10.1016/j.dss.2006.11.004

Fausset, C. B., Mayer, A. K., Rogers, W. A., \& Fisk, A. D. (2016). Understanding Aging in Place for Older Adults: A Needs Analysis. PsycEXTRA Dataset, 5(7), 521-525. https://doi.org/10.5014/ajot.2012.004234.Proprioceptive

Federici, S., \& Borsci, S. (2011). The use and non-use of assistive technology in Italy: Preliminary data. In Assistive Technology Research Series (Vol. 29, pp. 979-986). https://doi.org/10.3233/978-1-60750-814-4-979

Ferre, X., \& Bevan, N. (2011). Usability planner: A tool to support the process of selecting usability methods. Lecture Notes in Computer Science (Including Subseries Lecture Notes 
in Artificial Intelligence and Lecture Notes in Bioinformatics), 6949 LNCS(PART 4), 652655. https://doi.org/10.1007/978-3-642-23768-3_105

Finlay, M., \& Lyons, E. (2001). Methodological issues in interviewing and using self-report questionnaires with people with mental retardation. Psychological Assessment, 13(3), 319335. https://doi.org/10.1037//1040-3590.13.3.319

Fitchen, C. S., Hines, J., \& Amsel, R. (1985). Public awareness of physically disabled persons. International Journal of Rehabilitation Research, 8(4), 407-414.

Fitzpatrick, M. A., Knapp, M. L., \& Miller, G. R. (1985). All in the Family: Interpersonal Communication in Kin Handbook of Interpersonal Communication Edited by. Sage publications.

Fleizach, I. C. B., Clara, S., Us, C. A., Holden, P., Francisco, S., Us, C. A., ... Louboutin, R. Y. (2014). U.S. Patent 8706920. United States of America: United States Patent and Trademark office.

Folan, A., Barclay, L., Cooper, C., \& Robinson, M. (2015). Exploring the experience of clients with tetraplegia utilizing assistive technology for computer access. Disability and Rehabilitation: Assistive Technology, 10(1), 46-52.

https://doi.org/10.3109/17483107.2013.836686

Folstein, M. F., Folstein, S. E., \& McHugh, P. R. (1975). "Mini-mental state". A practical method for grading the cognitive state of patients for the clinician. Journal of Psychiatric Research, 12(3), 189-198. https://doi.org/10.1016/0022-3956(75)90026-6

Fontana, A., \& Frey, J. H. (1994). Interviewing: The Arts of Science. In Y. . Denzin (Ed.), Handbook of Qualitative Research (pp. 361-376). Thousand Oaks: Sage Publications. https://doi.org/10.1016/j.jconhyd.2010.08.009 
Francis, P., Balbo, S., \& Firth, L. (2009). Towards co-design with users who have autism spectrum disorders. Universal Access in the Information Society, 8(3), 123-135. https://doi.org/10.1007/s10209-008-0143-y

Gaver, B., Dunne, T., \& Pacenti, E. (1999). Design: cultural probes. Interactions, 6(1), 21-29. https://doi.org/10.1145/291224.291235

Geissler, G., Zinkhan, G., \& Watson, R. T. (2001). Web Home Page Complexity and Communication Effectiveness. Journal of the Association for Information Systems, 2(1), 146. Retrieved from https://www.researchgate.net/profile/Richard_Watson5/publication/220580556_Web_Home _Page_Complexity_and_Communication_Effectiveness/links/09e415123791e5f421000000. pdf

Ghazali, M., Ariffin, N. A. M., \& Omar, R. (2014). User Centered Design Practices in Healthcare: A Systematic Review. In Proceedings of the 3rd International Conference on User Science and Engineering (i-USEr) (pp. 91-96). IEEE.

Gill, A. (2011). Current think aloud practices. The University of Guelph.

Gladwell, M. (2008). Outliers: The Story of Success. Hachette UK. https://doi.org/10.1080/15210960903028818

Goguen, J. A. (1996). Formality and Informality in Requirements Engineering. In ICRE (Vol. 96, pp. 102-108). Colorado Springs, Colorado, USA: IEEE Computer Society.

Goodman, J., Cassim, J., Langdon, P., \& Clarkson, P. J. (2007). Involving People with Disabilities : Lessons from a Designer-Centred Inclusive Design Competition. In Include 2007 Proceedings.

Gorransson, B., Gulliksen, J., \& Boivie, I. (2003). The usability design process - Integrating 
user-centered systems design in the software development process. Software Process Improvement and Practice, 8(2), 111-131. https://doi.org/10.1002/spip.174

Government of Canada. (2015a). Disability in Canada: Initial findings from the Canadian Survey on Disability. Retrieved from http://www.statcan.gc.ca/pub/89-654-x/89-654-x2013002eng.htm

Government of Canada. (2015b). The Canadian Population in 2011: Age and Sex. Retrieved from http://www12.statcan.gc.ca/census-recensement/2011/as-sa/98-311-x/98-311x2011001-eng.cfm

Guillaume, C., Clochon, P., Denise, P., Rauchs, G., Guillery-Girard, B., Eustache, F., \& Desgranges, B. (2009). Early age-related changes in episodic memory retrieval as revealed by event-related potentials. NeuroReport, 20(2), 191-196. https://doi.org/10.1097/WNR.0b013e32831b44ca

Hall, L., \& Mallalieu, G. (2003). Identifying the Needs and Expectations of Users with Learning Disabilities. In Universal Access in HCI: Inclusive Design in the Information Society, Volume 4 of the Proceedings of the 10th International Conference on Human-Computer Interaction (HCI International 2003) (pp. 837- 841). Crete, Greece: Lawrence Erlbaum Associates.

Hamborg, K. C., \& Gediga, G. (1997). ISO Metrics Questionnaire for the evaluation of graphical user interfaces based on ISO 9241/10 (Short Version) - Version 2.01c. Osnabruck, Germany: International Standard Organization. Retrieved from http://www.dcs.ed.ac.uk/teaching/cs4/www/hci/questionnaires/isoes201.pdf Hawthorn, D. (2007). Interface design and engagement with older people. Behaviour \& Information Technology, 26(4), 333-341. https://doi.org/10.1080/01449290601176930 
Hawthorne, G., Davidson, N., Quinn, K., McCrate, F., Winkler, I., Lucas, R., ... Molzahn, A. (2006). Issues in conducting cross-cultural research: Implementation of an agreed international procotol designed by the WHOQOL Group for the conduct of focus groups eliciting the quality of life of older adults. Quality of Life Research, 15(7), 1257-1270. https://doi.org/10.1007/s11136-006-0062-4

Hemmings, T., Clarke, K., Rouncefield, M., Crabtree, A., \& Rodden, T. (2002). Probing the Probes. In Proceedings of the Participatory Design Conference (pp. 42-50). Malmo, Sweden. https://doi.org/10.1016/j.chembiol.2010.05.013

Hickey, A. M., \& Davis, A. M. (2003a). Elicitation Technique Selection: How Do Experts Do It? In Proceedings of the 11th IEEE International Requirements Engineering Conference (pp. 169-178). IEEE. Retrieved from http://www.cse.msu.edu/ chengb/RE491/Papers/elicitation-hickey-davis.pdf

Hickey, A. M., \& Davis, A. M. (2003b). Requirements elicitation and elicitation technique selection: Model for two knowledge-intensive software development processes. In Proceedings of the 36th Annual Hawaii International Conference on System Sciences, HICSS 2003. https://doi.org/10.1109/HICSS.2003.1174229

Hirasawa, N., Yamada-Kawai, K., Kasai, H., \& Ogata, S. (2010). Effectiveness of introducing Human-Centered Design process. In SICE Annual Conference 2010, Proceedings of (pp. 1430-1433). Taipei, Taiwan.

Holladay, J. T. (2004). Visual acuity measurements. Journal of Cataract and Refractive Surgery, 30(2), 287-290. https://doi.org/10.1016/j.jcrs.2004.01.014

Hurt, C. S., Burns, A., Brown, R. G., \& Barrowclough, C. (2010). Perceptions of subjective memory complaint in older adults: the Illness Perception Questionnaire - Memory (IPQ-M). 
International Psychogeriatrics, 22(5), 750-760.

https://doi.org/10.1017/S1041610209991542

Hussain, Z., Slany, W., \& Holzinger, A. (2009). Current State of Agile User-Centered Design: A Survey. In USAB '09 Proceedings of the 5th Symposium of the Workgroup HumanComputer Interaction and Usability Engineering of the Austrian Computer Society on HCI and Usability for e-Inclusion (Vol. 5889, pp. 416-427). Linz, Austria. https://doi.org/10.1007/978-3-642-10308-7_30

International Council of Ophthalmology. (1988). Visual Acuity Measurement Standard. Published in the Italian Journal of Ophthalmology II.

ISO. (1999). ISO 13407: Human Centred Design Process for Interactive Systems. Human Factors.

ISO 9241-11. (2017). ISO 13407: Human Centred Design Process for Interactive Systems. Retrieved from https://www.userfocus.co.uk/resources/iso9241/iso13407.html Jääskeläinen, R. (2010). Think-aloud protocol. In Handbook of translation studies (pp. 371374). John Benjamins Publishing company.

Jacko, J. A., Barreto, A. B., Marmet, G. J., Chu, J. Y. M., Bautsch, H. S., Scott, I. U., \& Rosa R.H., J. (2000). Low vision: The role of visual acuity in the efficiency of cursor movement. In Annual ACM Conference on Assistive Technologies, Proceedings (pp. 1-8). https://doi.org/10.1145/354324.354327

Javed, T., Maqsood, M. e, \& Durrani, Q. S. (2004). A study to investigate the impact of requirements instability on software defects. ACM SIGSOFT Software Engineering Notes, 29(4), 1-7. https://doi.org/10.1145/986710.986727

Jemni, M., Ghoul, O. El, Yahia, N. Ben, \& Boulares, M. (2007). Sign Language MMS to Make 
Cell Phones Accessible to the Deaf and Hard-of-hearing Community. In Conference \& Workshop on Assistive Technologies for People with Vision \& Hearing Impairments (pp. 16). Granada, Spain.

Jick, T. D. (1979). Mixing qualitative and quantitative methods: Triangulation in action. Administrative Science Quarterly, 24(4), 602-611.

Jochems, N. (2016). Designing Tablet Computers for the Elderly A User-Centered Design Approach. In International Conference on Human Aspects of IT for the Aged Population (pp. 42-51). Springer International Publishing.

Johnsen, S. O., Kilskar, S. S., \& Fossum, K. R. (2017). Missing focus on Human Factors Organizational and cognitive ergonomics - In the safety management for the petroleum industry. In Proceedings of the Institution of Mechanical Engineers, Part O: Journal of Risk and Reliability (Vol. 231, pp. 400-410). https://doi.org/10.1177/1748006X17698066

Jones, K. D. (2010). The unstructured clinical interview. Journal of Counseling \& Development, 88(2), 220-226. https://doi.org/10.1002/j.1556-6678.2010.tb00013.x

Jutai, J., Hooper, P., Strong, G., Cooper, L., Hutnik, C., Sheidow, T., ... Russell-Minda, E. (2005). Terminology, Demography, and Epidemiology of Low Vision. In Vision Rehabilitation Evidence-Based Review (VREBR) (pp. 1-61). London, ON.

Kaczmirek, L., \& Wolff, K. G. (2007). Survey Design for Visually Impaired and Blind People. In Universal Acess in Human Computer Interaction. Part I, Coping with Diversity (pp. 374381). Berlin, Heidelberg. https://doi.org/10.1007/978-3-540-73279-2_41

Kane, S. K., Frey, B., \& Wobbrock, J. O. (2013). Access Lens: A Gesture-Based Screen Reader for Real-World Documents. In Proceedings of the SIGCHI Conference on Human Factors in Computing Systems - CHI '13 (pp. 347-350). Paris, France: ACM. 
https://doi.org/10.1145/2470654.2470704

Keates, S., \& Clarkson, P. J. (2003). Countering design exclusion: bridging the gap between usability and accessibility. Universal Access in the Information Society, 2(3), 215-225. https://doi.org/10.1007/s10209-003-0059-5

Khong, C. W. (2000). A Review of Applied Ergonomics Techniques Adopted by Product Designers. In Proceedings of APCHI /ASEAN Ergonomics (Vol. 298, pp. 317-322).

Kim, H. N. (2010). Usable Accessibility and Haptic User Interface Design Approach.

Kim, H. N., Smith-Jackson, T. L., \& Kleiner, B. M. (2014). Accessible haptic user interface design approach for users with visual impairments. Universal Access in the Information Society, 13(4), 415-437. https://doi.org/10.1007/s10209-013-0325-0

Kim, S. Y. ., Karlawish, J. H. ., \& Caine, E. D. (2002). Current State of Research on DecisionMaking Competence of Cognitively Impaired Elderly Persons. The American Journal of Geriatric Psychiatry, 10(2), 151-165. https://doi.org/10.1097/00019442-200203000-00006

Kleeck, M. Van. (1999). US Patent No. 6008799. United States of America: United States Patent and Trademark office. Retrieved from https://patentimages.storage.googleapis.com/0b/f6/e3/b28660664ee641/US6008799.pdf Kotonya, G., \& Sommerville, I. (1996). Requirements engineering with viewpoints. Software Engineering Journal, 11(1), 5-18. https://doi.org/10.1049/sej.1996.0002

Kotonya, G., \& Sommerville, I. (1998). Requirements engineering: processes and techniques. Wiley Publishing. Retrieved from https://dl.acm.org/citation.cfm?id=552009

Kroll, T., Barbour, R., \& Harris, J. (2007). Using Focus Groups in Disability Research. Qualitatitve Health Research, 17(5), 690-698. https://doi.org/10.1177/1049732307301488 Krueger, R. A., \& Casey, M. A. (2014). Focus Groups: A Practical Guide for Applied Research 
(5th ed.). Singapore: Sage publications.

Kujala, S. (2003). User involvement: A review of the benefits and challenges. Behaviour and Information Technology, 22(1), 1-16. https://doi.org/10.1080/01449290301782

Kutiyanawala, A., Kulyukin, V., \& Nicholson, J. (2011). Teleassistance in Accessible Shopping for the Blind. In Proceedings of the 2011 International Conference on Internet Computing (pp. 1-4). Retrieved from http://apps.webofknowledge.com/full_record.do?product=UA\&search_mode=GeneralSearc h\&qid=22\&SID=1AJFVuOyVE8SFw3gC7i\&page $=1 \&$ doc $=21$

Leonardi, C., Mennecozzi, C., Not, E., Pianesi, F., Zancanaro, M., Gennai, F., \& Cristoforetti, A. (2009). Knocking on elders' door. In Proceedings of the 27th international conference on Human factors in computing systems - CHI 09 (pp. 1703-1711). Boston. https://doi.org/10.1145/1518701.1518963

Lines, L., \& Hone, K. S. (2002). Research Methods For Older Adults. In A New Research Agenda for Older Adults. Workshop at BCS HCI 2002 (pp. 36-37). London: British Computer Society HCI 2002.

Lloyd, W. J., Rosson, M. B., \& Arthur, J. D. (2002). Effectiveness of elicitation techniques in distributed requirements engineering. In Proceedings of the IEEE International Conference on Requirements Engineering (pp. 311-318). https://doi.org/10.1109/ICRE.2002.1048544

Louise Roberts, V., \& Fels, D. I. (2006). Methods for inclusion: Employing think aloud protocols in software usability studies with individuals who are deaf. International Journal of Human Computer Studies, 64(6), 489-501. https://doi.org/10.1016/j.ijhcs.2005.11.001

Luger, T. M., Houston, T. K., \& Suls, J. (2014). Older adult experience of online diagnosis: results from a scenario-based think-aloud protocol. Journal of Medical Internet Research, 
16(1). https://doi.org/10.2196/jmir.2924

Magnúsdóttir, H. S. (2011). USER CENTERED DESIGN METHODS USED BY GRADUATED STUDENTS Research report School of Computer Science. Reykjavik University. Reykjavik. Retrieved from http://skemman.is/stream/get/1946/9128/22902/1/Research_Report.pdf

Maguire, E. A., \& Frith, C. D. (2003). Aging affects the engagement of the hippocampus during autobiographical memory retrieval. Brain, 126(7), 1511-1523. https://doi.org/10.1093/brain/awg157

Maiden, N. A., \& Rugg, G. (1996). ACRE: selecting methods for requirements acquisition. Software Engineering Journal, 11(3), 183-192. https://doi.org/10.1049/sej.1996.0024

Mann, W. C., Goodall, S., Justiss, M. D., \& Tomita, M. (2002). Dissatisfaction and nonuse of assistive devices among frail elders. Assistive Technology, 14(November), 130-139. https://doi.org/10.1080/10400435.2002.10132062

Mao, J., Vredenburg, K., Smith, P. W., \& Carey, T. (2005). The state of User-centered design practice. Communications of the ACM, 48(3), 105-109. https://doi.org/10.1145/1047671.1047677

Martin, J. L., Murphy, E., Crowe, J. A., \& Norris, B. J. (2006). Capturing User Requirements in Medical Device Development: The Role of Ergonomics Capturing User Requirements in Medical Device Development: The. Physiological Measurement, 27(8), 1-19. Retrieved from http://eprints.nottingham.ac.uk/813/1/Capturing_user_requirements.pdf\%5Cnhttp://eprints.n ottingham.ac.uk/end_user_agreement.pdf

Masur, D. M., Sliwinski, M., Lipton, R. B., Blau, A. D., \& Crystal, H. A. (1994). Neuropsychological prediction of dementia and the absence of dementia in healthy elderly 
persons. Neurology, 44(8), 1427-1432. https://doi.org/10.1111/j.1532-5415.1995.tb05832.x

Matlin, M. W. (2008). Cognition (7th ed.). Wiley Publishing.

McCann, T., \& Clark, E. (2005). Using unstructured interviews with participants who have schizophrenia. Nurse Researcher, 13(1), 7-18. https://doi.org/10.7748/nr2005.07.13.1.7.c5996

McDonagh-Philip, D., \& Bruseberg, A. (2002). Focus groups to support the industrial/ product designer a review based on current literature and designer's feedback. Applied Ergonomics, 33(1), 27-38. https://doi.org/http://dx.doi.org/10.1016/S0003-6870(01)00053-9

McDougall, G. J. (1990). A review of screening instruments for assessing cognition and mental status in older adults. The Nurse Practitioner, 15(11), 18-28.

https://doi.org/10.1097/00006205-199011000-00003

Mchugh, M. L. (2013). The Chi-square test of independence Lessons in biostatistics. Biochemia Medica, 23(2), 143-9. https://doi.org/10.11613/BM.2013.018

McHugh, M. L. (2012). Interrater reliability: the kappa statistic. Biochemia Medica, 22(3), 276282. https://doi.org/10.11613/BM.2012.031

Mcleod, S. (2014). The Interview Method. Retrieved from https://www.simplypsychology.org/interviews.html

Mitzner, T. L., Boron, J. B., Fausset, C. B., Adams, A. E., Czaja, S. J., Dijkstra, K., ... Sharit, J. (2010). Older Adults Talk Technology: Technology Usage and Attitudes. Computers in Human Behavior, 26(6), 1710-1721. https://doi.org/10.1016/j.chb.2010.06.020.Older

Moore, L. W. (2002). Conducting research with visually impaired older adults. Qualitative Health Research, 12(4), 559-565. https://doi.org/10.1177/104973202129120070

Morgan, D. (1997a). Focus Groups as Qualitative Research. 
https://doi.org/10.4135/9781412984287

Morgan, D. (1997b). The Focus Group Guidebook. Thousand Oaks, California: Sage publications.

Morone, N. E., Lynch, C. S., Greco, C. M., Tindle, H. A., \& Weiner, D. K. (2008). “I Felt Like a New Person.” The Effects of Mindfulness Meditation on Older Adults With Chronic Pain: Qualitative Narrative Analysis of Diary Entries. Journal of Pain, 9(9), 841-848. https://doi.org/10.1016/j.jpain.2008.04.003

Morris, J. C., Storandt, M., Miller, J. P., McKeel, D. W., Price, J. L., Rubin, E. H., \& Berg, L. (2001). Mild Cognitive Impairment Represents Early-Stage Alzheimer Disease. Archives of Neurology, 58(3), 1475-1483. https://doi.org/10.1001/archneur.58.3.397

Morris, J. N., Fries, B. E., Mehr, D. R., Hawes, C., Phillips, C., Mor, V., \& Lipsitz, L. A. (1994). MDS Cognitive Performance Scaleㅇ. Journal of Gerontology, 49(4), 174-182. https://doi.org/https://doi.org/10.1093/geronj/49.4.M174

Morris, J. N., Howard, E. P., Steel, K., Perlman, C., Fries, B. E., Garms-Homolova, V., ... Szczerbinska, K. (2016). Updating the Cognitive Performance Scale. Journal of Geriatric Psychiatry and Neurology, 29(1), 47-55. https://doi.org/10.1177/0891988715598231

Moyle, W. (2002). Unstructured interviews: Challenges when participants have a major depressive illness. Journal of Advanced Nursing, 39(3), 266-273. https://doi.org/10.1046/j.1365-2648.2002.02273.x

Mruntinga, M. E., Mokkink, L. B., Knol, D. L., Nijpels, G., \& Jansen, A. P. D. (2014). Measurement properties of the Client-centered Care Questionnaire (CCCQ): factor structure, reliability and validity of a questionnaire to assess self-reported clientcenteredness of home care services in a population of frail, older people. Quality of Life 
Research: An International Journal of Quality of Life Aspects of Treatment, Care and Rehabilitation, 23(7), 2063-2072. https://doi.org/10.1007/s11136-014-0650-7

Musil, C. M., Ahn, S., Haug, M., Warner, C., Morris, D., \& Duffy, E. (1998). Health problems and health actions among community-dwelling older adults: results of a health diary study. Applied Nursing Research : ANR, 11(3), 138-147.

Naeini, H. S., \& Mosaddad, S. H. (2013). The Role of Ergonomics Issues in Engineering Education. In Procedia - Social and Behavioral Sciences (Vol. 102, pp. 587-590). Kuala Lumpur, Malaysia: Elsevier Ltd. https://doi.org/10.1016/j.sbspro.2013.10.775

Nasreddine, Z. (2005). Montreal cognitive assessment. Journal of the American Geriatrics Society, 53(4), 695-699. Retrieved from http://www.mocatest.org

Neumann, W. P., Village, J., Bristow, M., \& Salustri, F. A. (2015). Developing a Model for Innovation in Undergraduate Engineering Education - the Systematic Integration of Human-Centered Design. In Proceedings of the Canadian Engineering Education Association (pp. 1-5).

Ngwenyama, O., Guergachi, A., \& McLaren, T. (2007). Using the learning curve to maximize IT productivity: A decision analysis model for timing software upgrades. International Journal of Production Economics, 105(2), 524-535. https://doi.org/10.1016/j.jpe.2006.02.013

Nielsen, J. (1994). Usability inspection methods. In Conference companion on Human factors in computing systems - CHI '94 (pp. 413-414). Boston. https://doi.org/10.1145/259963.260531

Nielsen, J. (2012). Usability 101: Introduction to Usability. Retrieved from https://www.nngroup.com/articles/usability-101-introduction-to-usability/

Nisbet, P. (1996). Integrating assistive technologies: current practices and future possibilities. 
Medical Engineering \& Physics, 18(3), 193-202.

Nordström, M., Dunér, A., Olin, E., \& Wijk, H. (2009). Places, social relations and activities in the everyday lives of older adults with psychiatric disabilities: an interview study. International Psychogeriatrics, 21(2), 401-412. https://doi.org/10.1017/S1041610208008260

Nuseibeh, B., \& Easterbrook, S. (2000). Requirements engineering: a roadmap. In Proceedings of the conference on The future of Software engineering - ICSE '00 (Vol. 1, pp. 35-46). https://doi.org/10.1145/336512.336523

Orellano-Colon, E. M., Rivero-Mendez, M., Lizama, M., \& Jutai, J. W. (2017). Assistive technology unmet needs of independent living older Hispanics with functional limitations. Disability and Rehabilitation: Assistive Technology, 0(0), 1-7. https://doi.org/10.1080/17483107.2017.1300693

Page, T. (2014). Touchscreen mobile devices and older adults: a usability study. International Journal of Human Factors and Ergonomics, 3(1), 65-85. https://doi.org/10.1504/IJHFE.2014.062550

Pandit, N. R. (1996). The Qualitative Report The Creation of Theory: A Recent Application of the Grounded Theory Method The Creation of Theory: A Recent Application of the Grounded Theory Method. The Qualitative Report, 2(24), 1-15. Retrieved from http://nsuworks.nova.edu/tqr\%0Ahttp://nsuworks.nova.edu/tqr/vol2/iss $4 / 3$

Pattison, M., \& Stedmon, A. (2006). Inclusive design and human factors: Designing mobile phones for older users. PsychNology Journal, 4(3), 267-284.

Petersen, R. C., Smith, G. E., Invik, R. J., Kokmen, E., \& Tangalos, E. G. (1994). Memory function in very early Alzheimer's disease. Neurology, 44(5), 867-867. https://doi.org/http:/ 
/dx.doi.org/10.1212/WNL.44.5.867

Petersen, R. C., Smith, G. E., Waring, S. C., Invik, robert J., Tangalos, E. G., \& Kokmen, E. (1999). Mild cognitive impairment clinical characterization and outcome. Archives of Neurology, 56(3), 303-309.

Phillips, B., \& Zhao, H. (1993). Predictors of Assistive Technology Abandonment. Assistive Technology, 5(1), 36-45. https://doi.org/10.1080/10400435.1993.10132205

Pohl, K. (2010). Elicitation Techniques. In Requirements Engineering: Fundamentals, Principles, and Techniques (1st ed., pp. 407-445). Springer-Verlag Berlin Heidelberg.

Powell, R. A., \& Single, M. (1996). Methodology Matters-V Focus Groups. International Journal for Quality in Health Care, 8(5), 499-504.

Pressman, R. S. (2005). Software engineering: a practitioner's approach. Palgrave Macmillan. Pugh, S. (1991). Total Design: Integrated Methods for Successful Product Engineering. Addison-Wesley.

Putnam, C., \& Rose, E. (2009). Adapting User-Centered Design Methods to Design for Diverse Populations. Information Technologies \& International Development, 5(4), 51-74. https://doi.org/10.1002/jbm.a.31889

Rauch, T., \& Wilson, T. (1995). UPA and CHI surveys on usability processes. ACM SIGCHI Bulletin, 27(3), 23-25. https://doi.org/10.1145/221296.221303

Ray, P. L., Cox, A. P., Jensen, M., Allen, T., Duncan, W., \& Diehl, A. D. (2016). Representing vision and blindness. Journal of Biomedical Semantics, 7(1), 1-12. https://doi.org/10.1186/s13326-016-0058-0

Raynes, N., Coulthard, L., Glenister, C., \& Temple, B. (2004). Age does not come alone: Identifying and implementing older people's views of quality in home care services. Quality 
in Ageing and Older Adults Quality Ageing Older Adults, 5(1), 24-31.

Reisberg, B., Ferris, S. H., de Leon, M. J., \& Crook, T. (1982). Global Deterioration Scale. American Journal of Psychiatry, 139, 1136-1139. Retrieved from http://web.missouri.edu/ proste/tool/cog/Global-Deterioration-Scale.pdf\%0D

Reynolds, W. M. (1979). The Utility of Multiple-Choice Test Formats With Mildly Retarded Adolescents. Educational and Psychological Measurement, 39(2), 325-331. https://doi.org/10.1177/001316447903900210

Ribera, M., Porras, M., Boldu, M., Termens, M., Sule, A., \& Paris, P. (2009). Web Content Accessibility Guidelines 2.0. W3C (Vol. 43). https://doi.org/10.1108/00330330910998048

Rice, M., \& Alm, N. (2008). Designing new interfaces for digital interactive television usable by older adults. Computers in Entertainment, 6(1), 1-20. https://doi.org/10.1145/1350843.1350849

Riemer-Reiss, M. L., \& Wacker, R. R. (2000). Factors associated with assistive tech- nology discontinuance among individuals with disabilities. The Journal of Rehabilitation, 66(3), $44-50$.

Rosenhall, U., Nordin, V., Sandstrom, M., Ahlsen, G., \& Gillberg, C. (1999). Autism and Hearing Loss. Journal of Autism \& Developmental Disorders, 29(5), 349-357. https://doi.org/https://doi.org/10.1023/A:1023022709710

Rubin, J., \& Chisnell, D. (2008). Handbook of usability testing : How to plan, design, and conduct effective tests. Indianapolis, IN: Wiley Pub. (2nd ed.). Wiley Publishing, Inc. https://doi.org/10.1007/s13398-014-0173-7.2

Sacks, S., \& Wolffe, K. E. (2006). Teaching Social Skills to Adolescents and Young Adults with Visual Impairments. In Teaching social skills to students with visual impairments: From 
theory to practice (p. 42). American Foundation for the Blind.

Sætren, G. B., Hogenboom, S., \& Laumann, K. (2016). A study of a technological development process: Human factors-the forgotten factors? Cognition, Technology \& Work, 18(3), $595-611$.

Scheiman, M., Scheiman, M., \& Whittaker, S. G. (2006). Low Vision Rehabilitation: A Practical Guide for Occupational Therapists (1st ed.). Slack Incorporated.

Sellen, K. M., Massimi, M. A., Lottridge, D. M., Truong, K. N., \& Bittle, S. A. (2009). The People-Prototype Problem: Understanding the Interaction Between Prototype Format and User Group. In CHI '09 Proceedings of the SIGCHI Conference on Human Factors in Computing Systems (pp. 635-638). https://doi.org/10.1145/1518701.1518799

Shah, S., \& Robinson, I. (2006). User involvement in healthcare technology development and assessment : Structured literature review. The International Journal of Health Care Quality Assurance, 19(6), 500-515.

Sharp, H., Finkelstein, A., \& Galal, G. (1999). Stakeholder identification in the requirements engineering process. In Proceedings. Tenth International Workshop on Database and Expert Systems Applications. DEXA 99 (pp. 387-391).

https://doi.org/10.1109/DEXA.1999.795198

Sharp, H., Rogers, Y., \& Preece, J. (2007). Interaction design: beyond human-computer interaction. In Data Gathering (3rd ed., Vol. 11, pp. 222-269). John Wilry \& Sons Ltd. https://doi.org/10.1162/leon.2005.38.5.401

Siek, K. A., Khan, D. U., Ross, S. E., Haverhals, L. M., Meyers, J., \& Cali, S. R. (2011). Designing a personal health application for older adults to manage medications: A comprehensive case study. Journal of Medical Systems, 35(5), 1099-1121. 
https://doi.org/10.1007/s10916-011-9719-9

Sigelman, C. K., Carol J, S., Jane L, W., Cynthia L, S., Sherrilyn G, H., Paulette W, M., ...

Gerard J, B. (1981). Issues in interviewing mentally retarded persons: an empirical study. Monograph of the American Association of Mental Deficiency, 4, 114-129.

Sim, J. (1998). Collecting and analysing qualitative data: issues raised by the focus group. Journal of Advanced Nursing, 28(2), 345-352. https://doi.org/10.1016/S00012092(06)62388-0

Simpson, R., \& Koester, H. H. (1999). Adaptive one switch row column scanning. IEEE Transactions on Rehabilitation Engineering, 7(4), 464-473. https://doi.org/10.1109/86.808950

Snellen, H. (1873). Probebuchstaben zur Bestimmung der Sehschärfe: Band 1. H. Peters.

Soares, M. M. (2012). Translating user needs into product design for disabled people: a study of wheelchairs. Theoretical Issues in Ergonomics Science, 13(1), 92-120. Retrieved from http://dx.doi.org/10.1080/1463922X.2010.512989

Sommerville, I., \& Sawyer, P. (1997). Requirements engineering: a good practice guide (1st ed.). New York City: John Wiley \& Sons, Inc.

Stanton, N., \& Salmon, P. (2004). Human Factors Design \& Evaluation Methods Review. Human Factors Integration Defence Technology Centre. Somerset.

Stoller, E. P. (1993). Interpretations of Symptoms by older People: A health Diary Study of illness Behavior. Journal of Ageing and Health, 5(1), 58-81.

Stoller, E. P., Forster, L. E., \& Portugal, S. (1993). Self-care responses to symptoms by older people. A health diary study of illness behavior. Medical Care, 31(1), 24-42.

Sturtz, C. R. (2013). U.S. Patent No. 7768499. United States of America: United States Patent 
and Trademark office. https://doi.org/10.1197/jamia.M1139.Adar

Sujan Samuel Roy, J., Fels, D. I., \& Neumann, W. P. (2017). HUMAN CAPABILITY

DEMANDS REQUIRED FROM THE ELDERLY AND DISABLED PARTICIPANTS IN THE USER CENTERED DESIGN NEEDS ELICITATION METHODS-A SURVEY

STUDY. In Joint proceedings 48th Annual Conference of the Association of Canadian

Ergonomists $(A C E) \&$ 12th International Symposium on Human Factors in Organizational

Design and Management (pp. 496-502). Banff,AB, Canada: Association of Canadian

Ergonomists.

Sujan Samuel Roy, J., Neumann, W. P., \& Fels, D. I. (2016). User Centered Design Methods and Their Application in Older Adult Community. In International Conference on Human Interface and the Management of Information, Springer International Publishing. (Vol. 9734, pp. 462-472). Toronto. https://doi.org/10.1007/978-3-319-40349-6_44

Sun, Z. (2013). User Involvement in System Development Process. In Proceedings of the 2nd International Conference on Computer Science and Electronics Engineering (ICCSEE 2013) (pp. 410-413). https://doi.org/10.2991/iccsee.2013.105

Sustar, H., Pfeil, U., \& Zaphiris, P. (2008). Requirements elicitation with and for older adults. IEEE Software, 25(3), 16-17. https://doi.org/10.1109/MS.2008.69

Takeda, T. (2004). U.S. Patent No. 20040013279A1. United States: United States Patent and Trademark office. https://doi.org/US 2013/0154292 A1

Tenhue, N. (2016). User Experience (UX) - Primary and Secondary Users in Healthcare.

Retrieved from https://www.linkedin.com/pulse/user-experience-primary-secondary-usershealthcare-nicholas-tenhue

Terry, W. S. (1988). 1988 everyday forgetting. Psychological Reports, 62(1), 299-303. 
https://doi.org/https://doi.org/10.2466/pr0.1988.62.1.299

Thoring, K., Luippold, C., \& Mueller, R. M. (2013). Opening the Cultural Probes Box : A Critical Reflection and Analysis of the Cultural Probes Method. In 5th International Congress of International Association of Societies of Design Research (IASDR) (pp. 597603). Glasgow: The Design Society.

Toor, I. K., Tabiat-Pour, S., \& Critchlow, S. B. (2015). Mouth sticks: Their past, present and future. British Dental Journal, 219(5), 209-215. https://doi.org/10.1038/sj.bdj.2015.681

Troyer, A. K., \& Rich, J. B. (2002). Psychometric Properties of a New Metamemory Questionnaire for Older Adults. The Journals of Gerontology Series B: Psychological Sciences and Social Sciences, 57B(1), P19-P27. https://doi.org/10.1093/geronb/57.1.P19

Turpin, G., Armstrong, J., Frost, P., Fine, B., Ward, C., \& Pinnington, L. (2005). Evaluation of alternative computer input devices used by people with disabilities. Journal of Medical Engineering \& Technology, 29(3), 119-29. https://doi.org/10.1080/03091900500075317

Vanderheiden, G. C., \& Jordan, B. J. (2012). Design for people with functional limitations. In G. Salvendy (Ed.), Handbook of Human Factors and Ergonomics (4th ed., pp. 1407-1441). Hoboken, NJ, USA: John Wiley \& Sons, Inc. https://doi.org/10.1002/9781118131350.ch51 Vázquez, M., \& Steinfeld, A. (2012). Helping Visually Impaired Users Properly Aim a Camera. In Proceedings of the 14th International ACM SIGACCESS Conference on Computers and Accessibility (pp. 95-102). https://doi.org/10.1145/2384916.2384934

Venkatesh, V., \& Davis, F. D. (1996). A Model of the Antecedents of Perceived Ease of Use: Development and Test. Decision Science, 27(3), 451-481. https://doi.org/10.1111/j.15405915.1996.tb01822.x

Verbrugge, L. M., \& Ascione, F. J. (1987). Exploring the iceberg: common symptoms and how 
people care for them. Medical Care, 25(6), 539-569. https://doi.org/10.1097/00005650198706000-00008

Vijayan, J., \& Raju, G. (2011). A New approach to Requirements Elicitation Using Paper Prototype. International Journal of Advanced Science and Technology, 28, 9-16.

Vimont, C. (2016). What Does 20/20 Vision Mean? Retrieved from https://www.aao.org/eyehealth/tips-prevention/what-does-20-20-vision-mean

Vredenburg, K., Isensee, S., \& Righi, C. (2004). User-Centered Design: An Integrated Approach. IEEE Transactions on Professional Communication, 47(1), 75-77. https://doi.org/10.1109/TPC.2004.824283

Vredenburg, K., Mao, J.-Y., Smith, P. W., \& Carey, T. (2002). A survey of user-centered design practice. In Proceedings of the SIGCHI conference on Human factors in computing systems Changing our world, changing ourselves - CHI '02 (p. 471). https://doi.org/10.1145/503457.503460

Wang, R. H., Korotchenko, A., Hurd Clarke, L., Mortenson, W. Ben, \& Mihailidis, A. (2013). Power mobility with collision avoidance for older adults: user, caregiver, and prescriber perspectives. Journal of Rehabilitation Research and Development, 50(9), 1287-1300. https://doi.org/10.1682/JRRD.2012.10.0181

Welsh, K., Butters, N., \& Hughes, J. (1991). Detection of Abnormal Memory Decline in Mild Cases of Alzheimer's Disease Using CERAD Neuropsychological Measures. Archives of Neurology, 48(3), 278-281. https://doi.org/10.1001/archneur.1991.00530150046016

Wherton, J., Sugarhood, P., Procter, R., Rouncefield, M., Dewsbury, G., Hinder, S., \& Greenhalgh, T. (2012a). Designing assisted living technologies "in the wild": preliminary experiences with cultural probe methodology. BMC Medical Research Methodology, 
12(188), 1-13. https://doi.org/10.1186/1471-2288-12-188

Wherton, J., Sugarhood, P., Procter, R., Rouncefield, M., Dewsbury, G., Hinder, S., \&

Greenhalgh, T. (2012b). Designing assisted living technologies "in the wild": preliminary experiences with cultural probe methodology. BMC Med Res Methodology, 12(188), 1-13. https://doi.org/10.1186/1471-2288-12-188

Williamson, G. (2014). Loudness. Retrieved from https://www.sltinfo.com/loudness/

Witkin, B. R., \& Altschuld, J. W. (1995). Planning and conducting needs assessments: A practical guide. London: Sage publications.

Wöckl, B., Yildizoglu, U., Buber, I., Aparicio Diaz, B., Kruijff, E., \& Tscheligi, M. (2012). Basic senior personas: a representative design tool covering the spectrum of European older adults. In Proceedings of the 14th international ACM SIGACCESS conference on Computers and accessibility - ASSETS '12 (pp. 25-32). New York City: ACM. https://doi.org/10.1145/2384916.2384922

Wood, J., \& Silver, D. (1995). Joint application development (2nd ed.). New York City: John Wiley \& Sons, Inc.

World Heritage Encyclopedia. (1965). VISUAL ACUITY. In World Heritage Encyclopedia. World Heritage Encyclopedia. Retrieved from http://www.worldlibrary.org/articles/visual_acuity

Zhou, J., \& Salvendy, G. (2015). Human Aspects of IT for the Aged Population Design for Aging: First international conference, ITAP 2015 held as part of HCI international 2015 Los Angeles, CA, USA, August 2-7, 2015 proceedings, part I. Lecture Notes in Computer Science (Including Subseries Lecture Notes in Artificial Intelligence and Lecture Notes in Bioinformatics), 9193, 354-364. https://doi.org/10.1007/978-3-319-20892- 
